Aus der Abteilung Hals-Nasen-Ohrenheilkunde (Prof. Dr. med. Ch. Matthias) im Zentrum Augenheilkunde und Hals-Nasen-Ohrenheilkunde der Medizinischen Fakultät der Universität Göttingen

\title{
Endozytose der inneren Haarzelle
}

\author{
INAUGURAL-DISSERTATION
}

zur Erlangung des Doktorgrades

der Medizinischen Fakultät

der Georg-August-Universität zu Göttingen

vorgelegt von

Christine Lenz

aus Hamburg

Göttingen 2011 
Dekan:

I. Berichtserstatter:

II. Berichtserstatter/in:

III. Berichtserstatter/in:

Tag der mündlichen Prüfung:
Prof. Dr. med. C. Frömmel

Prof. Dr. med. T. Moser

Prof. Dr. rer. nat. P. Schu

13.12.2011 


\section{Inhaltsverzeichnis}

ABKÜRZUNGSVERZEICHNIS

1 EINLEITUNG UND ZIELE DIESER ARBEIT 2

2 THEORIE UND GRUNDLAGEN 3

2.1 Der Hörvorgang und beteiligte Strukturen 3

2.1.1 Das Corti-Organ 3

2.1.2 Innere Haarzelle 4

2.1.3 Afferente Synapse 4

2.2 Endozytose $\quad 6$

2.2.1 Übersicht über verschiedene Endozytosemechanismen 7

2.2.2 Endozytose an der Synapse 11

2.2.3 Besonderheiten der Endozytose an der Bänder-Synapse 13

$\begin{array}{lll}2.3 & \text { Dynamin } & 15\end{array}$

$\begin{array}{lll}2.4 & \text { Objektive audiologische Testverfahren } & 19\end{array}$

2.4.1 Frühe auditorisch evozierte Poteltiale - FAEP 19

$\begin{array}{ll}\text { 2.4.2 Otoakustische Emissionen - OAE } & 20\end{array}$

3 MATERIAL UND METHODEN 22

$\begin{array}{llr}3.1 & \text { Versuchstiere } & 22\end{array}$

$\begin{array}{lll}3.2 & \text { Immunhistochemie } & 22\end{array}$

3.2.1 Präparation des Corti-Organes 22

$\begin{array}{lll}3.2 .2 & \text { Färbung } 23\end{array}$

$\begin{array}{lll}3.3 & \text { Konfokale Lasermikroskopie } & 24\end{array}$

$\begin{array}{lll}3.4 & \text { Synapsenzählung } & 24\end{array}$

$\begin{array}{llr}3.5 & \text { Audiologie } & 25\end{array}$

3.5.1 Allgemein 25

3.5.2 Messung der FAEP 25 
4.1 Nachweis endozytotischer Proteine der IHZ

4.2 Dynamin-Mutante: $D N M 1 A^{f t f l f t f l} \quad 37$

4.2.1 Morphologische Analyse $\quad 37$

4.2.1.1 Anatomie des Corti-Organs 37

4.2.1.2 Synapsen 38

4.2.2 Subzelluläre Verteilung endozytotischer Proteine 41

4.2.3 Funktionelle Analyse 43

$\begin{array}{lll}\text { 4.2.3.1 Schwellenunterschiede in frequenzspezifischer BERA } & 43\end{array}$

4.2.3.2 Stimulation mit Klickreizen - Latenzen, Amplituden 44

$\begin{array}{ll}\text { 4.2.3.3 Unveränderte DPOAE } & 50\end{array}$

5 DISKUSSION $\quad 52$

5.1 Expressionsanalyse endozytotischer Proteine 52

5.1.1 Endozytoseformen der IHZ 52

5.1.2 Isoformen endozytotischer Proteine der IHZ 55

5.1.3 Lokalisation der Endozytose $\quad 56$

5.2 Intaktes Dynamin 1A ist wesentlich für den Hörvorgang 57

5.2.1 Lokalisation und Grundlage des Defektes $\quad 58$

5.2.2 Aktivitäts-abhängig erhöhter Bedarf an Dynamin 1 bzw. 1A? 62

$\begin{array}{lll}6 & \text { ZUSAMMENFASSUNG } & 66\end{array}$

7 ABBILDUNGS- UND TABELLENVERZEICHNIS 68

8 LITERATURVERZEICHNIS $\quad 70$ 


\section{Abkürzungsverzeichnis}

ÄHZ

AMPA

AP

BERA

CLASP

CtBP2

DNM 1A

DPOAE

FAEP

ftfl

GED

GluR2/3

GTP

GTP $\gamma \mathrm{S}$

IHZ

IRM

LC

OAE

PA5

$\mathrm{PH}$

PRD

Äußere Haarzelle

$\alpha$-Amino-3-Hydroxy-5-Methyl-4-Isoxazolpropionsäure

Adapter-Proteine

PtdIns(4,5) $\mathrm{P}_{2}$ Phosphatidyl 4,5-Bisphosphat

RRP Ready Releasable Pool

SEOAE Simultan evozierte otoakustische Emissionen

SH3 Src-homology region 3

SOAE Spontane otoakustische Emissionen

TDT Tucker-Davis-Technologies

TEOAE Transitorisch evozierte otoakustische Emissionen

TIRFM Total internal reflection fluorescence microscopy 


\section{Einleitung und Ziele dieser Arbeit}

Das Innenohr ist eines der zentralen Bestandteile im Hörvorgang. Im Besonderen sind dort neben den äußeren Haarzellen die inneren Haarzellen (IHZ) als sekundäre Sinneszellen lokalisiert. Um die Weiterleitung von Stimuli zu gewährleisten, müssen sie fortwährend Exozytose mit einer hohen Rate unterhalten. Im Sinne des Vesikelrecyclings ist daher auch die kompensatorische Endozytose zur Rückgewinnung der Membran entscheidend. Dieser Vorgang der Endozytose ist zwar Bestandteil einer jeden funktionierenden Zelle, differiert jedoch in Abhängigkeit vom Zelltyp in Bezug auf die verschiedenen Formen und beteiligten Proteine.

Bis zu dem jetzigen Zeitpunkt existieren wenige Arbeiten, die den Fokus auf die Endozytose in IHZ legen. Aus diesem Grund ist es Ziel der Arbeit, Erkenntnisse über die Endozytose in IHZ zu gewinnen. Darüber hinaus wird eines der zentralen Proteine der Vesikelabspaltung Dynamin 1 -im Detail untersucht.

Um eine Vorstellung davon zu erhalten, welche Wege der Endozytose an der sogenannten Bänder-Synapse der Cochlea ablaufen, wird die Expression einzelner endozytotischer Proteine geprüft. Es soll mittels immunhistochemischer Färbung ermittelt werden, ob sich bestimmte Proteine als Vertreter verschiedener Wege darstellen lassen.

In einem zweiten Schritt geht es spezifisch um die Auswirkung einer Punktmutation im Dynamin-1-Gen, fitful (ftfl) bezeichnet. Das Besondere dieser Mutation besteht darin, dass im Gegensatz zu bisherigen Arbeiten nur eine der zwei Isoformen, Dynamin 1A (DNM 1A), betroffen ist. Unter Verwendung dieser Maus-Mutante eröffnet sich die Möglichkeit, Isoform-spezifische Aussagen treffen zu können. Zu diesem Zweck sollen sowohl immunhistochemische Färbungen vorgenommen als auch objektive Hörtests durchgeführt werden. Im Einzelnen ergeben sich aus den beiden Aspekten folgende Fragestellungen:

1. Welche endozytotischen Proteine exprimiert die IHZ? Welche Wege der Endozytose sind dadurch potentiell möglich?

2. Hat die Mutation des Dynamin-1A-Gens Auswirkungen auf die Morphologie und Synapsenanzahl der Haarzellen oder auf die Verteilung endozytotischer Proteine?

3. Ist ein intaktes Dynamin 1A wichtig für den Hörvorgang? Wenn ja, wie präsentiert sich ein möglicher Defekt und auf welcher Grundlage? Wo ist er zu lokalisieren? Ergeben sich aus den Ergebnissen Charakteristika für die Funktion von Dynamin $1 \mathrm{~A} ?$ 


\section{Theorie und Grundlagen}

\subsection{Der Hörvorgang und beteiligte Strukturen}

Um aus einem akustischen Stimulus eine Reizantwort im Gehirn generieren zu können, bedarf es des komplexen Aufbaus des Hörorgans im Zusammenspiel mit der hochspezialisierten synaptischen Verschaltung des zentralen Nervensystems.

Nachdem der Schall den äußeren Gehörgang passiert hat, werden die Druckschwankungen der Luft in Schwingungen der folgenden Strukturen umgesetzt. Im Anschluss an das Trommelfell und die Gehörknöchelchen des Mittelohrs werden die Flüssigkeiten und Membranen des Innenohrs entsprechend ausgelenkt. Entlang der Basilarmembran, siehe Abb. 2.1, entsteht dadurch eine so genannte Wanderwelle, die sich von der Basis bis zum Apex der Cochlea fortsetzt. Die eingangs sehr kleinen Amplituden werden unter anderem aufgrund der Schwingungseigenschaften der Basilarmembran an einem frequenzspezifischen Ort verstärkt, wobei tiefe Frequenzen in der Nähe des Apex und hohe Frequenzen in der Nähe der Basis abgebildet werden.

\subsubsection{Das Corti-Organ}

Der Basilarmembran sitzt als eigentlicher sensorischer Apparat des Innenohres das CortiOrgan auf, siehe Abb. 2.1.

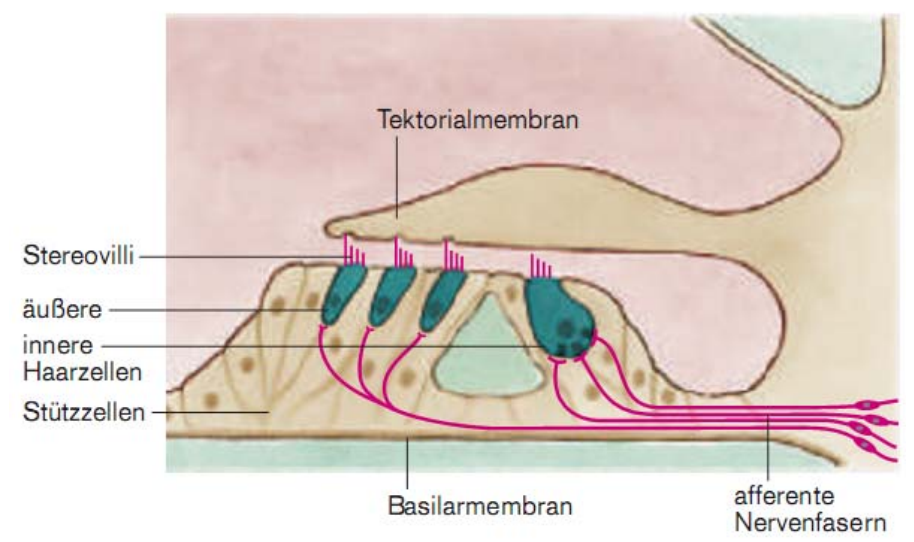

Abb. 2.1: Querschnitt durch das Corti-Organ. Entnommen aus Klinke (2005), S. 663. 
Es enthält 16000 Haarzellen (Hudspeth 2000) sowie eine Vielzahl an Stützzellen. Wie der Abb. $2.1 \mathrm{zu}$ entnehmen ist, existieren eine einzelne Reihe innerer Haarzellen (IHZ) und drei Reihen äußerer Haarzellen (ÄHZ), an deren oberem Pol sich jeweils bis zu 100 Stereozilien befinden. Aufgabe der Sinneszellen ist die Umwandlung des mechanischen Schallsignals in ein bioelektrisches bzw. ein biochemisches körpereigenes Signal. Der erste Schritt besteht in der mechanoelektrischen Transduktion. Aufgrund einer Deflektion der Stereozilien am Ort der maximalen Amplitudenverstärkung kommt es zur Öffnung mechanosensitiver Transduktionskanäle, die durch einen Kationeneinstrom zu einer Depolarisation der Zelle führt. Die ÄHZ nutzen das durch diesen Vorgang entstehende Rezeptorpotential, um sich zu verkürzen und bei Hyperpolarisation wieder zu verlängern, wobei das Protein Prestin den molekularen Motor darstellt (Zheng et al. 2000). Diese oszillierenden Längenbewegungen führen bis zu einem bestimmten Lautstärkepegel im Sinne eines Verstärkerprozesses (Dallos und Fakler 2002; Ashmore 2008) zu einer gesteigerten Aktivierung der IHZ, bei sehr hohen Pegeln dagegen wirken sie dämpfend (Kompression).

\subsubsection{Innere Haarzelle}

Die IHZ ist eine polarisierte Zelle epithelialen Ursprungs (Streit 2001), deren Funktionen sich einem apikalen und einem basolateralen Kompartiment zuordnen lassen. Ersteres ist zuständig für die zuvor beschriebene mechanoelektrische Transduktion, während der basolaterale Anteil den zweiten Schritt der Umsetzung des akustischen Stimulus übernimmt. Dieser besteht in der Signalübertragung von der sekundären Sinneszelle auf die afferente Synapse, die so genannte Transformation.

Dabei löst das Rezeptorpotential, das bis zu $25 \mathrm{mV}$ annimmt (Hudspeth 2000), einen Kalziumeinstrom aus. Getriggert durch diesen Einstrom kommt es zur Fusion der präsynaptischen Vesikel mit der Plasmamembran (Roberts et al. 1990) und damit zur Freisetzung des Transmitters in den synaptischen Spalt. Als Transmitter fungiert Glutamat, das an postsynaptische AMPA-Rezeptoren bindet (Matsubara et al. 1996; Glowatzki und Fuchs 2002).

\subsubsection{Afferente Synapse}

Während die ÄHZ vorwiegend efferent innerviert werden, bildet die IHZ hauptsächlich afferente Synapsen aus - die der Maus beispielsweise insgesamt 5-20 (Meyer AC et al. 2009; Meyer AC und Moser 2010). Über 90\% der Ganglienzellen enden an den IHZ, wobei eine jede nur input von einer einzelnen Haarzelle erhält (Kiang et al. 1982). So ist 
gewährleistet, dass unterschiedliche Qualitäten des Stimulus auf Ebene von Intensität und Frequenz getrennt voneinander weitergeleitet werden können.

Im Gegensatz zu anderen Synapsen des zentralen Nervensystems zeichnet sich die Haarzelle dadurch aus, dass sie den initialen Stimulus nicht in Form eines Aktionspotentials, sondern als Rezeptorpotential umsetzt, das nachfolgend in ein bestimmtes Muster postsynaptischer Spikes transformiert wird. Darüber hinaus erzeugt die IHZ auch ohne jeglichen Stimulus stetig spontan postsynaptische Aktionspotentiale bis über $100 \mathrm{~Hz}$ (Rose et al. 1967; Liberman 1978; Sewell 1984; Guth et al. 1991).

Um dieser Funktion gerecht zu werden, bedarf es nach dem Stand der derzeitigen Forschung spezieller Strukturen - der so genannten Bänder oder ribbons, siehe Abb. 2.2. Es handelt sich dabei um präsynaptische Organelle, die neben den IHZ auch in den Photorezeptoren und Bipolarzellen der Retina sowie in den Haarzellen des Vestibularorgans wiederzufinden sind (LoGiudice und Matthews 2009). Jeweils eine aktive Zone der Präsynapse enthält ein synaptisches Band, das genau einem postsynaptischen Terminal gegenüberliegt. Die Anzahl der Bänder und damit auch der Synapsen pro Haarzelle variiert unter den Spezies (Nouvian et al. 2006) sowie teilweise entlang der tonotopischen Achse (Meyer AC et al. 2009).

Neben einer Vielzahl zytosolischer Vesikel (Spicer et al. 1999) und dem an die Plasmamembran gebundenen ready releasable pool (RRP) sind abhängig von der Spezies 50-380 Vesikel (Nouvian et al. 2006) über $20 \mathrm{~nm}$ lange Ärmchen an den Bändern selber befestigt (Lenzi et al. 1999).

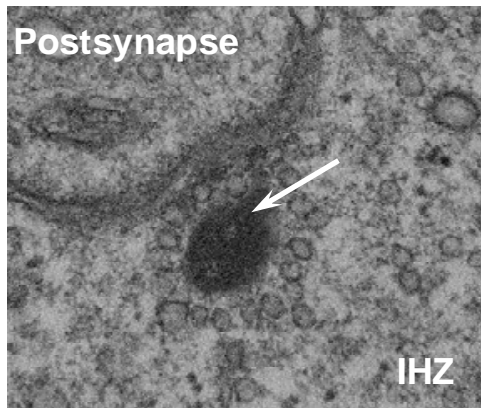

Abb. 2.2: Elektronenmikroskopische Aufnahme einer afferenten Synapse. In der Bildmitte ist ein Band der Haarzelle in Form einer elektronendichten, ovalen Struktur (Pfeil) mit angelagerten synaptischen Vesikeln zu sehen. Unveröffentlichtes Material der Arbeitsgruppe Moser in Zusammenarbeit mit Riedel, Max-Planck-Institut für biophysikalische Chemie.

Diese in Form von so genannten Bänder-Synapsen spezialisierten Zellen sind nicht nur in der Lage, innerhalb kürzester Zeit außerordentlich hohe Raten an Exozytose zu erzielen 
(Moser und Beutner 2000), sondern auch die synaptische Transmission für Sekunden zu unterhalten (Parsons et al. 1994; Moser und Beutner 2000). Angesichts dessen ist es zwingend erforderlich, dass die in dem hohen Maß exozytierte Membran zurückgewonnen wird, um wieder als Vesikel bereitgestellt zu werden und die Plasmamembran im Gleichgewicht halten zu können. Dies wird in Form von Endozytose erfüllt - anhand von Kapazitätsmessungen lässt sich die Membranwiedergewinnung im Anschluss an Stimulation von IHZ und damit im Anschluss an den Vorgang der Exozytose detektieren (Beutner et al. 2001).

Ein weiterer Gesichtspunkt, der unter der anhaltenden Transmitterausschüttung an Bedeutung gewinnt, besteht in der Regulation postsynaptischer AMPA-Rezeptoren. Durch die Präsentation einer unterschiedlichen Anzahl von Rezeptoren an der postsynaptischen Zelloberfläche können die Stärke der synaptischen Übertragung gesteuert und exzitotoxische Effekte verhindert werden (Chen $Z$ et al. 2007). Durch die Reinternalisierung der Rezeptoren mittels Endozytose wird diese Regulation gewährleistet.

Im Folgenden soll zunächst ein allgemeiner Überblick über den Vorgang der Endozytose gegeben werden, um diesen anschließend im Speziellen an Synapsen und an der BänderSynapse zu betrachten.

\subsection{Endozytose}

Die Plasmamembran stellt eine selektive Barriere dar, die von Makromolekülen meist nicht überwunden werden kann. Dennoch ist es notwendig, dass die Zelle unabhängig von den Permeabilitätseigenschaften der Membran bestimmte Stoffe aufnehmen kann. Diese Aufnahme findet in von Zellmembran-Abschnitten umschlossenen Vesikeln statt und wird als Endozytose bezeichnet. Im Einzelnen ist der Vorgang elementar zur Internalisierung von flüssigem Außenmedium, geformten Elementen (Viren, Bakterien, Parasiten), Rezeptoren, extrazellulären Liganden und Oberflächenproteinen, die zum weiteren Abbau bestimmt sind. Des Weiteren spielt, wie oben dargestellt, die Exozytose-gekoppelte Endozytose im Sinne des so genannten Vesikel-Recyclings und zur Wahrung der Größe und Spezifität der Zelloberfläche besonders in transmitter- bzw. hormonausschüttenden Zellen eine entscheidende Rolle. Es existieren verschiedene Wege der Endozytose, der Ablauf jedoch umfasst bei allen 1. die Erkennung des Membranabschnittes, 2. das Einstülpen der Membran und 3. das anschließende Abschnüren des Vesikels. 


\subsection{1 Übersicht über verschiedene Endozytosemechanismen}

Die allgemeine Klassifizierung der unterschiedlichen Mechanismen der Endozytose an der Zelle erfolgt anhand verschiedener Kriterien wie Größe der Membranabschnitte, Inhalt der endozytierten Vesikel und beteiligte Proteine.

Hinsichtlich der Endozytose kleinerer Vesikel, der Mikropinozytose, kann nach einer in der Literatur sehr gängigen Einteilung unter Berücksichtigung der involvierten Proteine zwischen Clathrin-abhängiger und Clathrin-unabhängiger Endozytose unterschieden werden, siehe Abb. 2.3.

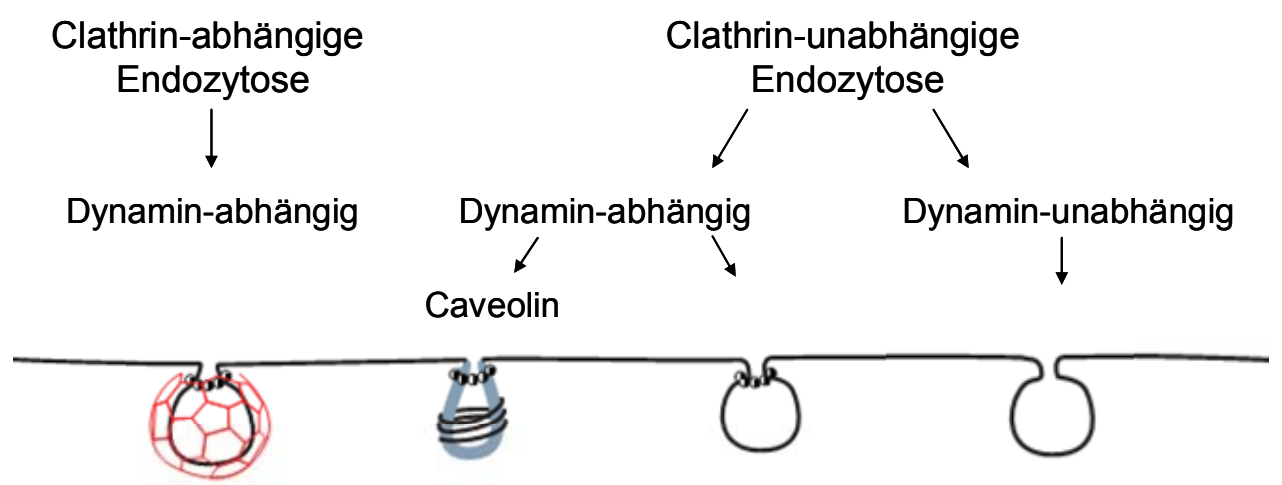

Abb. 2.3: Einteilung der Endozytose-Formen entsprechend der Beteiligung verschiedener Proteine. Clathrin rote gitterförmige Struktur, Dynamin - perlschnurartige Struktur am Vesikelhals, Caveolin - blauer Saum. Modifiziert nach Conner und Schmid (2003), S.37.

In einem zweiten Betrachtungsschritt wird die Erforderlichkeit Dynamins für den jeweiligen Weg als Kriterium herangezogen. Bei dem Protein handelt es sich um eine Guanosintriphosphat(GTP)ase, die als kettenförmige Struktur am Vesikelhals für dessen Abschnürung sorgt. Die Clathrin-abhängige Endozytose setzt die Anwesenheit Dynamins als unentbehrlich voraus. Die Clathrin-unabhängigen Formen sind dagegen nur anteilig darauf angewiesen, beispielhaft wird hier der Caveolin-abhängige Weg dargestellt.

\section{Clathrin-abhängige Endozytose}

Bei der Clathrin-vermittelten Endozytose handelt es sich um den Weg, der am intensivsten erforscht und dadurch auf molekularer Ebene am genauesten beschrieben ist. Lange Zeit wurde er mit dem Begriff der „Rezeptor-vermittelten Endozytose“" gleichgesetzt, wobei dies eine Fehlbezeichnung ist, da einerseits andere Wege gleichermaßen Interaktionen 
zwischen Rezeptor und Ligand voraussetzen und andererseits auch die konstitutive Form der Endozytose eine Variante der Clathrin-vermittelten Endozytose darstellt. Aufgrund der Formation eines polygonalen, gitterartigen Clathrin-Mantels entlang des entsprechenden Membranabschnittes entstehen morphologisch charakteristisch umhüllte Vesikel, siehe Abb. 2.4 .
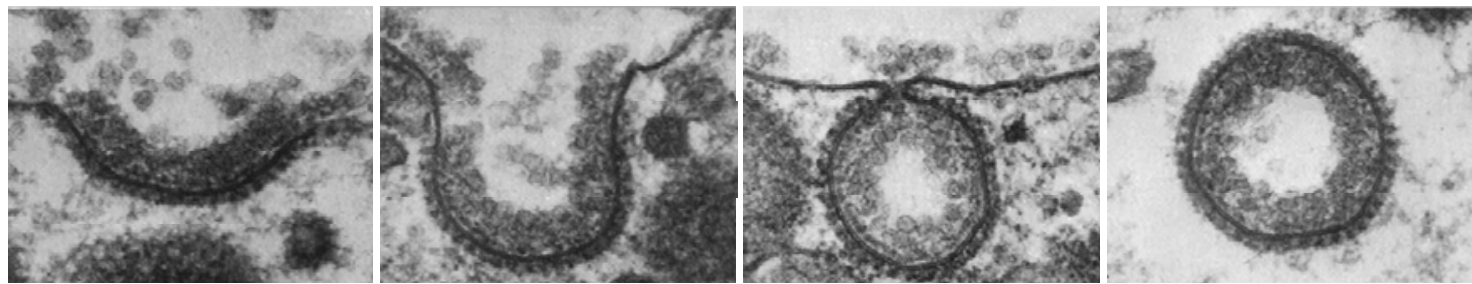

Abb. 2.4: Verschiedene Stadien der Vesikelformation mit charakteristischem Clathrin-Saum. Entnommen aus Perry und Gilbert (1979), S.266.

Clathrin ist eine dreiarmige Struktur bestehend aus drei schweren Untereinheiten (Kirchhausen et al. 1987), die jeweils mit einer leichten Untereinheit fest verbunden sind. Bei diesen so genannten leichten Ketten (light chain $=$ LC) lassen sich nicht nur im Allgemeinen zwei verschiedene Formen $-\mathrm{LC}_{\mathrm{a}}$ und $\mathrm{LC}_{\mathrm{b}}-$ unterscheiden (Creutz und Harrison 1984), durch alternatives Splicing hervorgerufen existieren außerdem neuronale Varianten (Jackson et al. 1987). Gemeinsam bilden die schweren und leichten Ketten die Struktur eines so genannten Triskelions aus (Ungewickell und Branton 1981), siehe Abb. 2.5 (a). Mehrere dieser Triskelien wiederum formieren sich zu der gitterartigen Struktur auf der Oberfläche der Vesikel.

Neben der Anwesenheit von Clathrin ist eine Vielzahl an Adapter- und akzessorischen Proteinen erforderlich, um den Vorgang von der Anreicherung der zu befördernden Moleküle innerhalb des bestimmten Membranabschnittes bis hin zu dessen Invagination und anschließender Abschnürung zu gewährleisten, siehe auch Abb. 2.5 (c) (Mousavi et al. 2004; Doherty und McMahon 2009; Traub 2009).

Die Adapter-Proteine (AP) sind definiert als eine Klasse von Proteinen, die in der Lage sind, die zu transportierenden Moleküle der Membran mit den Elementen des Clathrin-Mantels zu verbinden (Traub 2003). Darunter stellt AP2 einen zentralen Proteinkomplex dar (Keen 1987), siehe Abb. 2.5 (b). 
a

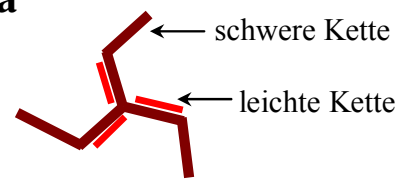

b

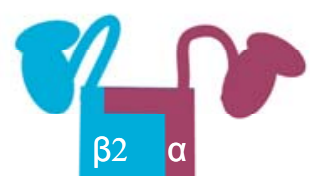

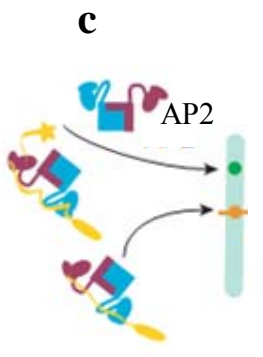
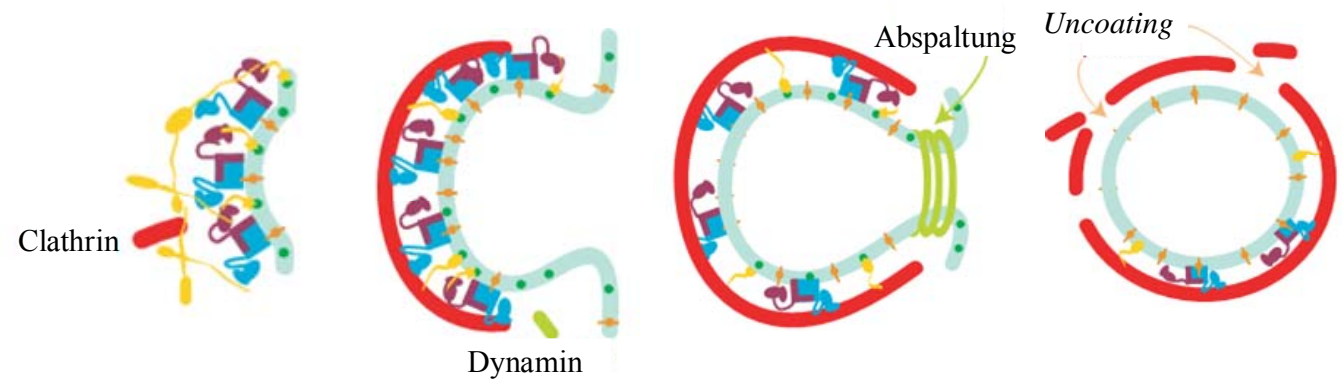

Dynamin

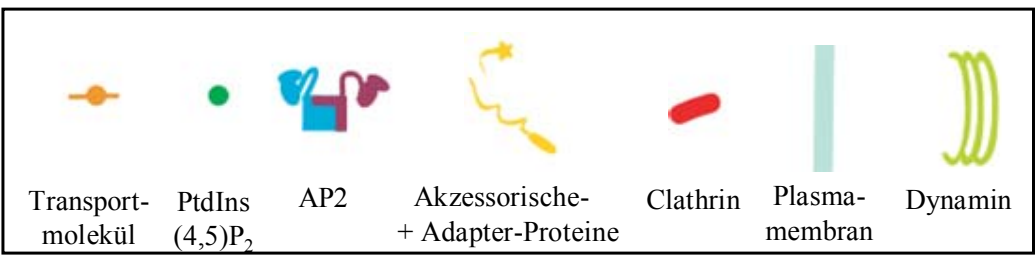

Abb. 2.5: (a) Clathrin Triskelion. (b) AP2. (c) Clathrin-vermittelten Endozytose schematisch dargestellt. Schritte von der Anlagerung der Adapter-Proteine über die Invagination der Membran unter der Gitterausbildung Clathrins bis hin zur Abspaltung des Vesikels sowie dessen Hülle. Teilweise modifiziert nach Schmid und McMahon (2007), S.885.

Nach der Selektion des Membranabschnittes und Bildung des Clathrin-Mantels wird in einem weiteren Schritt durch akzessorische Proteine die Membrankrümmung induziert (McMahon und Gallop 2005; Itoh und De Camilli 2006; Ungewickell und Hinrichsen 2007). Für die anschließende Einwärtsbewegung der Membran ist die Beteiligung von Aktinfilamenten und zugehörigen Proteinen erforderlich (Galletta und Cooper 2009). Um die Abschnürung des Vesikels zu initiieren, interagieren Proteine, die eine so genannte Srchomology region 3(SH3) Domäne enthalten, mit der Proline rich domain (PRD) der GTPase Dynamin (Slepnev und De Camilli 2000; Kim und Chang 2006), siehe auch Kapitel 2.3. Auf diese Weise sorgen sie für eine Rekrutierung Dynamins zur Membran, welches unter GTPHydrolyse zur Abschnürung und Freisetzung des Vesikels führt. Abschließend kommt es als Voraussetzung zur Verschmelzung mit endosomalen Kompartimenten (Altstiel und Branton 1983) zur Abkopplung des Clathrin-Mantels, dem so genannten uncoating (Verstreken et al. 2003; Eisenberg und Greene 2007). 


\section{Clathrin-unabhängige Endozytose}

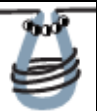

Im Bereich der Clathrin-unabhängigen und Dynamin-abhängigen Endozytose ist der

Caveolin-vermittelte Mechanismus recht gut untersucht. Bei Caveolae handelt es sich um 50-80 nm große Plasmamembraninvaginationen, die dadurch gekennzeichnet sind, dass sie eine der drei bekannten Formen der Caveolin-Protein-Familie enthalten (Rothberg et al. 1992), zumeist Caveolin 1. Die Membran ist in dem betroffenen Abschnitt mit Glykosphingolipiden, Sphingomyelin und Cholesterol angereichert (Sharma et al. 2004), wobei Caveolin-1 Cholesterol bindet (Murata et al. 1995). Für die Abschnürung der Vesikel ist hier die Isoform Dynamin 2 (Yao et al. 2005) erforderlich.

Trotz der beschriebenen Erkenntnisse ist die Bedeutung der Caveolae bezogen auf Endozytose strittig. Es konnte gezeigt werden, dass Caveolae in unstimulierten Zellen relativ stabil entlang der Plasmamembran verbleiben (Thomsen et al. 2002) und nur etwa 2\% pro Minute endozytiert werden (Kirkham et al. 2005). Eine Rolle in der konstitutionellen Endozytose wurde so weitestgehend ausgeschlossen. Unter Stimulation unter anderem mit Cholesterol und Glykosphingolipiden konnte jedoch die Caveolin-vermittelte Endozytose angeregt werden (Sharma et al. 2004). Auch über den Umfang und die Details der verschiedenen weiteren Funktionen wie zum Beispiel im Rahmen der Zelladhäsion, Transzytose, Signalvermittlung, Lipidregulation und als Sensor mechanischer Stimuli besteht noch Klärungsbedarf, siehe Übersichtsartikel Parton und Simons (2007) sowie Doherty und McMahon (2009).

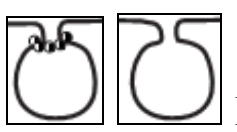

Darüber hinaus ist eine Vielzahl weiterer Clathrin-unabhängiger Wege immer mehr in den Mittelpunkt der aktuellen Forschung gerückt (Mayor und Pagano 2007; Hansen und Nichols 2009). Sie setzen je nach Mechanismus unter anderem eine Beteiligung von Flotillin, kleiner GTPasen wie zum Beispiel RhoA, CDC42 und Arf6 und einer speziellen Zusammensetzung der Membranlipide in dem entsprechenden Abschnitt voraus. Entgegen der Vorstellung, dass Dynamin zur Abschnürung jeglicher Vesikel notwendig und dadurch Voraussetzung aller Endozytoseformen ist, konnte unter anderem anhand von DynaminMutanten nachgewiesen werden, dass Dynamin-unabhängige Wege existieren (Damke et al. 1995; Guha et al. 2003; Xu et al. 2008). 


\subsubsection{Endozytose an der Synapse}

An Transmitter-ausschüttenden Zellen findet der Prozess der Endozytose im Unterschied zu anderen Zellen in erster Linie zwecks Recyclings synaptischer Vesikel statt. In dem Zusammenhang ist die Tatsache zu sehen, dass an Synapsen noch weitere Formen der Endozytose als die zuvor besprochenen zu finden sind. Neben dem klassischen Weg der Clathrin-vermittelten Endozytose existieren alternativ die so genannte „kiss-and-run“- und die bulk-Endozytose, siehe Abb. 2.6.

Dabei ist es von Interesse, bei welcher Stimulusintensität welcher der dargestellten Wege stattfindet. Überdies bestehen kinetische Unterschiede - es existieren endozytotische Vorgänge mit einer schnellen und mit einer langsamen Zeitkonstante (Wu LG et al. 2007; Smith et al. 2008). Eine genaue Zuordnung von Stimulus, Endozytose-Form und Geschwindigkeit wird kontrovers diskutiert und ist zu diesem Zeitpunkt nur vereinzelt sicher festzulegen.

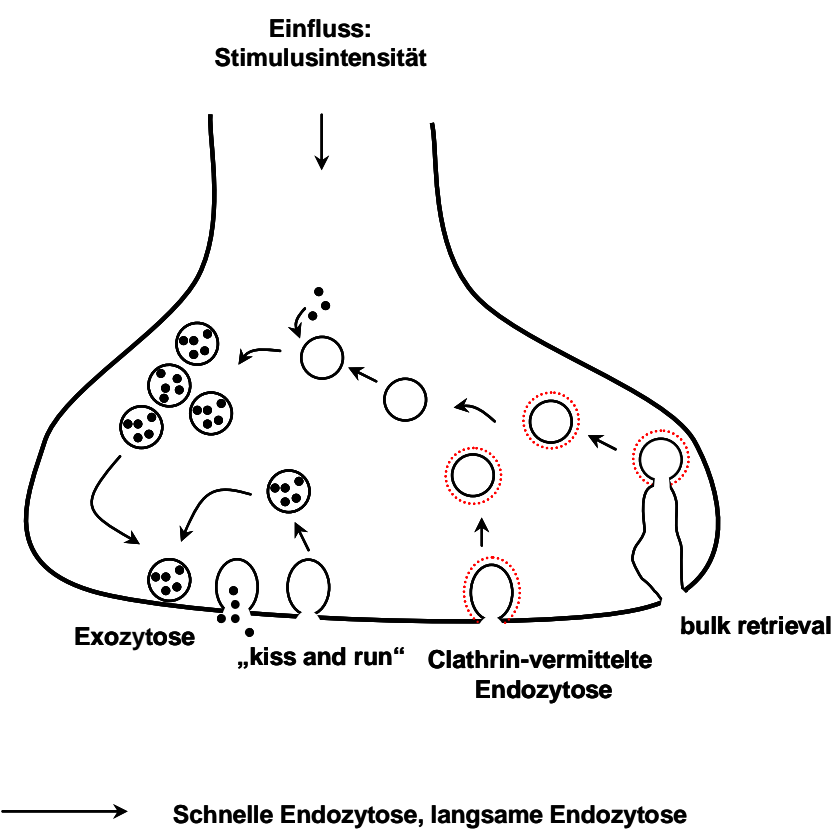

Abb. 2.6: Wege der Reinternalisierung von Vesikeln an der Synapse in Abhängigkeit der Stimulusintensität.

\section{Clathrin-vermittelte Endozytose}

Generell ähnelt die kompensatorische Endozytose am synaptischen Spalt der zuvor besprochenen konstitutiven oder Liganden-stimulierten Clathrin-abhängigen Endozytose anderer Zellen. Dennoch ergeben sich einige Synapsen-spezifische Eigenheiten. Gad et al. (1998) konnten zeigen, dass der Vorgang der Internalisierung in Abhängigkeit der intrazellulären Kalziumkonzentration und damit der Exozytose steht. Ebenso ist bekannt, dass 
von diversen Proteinen ZNS-spezifische Isoformen oder neuronale Splicing-Varianten (Grabowski 1998) existieren. Dieses Phänomen trifft auch auf einige der an der Endozytose beteiligten Proteine $\mathrm{zu}$ - es bestehen unter anderem neuronale Splicing-Varianten der leichten Untereinheit von Clathrin sowie von AP2 $\alpha$ und Dynamin (Slepnev und De Camilli 2000).

Die Clathrin-vermittelte Form stellt mit einer Zeitkonstante von ca. $15 \mathrm{sec}$ einen relativ langsamen Vorgang dar (Granseth et al. 2006; Balaji und Ryan 2007; Xu et al. 2008), wobei dies noch nicht für alle Synapsenformen belegt werden konnte (Wu LG et al. 2007). Neben ihrer Rolle an der Präsynapse ist die Clathrin-vermittelte Endozytose ebenfalls an der Postsynapse in Form von Rezeptorinternalisierung von Bedeutung (Sheng und Kim 2002).

\section{„kiss-and-run“}

Bei dem noch immer kontrovers diskutierten Weg „kiss-and-run“ handelt es sich im Gegensatz zum klassischen Clathrin-vermittelten Weg um eine sich transient öffnende so genannte „Fusions-Pore“, siehe Abb. 2.6. Das zwecks Exozytose an die Membran angelagerte Vesikel schüttet dabei über jene Pore seinen Inhalt in den synaptischen Spalt aus, ohne komplett mit der Plasmamembran zu fusionieren. Stattdessen wird das Vesikel direkt wieder zurück gewonnen (Ceccarelli et al. 1972; 1973; Ales et al. 1999; Aravanis et al. 2003; Wang et al. 2003; He et al. 2006; Zhang et al. 2009).

Der Mechanismus böte zwei Vorteile. Einerseits könnte die schmale Pore die Transmitterausschüttung aus dem Vesikel regulieren (He et al. 2006; He und Wu LG 2007). Andererseits kann der Vorstellung nach ein eben wieder aufgenommenes Vesikel direkt erneut zur Ausschüttung bereit stehen, ohne dass eine langsame enzymatische Abspaltung eines Clathrin-Mantels und der Weg über endosomale Kompartimente stattfinden muss. Aus diesem Grund gilt „kiss-and-run“ als potentielle Form der schnellen Komponente der Endozytose mit einer Zeitkonstante von $<1$ Sekunde (Gandhi und Stevens 2003). Dennoch ist es aufgrund der Tatsache, dass es schwierig ist, „kiss-and-run“ experimentell einwandfrei zu bestätigen, strittig, ob diese Form existiert und einen relevanten Anteil der synaptischen Endozytose übernimmt (He und Wu LG 2007; Smith et al. 2008). 


\section{bulk retrieval}

Dieser Weg unterscheidet sich von den beiden vorhergehenden dadurch, dass keine einzelnen Vesikel, sondern große Abschnitte der Membran, die folgend Endosomen bilden, invaginiert werden. Synaptische Vesikel werden anschließend Clathrin-vermittelt aus den Endosomen generiert (Takei et al. 1996). Dieser Mechanismus konnte für verschiedene neuronale Systeme gezeigt werden, zum Beispiel für die neuromuskuläre Endplatte (Richards et al. 2000; Teng und Wilkinson 2000) und Held'sche Calyx (de Lange et al. 2003), siehe auch Übersichtsartikel Clayton und Cousin (2009). An neuronalen Primärzellkulturen des Hippocampus konnte nachgewiesen werden, dass diese Form der Endozytose besonders durch starke Stimulation ausgelöst wird (Evans und Cousin 2007; Wu W und Wu LG 2007; Clayton et al. 2008). Eine Schlüsselrolle in der bulk-Endozytose scheinen die so genannten Dephosphine und deren Aktivitäts-abhängige Dephosphorylierung durch die Kalzium-abhängige Phosphatase Calcineurin zu spielen (Evans und Cousin 2007). Zu Ihnen gehört auch Dynamin 1 (Cousin und Robinson 2001).

Insgesamt stellt dieser immer noch nicht vollständig geklärte Weg eine Möglichkeit dar, unter hoher Aktivität Struktur und Funktion der Präsynapse aufrecht zu erhalten.

\subsubsection{Besonderheiten der Endozytose an der Bänder-Synapse}

Konventionelle Neuronen werden episodisch auf ein Aktionspotential hin aktiv. Im Gegensatz dazu erhalten Bänder-Synapsen eine kontinuierliche Transmitterausschüttung aufrecht und müssen gleichzeitig in der Lage sein, sehr hohe Raten an Vesikelfusionen zu erreichen. Deshalb werden die Eigenschaften bezüglich der Membran-Wiedergewinnung hier gesondert charakterisiert.

Die Rolle des konventionellen Clathrin-vermittelten Weges an Bänder-Synapsen als potentieller Vertreter der langsamen Komponente ist im Laufe der Zeit mehrfach grundsätzlich in Frage gestellt worden (Heidelberger 2001; Heidelberger et al. 2002; Paillart et al. 2003). Dennoch konnte bereits in sehr frühen Untersuchungen zumindest die Beobachtung umhüllter Vesikel in Bänder-Synapsen gemacht werden. Dies gelang nicht nur für Photorezeptorzellen der Retina (Rea et al. 2004), sondern auch für Sacculus-Haarzellen (Hama und Saito 1977; Kachar et al. 1997; Lenzi et al. 1999) und für IHZ und ÄHZ der Cochlea (Siegel und Brownell 1986; Leake und Snyder 1987; Nadol 1990; Sendin et al. 2007). Einen indirekten Nachweis für einen Clathrin-vermittelten Weg lieferten Jockusch et al. (2005), indem sie an der Bänder-Synapse der retinalen Bipolarzelle durch Inhibition 
Clathrin-involvierender Interaktionen eine Unterbindung der langsamen Komponente der Endozytose erzielten.

Generell ist, wie zuvor für die konventionelle Synapse beschrieben, sowohl eine langsame als auch eine schnelle Komponente der Endozytose zu verzeichnen, erstmals durch Von Gersdorff und Matthews (1994) für die Retina nachgewiesen. Für die IHZ der Maus konnte anhand von Kapazitätsmessungen gezeigt werden, dass sich in Abhängigkeit der intrazellulären Kalziumkonzentration die Zeitkonstante der Endozytose von ca. $15 \mathrm{~s}$ auf ca. $300 \mathrm{~ms}$ beschleunigte (Beutner et al. 2001). Dies ist ein Hinweis dafür, dass die Kalziumkonzentration nicht nur die Exozytose triggert, sondern gleichzeitig auch den Weg der Rückgewinnung beeinflusst. Eine Vielzahl von Studien beschäftigt sich damit, welche endozytotischen Mechanismen den beiden kinetischen Komponenten zugrunde liegen.

Als möglicher Mechanismus für die schnelle Komponente wird „kiss-and-run“ diskutiert. Dennoch ist es bisher nicht gelungen, diesen Weg für die Bänder-Synapse zu verifizieren. Unter Verwendung von total internal reflection fluorescence microscopy (TIRFM), um die Fusion einzelner mit Membranfarbstoff (FM1-43) markierter Vesikel zu verfolgen, kam es zu einem vollständigen Verlust des Farbstoffes als Hinweis auf eine komplette Fusion (Zenisek et al. 2002). Llobet et al. (2003) betrachteten mit Hilfe von interference reflection microscopy (IRM) Änderungen der Membran selbst. Unter Exozytose kam es zur Expansion derselben, so dass auch hier von einer vollständigen Fusion ausgegangen wird. Die beschriebenen Ergebnisse beziehen sich auf retinale Bipolarzellen, Belege für die IHZ stehen aus.

Im Gegensatz zu „kiss-and-run“ liegen Daten vor, die das Vorkommen von bulk-Endozytose an Bänder-Synapsen unterstützen. Mit Hilfe von Elektronenmikroskopie konnte an Sacculus-Haarzellen des Frosches gezeigt werden, dass nach langer Stimulation vermehrt große Membraninvaginationen bzw. große Zisternen in der Nähe der Plasmamembran vorliegen (Lenzi et al. 2002). Ebenfalls anhand von Elektronenmikroskopie wurde der Weg Ferritin-markierter Membran in Bipolarzellen verfolgt (Paillart et al. 2003). Nach langer sowie kurzer Stimulation fanden sich vorwiegend Endosomen vielfacher Größe der synaptischen Vesikel in der Nähe der Plasmamembran oder im Begriff, von dieser abgeschnürt zu werden.

Die Synthese der Resultate unterstreicht, dass grundlegend zu klären ist, welche endozytotischen Mechanismen an der Bänder-Synapse existieren. Erschwert wird dies durch die 
Heterogenität der Bänder-Synapsen. Belege für die verschiedenen Endozytose-Formen müssen zunächst an den einzelnen Bänder-Synapsen (Bipolarzellen, Photorezeporen, Haarzellen) erhoben werden, bevor eine fundierte Gesamtaussage formuliert werden kann. Dabei ist die Datenlage besonders für die IHZ spärlich.

Neben der Frage nach den Formen der Internalisierung ist die Lokalisation der Endozytose in IHZ strittig. Frühe Experimente zeigten Vesikel im Besonderen im basalen Kompartiment der IHZ mit anschließendem Transport in den apikalen Bereich zu lysosomalen und multivesikulären Strukturen (Siegel und Brownell 1986; Leake und Snyder 1987). Auch in Sacculus-Haarzellen wurden endozytotische Ereignisse fast ausschließlich im Bereich der aktiven Zone beobachtet (Lenzi et al. 2002). Meyer J et al. (2001) dagegen konnten mit Hilfe des fluoreszierenden Membran-Farbstoffes FM1-43 in IHZ und ÄHZ des Meerschweinchens Anfärbungen des basalen sowie des apikalen Pols nachweisen. Die Theorie einer apikalen Form der Endozytose in IHZ wurde durch weitere Arbeiten unterstützt (Kachar et al. 1997; Seiler und Nicolson 1999; Griesinger et al. 2002), wobei auf Grundlage dieser Daten nicht auszuschließen ist, dass es sich um einen seperaten Vesikelzyklus handelt.

\subsection{Dynamin}

Die große GTPase Dynamin ist wie zuvor dargestellt essentiell für den Vorgang der Endozytose und soll im Hinblick auf die Fragestellung dieser Arbeit detaillierter vorgestellt werden.

Initial wurde sie als Mikrotubuli-bindendes Protein entdeckt (Shpetner und Vallee 1989), um kurz darauf mit dem Genprodukt shibire in Drosophila in Verbindung gebracht zu werden (van der Bliek und Meyerowitz 1991). Shibire-Mutanten weisen aufgrund einer

Blockade eines späten Stadiums der Endozytose eine temperatursensitive Paralyse auf (Koenig und Ikeda 1989), so dass auf diese Weise erstmals die Bedeutung Dynamins im Rahmen der Endozytose vermutet wurde. Versuche an Zellkulturen mit Überexpression dominant negativer Mutanten-Formen Dynamins stützten diese These (Herskovits et al. 1993; van der Bliek et al. 1993; Damke et al. 1994). Im Folgenden wurde Dynamin an Clathrin-gesäumten pits und an den Hälsen der daraus entstehenden Clathrin-Vesikel lokalisiert (Takei et al. 1995), so dass in der Zusammenschau mit weiteren in-vitro- 
Ergebnissen (Hinshaw und Schmid 1995) die Rolle Dynamins in der Vesikel-Abspaltung gesehen werden konnte.

Es existieren drei Isoformen des klassischen Dynamins, wobei sie ein unterschiedliches Verteilungsmuster aufweisen. Dynamin 1 (Obar et al. 1990) ist eine ZNS-spezifische Form, die vorwiegend präsynaptisch lokalisiert ist (Powell und Robinson 1995; Gray et al. 2003), wohingegen Dynamin 2 ubiquitär zu finden ist (Cook et al. 1994). Dynamin 3 galt zunächst als Testis-spezifisch (Nakata et al. 1993), bis nachgewiesen werden konnte, dass es zusätzlich sowohl in Herz und Lunge als auch im ZNS vorhanden ist, hier vornehmlich im Bereich des postsynaptischen Kompartimentes (Cook et al. 1996; Lu et al. 2007).

Des Weiteren bilden die Isoformen jeweils Splicing-Varianten aus (Cao et al. 1998). Für diese Arbeit ist es von Bedeutung, dass unter anderem die Isoformen Dynamin 1A und 1B existieren, die sich durch ein alternatives in der Mittel-Domäne, siehe Abb. 2.7, befindliches Exon unterscheiden (Cao et al. 1998). Sie nehmen während der Entwicklung unterschiedliche Schwerpunkte ein. Während Dynamin 1B die höchste Expression während der embryonalen und frühen postnatalen Entwicklung zeigt und anschließend bei einsetzender Synaptogenese wieder abnimmt, steigt die Expression von Dynamin 1A zu diesem Zeitpunkt an (Boumil et al. 2010).

Das Dynamin-Gen kodiert für verschiedene Domänen, siehe Abb. 2.7, denen jeweils bestimmte Funktionen zugeordnet werden können.

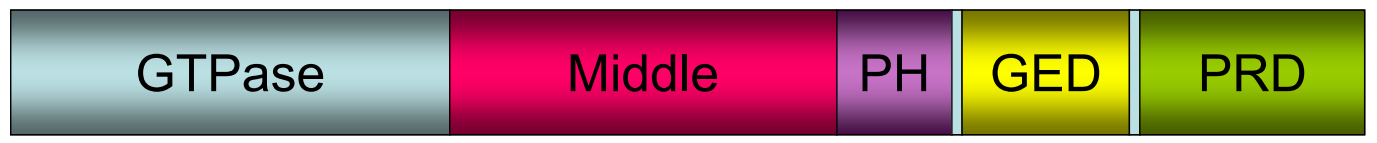

Abb. 2.7 Schematische Architektur von Dynamin 1, modifiziert nach Slepnev und de Camilli (2000), S.163.

Am N-Terminus befindet sich die GTPase-Domäne, die drei GTP-bindende Motive enthält. Ihre katalytische Aktivität kann im Unterschied zu anderen GTPasen durch die Oligomerisation Dynamins in Ringe oder Spiralen weit mehr als 50fach stimuliert werden (Sever et al. 1999; Stowell et al. 1999). Für diese Ausbildung tetramerischer Strukturen aus Monomeren sowie für eine höhergradige Oligomerisation sorgt die Mittel-Domäne (Ramachandran et al. 2007). Die pleckstrin homology domain (PH) bindet PtdIns(4,5) $\mathrm{P}_{2}$, 
wobei diese Interaktion zum einen Membran-Bindung garantiert und zum anderen ebenfalls die GTPase-Aktivität stimuliert (Zheng et al. 1996). Die GTPase effector domain (GED) ist ebenfalls an der Oligomerisierung Dynamins beteiligt (Smirnova et al. 1999) und fungiert als GTPase aktivierendes Protein (Muhlberg et al. 1997). Am C-Terminus liegt die prolinerich domain (PRD), die in der Lage ist, in den Endozytosevorgang involvierte Proteine mit einer SH3-Domäne zu binden, wie zum Beispiel Amphiphysin und Endophysin (Hinshaw 2000; Yoshida et al. 2004).

Der genaue Mechanismus der Arbeitsweise Dynamins ist bis zum jetzigen Zeitpunkt ungeklärt. Es liegen bezüglich der Konformationsänderungen während des GTP-HydrolyseZyklus divergente Ergebnisse vor. Elektronenmikroskopische Beobachtungen ergaben einerseits, dass die Bindung von GTP eine Konstriktion der spiralförmig angeordneten Moleküle nach sich zieht (Chen YJ et al. 2004; Danino et al. 2004), siehe Abb. 2.8 (b). Andererseits zeigten Untersuchungen, dass es unter GTP-Hydrolyse zu einer Verlängerung der „Dynamin-Spirale“ und damit zu einer Vergrößerung des Abstands des Vesikels zur Membran kommt (Stowell et al. 1999), siehe Abb. 2.8 (c).
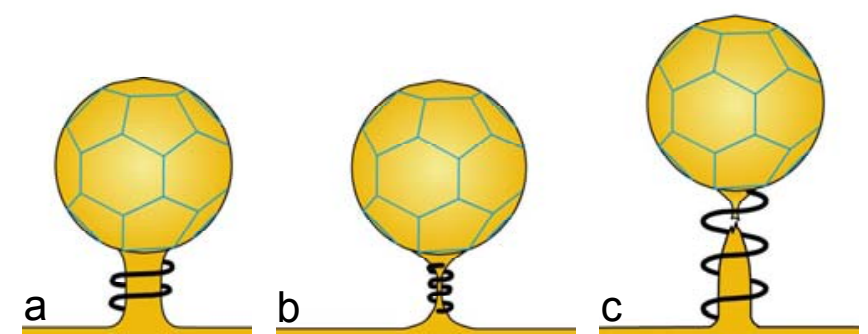

Abb. 2.8: Modell potentieller Funktionsweisen von Dynamin. (a) Gemeinsamer Ausganspunkt: spiralförmige Anlagerung des Moleküls an den Vesikelhals. (b) Konstriktion. (c) Ausdehnung der Spirale mit konsekutiver Abspaltung. Entnommen der McMahon Homepage (www.endocytosis.org/).

Außerdem wird die Rotation des Vesikelhalses als Ursache für dessen Abschnürung in Betracht gezogen (Roux et al. 2006). Eine alternative Aufgabe Dynamins könnte sich im Rahmen der Regulation der Endozytose befinden (Sever et al. 1999; 2000). Narayanan et al. (2005) schlagen ein Modell vor, in dem Dynamin beide Aufgaben - sowohl die regulatorische als auch die mechanische - erfüllt.

Neben der Funktionsweise des Proteins stellt sich nicht nur die Frage, in welche der verschiedenen Endozytose-Wege Dynamin involviert ist, siehe Kapitel 2.2.1, sondern auch, 
bei welcher Stimulationsintensität es am synaptischen Spalt benötigt wird und ob es dort schnelle und/oder langsame Formen unterstützt.

Unter dem Einsatz pharmakologischer Inhibitoren konnte gezeigt werden, dass sowohl die langsame (Yamashita et al. 2005) als auch die schnelle Form der synaptischen Endozytose in Abhängigkeit von GTP-Hydrolyse stattfindet (Jockusch et al. 2005). Im Gegensatz zu diesen beiden Arbeiten, die GTP $\gamma \mathrm{S}$ als Inhibitor einsetzen und dadurch eine eher unspezifische Blockade erzielen, inhibiert das kleine Molekül dynasore spezifisch die GTPase-Aktivität von Dynamin 1 und 2 (Macia et al. 2006). Basierend auf der Applikation von dynasore fand sich Dynamin als Voraussetzung der synaptischen Endozytose sowohl im Anschluss an starke als auch an schwache bzw. kurze Stimulation. Die Autoren gehen in diesem Fall von einer Inhibition der Clathrin-abhängigen Endozytose sowie von ,kiss-andrun“" aus (Newton et al. 2006).

Im Gegensatz zu den angeführten Arbeiten eröffnen knock-out-Mausmodelle die Möglichkeit, Isoform-spezifische Aussagen treffen zu können. Unter Verwendung dieser Methode ergeben sich für Dynamin 1 jedoch inkonsistente Aussagen. Ferguson et al. (2007) beobachteten an primären Dynamin-1-knock-out-Neuronen die Entstehung zusammenhängender Clathrin-ummantelter Membraninvaginationen. Dies wurde als Hinweis auf einen nicht intakten Ablauf der Abschnürung Clathrin-umhüllter Vesikel betrachtet. Ferner wurde eine Zunahme eines endozytotischen Defizits bei starker Stimulation festgestellt. Folglich wäre sowohl eine Beteiligung Dynamins an der Clathrin-vermittelten Endozytose als auch an bulk retrieval als dominierende Form auf starke Stimulation denkbar. Unterstützt wird diese Überlegung durch kürzlich gewonnene Daten, die demonstrieren, dass Dynamin 1 essentiell für den Prozess des bulk retrievals ist (Clayton et al. 2009).

Lou et al. (2008) konnten an Dynamin-1-knock-out-Mäusen ebenfalls nachweisen, dass die an starke Stimulation gekoppelte Endozytose beeinträchtigt ist. Allerdings legen die Resultate nahe, dass es sich bei dieser Form nicht um bulk retrieval, sondern um einen rein Clathrin-abhängigen Weg handelt. Hayashi et al. (2008) beobachteten auf massive Stimulation hin trotz Dynamin-1-knock-out Endosomen-artige Formationen und deuteten diesen Umstand als Anzeichen Dynamin-1-unabhängiger bulk-Endozytose.

Aus der Zusammenschau der angeführten Ergebnisse wird deutlich, dass nicht nur die molekulare Funktionsweise Dynamins, sondern auch dessen Beteiligung an den verschiedenen Endozytose-Mechanismen noch weiter zu klären ist. 


\subsection{Objektive audiologische Testverfahren}

\subsubsection{Frühe auditorisch evozierte Poteltiale - FAEP}

Die elektrische Reaktionsaudiometrie (electric response audiometry $=$ ERA) ist ein Verfahren, bei dem durch akustische Reize hervorgerufene elektrische Potentiale mittels Elektroden abgeleitet werden. Dabei erscheinen die Aktionspotentiale des Hörnervs des Menschen je nach Reizstärke mit einer Latenz von 1-5 ms, die Hirnstammreaktionen nach bis zu 10 ms und Subkortex und Kortex erst nach 50-150 ms. Entsprechend ist gegenüber anderen auditorischen Verfahren die Möglichkeit gegeben, Schädigungen entlang der gesamten Hörbahn zu diagnostizieren.

Bei der in dieser Arbeit angewandten brainstem electric response audiometry (BERA) werden frühe auditorisch evozierte Potentiale, die so genannten FAEP, des Hörnervs und des Hirnstamms gemessen. Dabei entsteht ein charakteristisches Antwortmuster, das nach Erstbeschreiber Jewett (1970) aus sieben Wellen besteht, siehe Abb. 2.9.

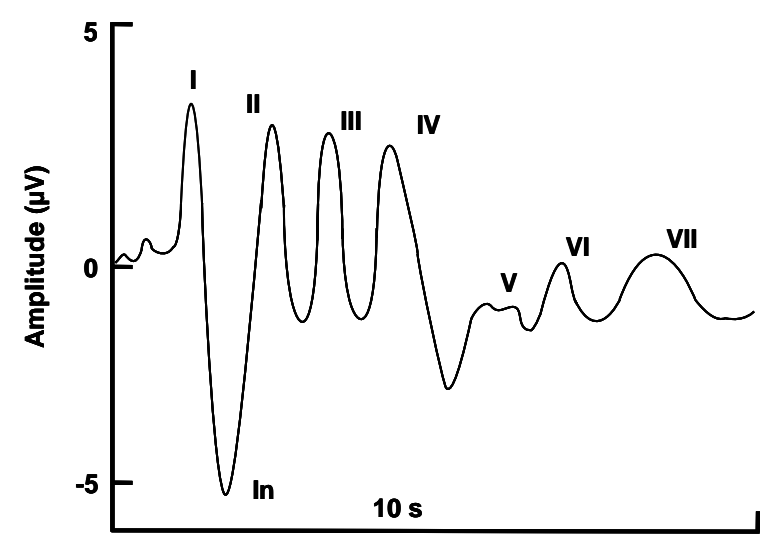

Abb. 2.9: Registrierung akustisch evozierter Potentiale mit Ableitung zwischen Mastoid und Vertex, hier der Maus.

Ziel intensiver Forschung ist die Zuordnung anatomischer Strukturen zu den einzelnen Wellen, siehe Übersichtartikel Biacabe et al. (2001) sowie Melcher et al. (1996 a; 1996 b) bzw. Melcher und Kiang (1996). Voraussetzung dafür sind Kenntnisse über die komplexe Verschaltung und Fortleitung akustischer Stimuli, siehe Abb. 2.10. 


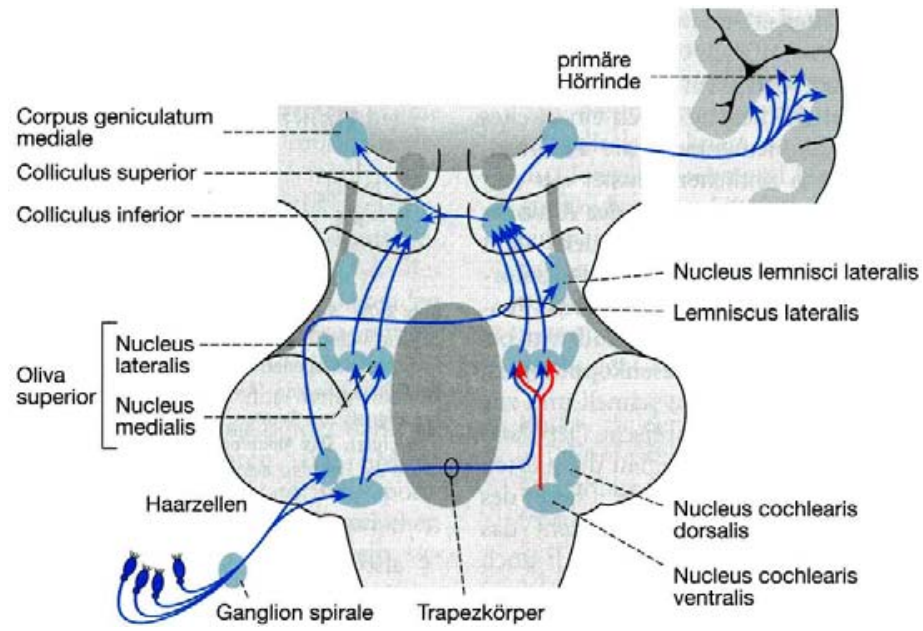

Abb. 2.10: Schematische Darstellung der Hörbahn. Gezeigt sind die wichtigsten, von der linken Cochlea aufsteigenden Projektionen. Durch kontralaterale Verbindungen findet die Verarbeitung der Information zu einem großen Teil in der rechten Gehirnhälfte statt. Entnommen aus Oliver und Fakler (2004), S.150.

Sowohl Welle I als auch $\mathrm{I}_{\mathrm{n}}$ werden den cochleären Spiralganglienzellen zugeordnet. Diese wiederum sind auf eine adäquate Stimulation durch die Sinneszellen angewiesen, so dass sich deren Funktion ebenfalls in der Welle I und $I_{n}$ wiederfindet. Die Welle II wird durch die Zellen des Nucleus cochlearis generiert. Die Welle III nimmt ihren Ursprung ebenfalls aus den Zellen des Nucleus cochlearis als auch aus denen des kontralateralen Nucleus olivaris superior. Die Welle IV entsteht durch ipsi- und kontralaterale Zellen des Nucleus olivaris superior sowie durch den anteroventralen Kern des Nucleus cochlearis. Letzterer trägt auch zur Entstehung der Welle V bei sowie auch die Zellen des Lemniscus lateralis und des Colliculus inferior. Welle VI und VII treten nur unsicher auf, so dass hier auf eine Zuordnung verzichtet wird.

\subsubsection{Otoakustische Emissionen - OAE}

Bei den otoakustischen Emissionen (OAE) handelt es sich um Töne cochleären Ursprungs, die mit einem in den Gehörgang eingepassten Mikrophon aufgenommen werden können. Dieses Messverfahren stellt im Vergleich zur Hirnstammaudiometrie ein schnelles und einfaches Verfahren dar und wird klinisch sowie im Bereich der Forschung als nichtinvasives Instrument vielfach verwendet, siehe Übersichtsartikel Kemp (2002).

Die otoakustischen Emissionen werden von den ÄHZ und ihren assoziierten mechanischen Strukturen generiert. Generell kann unterschieden werden in spontane OAE (SOAE), die 
ohne jeglichen akustischen Reiz fortwährend emittiert werden und evozierte Emissionen, die auf akustische Stimulation hin entstehen. Letztere wiederum werden in transitorisch und simultan evozierte OAE (TEOAE und SEOAE) sowie Distorsionsprodukte otoakustischer Emissionen (DPOAE) unterteilt. Während TEOAE durch kurze Schallimpulse ausgelöst werden und die Anregung eines weiten Teils der Cochlea widerspiegeln, haben SEOAE die Frequenz des anregenden Tones.

Die in dieser Arbeit gemessenen DPOAE werden mit zwei Tönen benachbarter Frequenz ausgelöst und geben die Emissionen aus der schmalen Überlappungszone der Wanderwellen der Primärtöne wieder. Ihre Frequenz setzt sich aus der Kombination der Primärtonfrequenzen $f_{1}$ und $f_{2}$ zusammen und erreicht bei der Frequenz $2 f_{1}-f_{2}$ die größte Schalldruckamplitude. 


\section{$3 \quad$ Material und Methoden}

\subsection{Versuchstiere}

Die Versuchstiere mit dem Hintergrund FVB/NJ stammen aus dem Jackson Labarotory (Bar Harbor, ME, USA). Die spontan aufgetretene Mutation fitful befindet sich im Exon 11 des Dynamin-1A-Gens, das für die Mitteldomäne kodiert. Es handelt sich dabei um eine Punktmutation in Form eines Basenaustausches, die zur Substitution der Aminosäure 408 Alanin durch Threonin führt, dabei jedoch die alternative Isoform Dynamin 1B nicht beeinträchtigt. Phänotypisch sind bei den heterozygoten Tieren nach zunächst unauffälliger Entwicklung im Alter von 2-3 Monaten generalisierte, tonisch-klonische epileptische Anfälle zu beobachten (darauf basierend erfolgte die Benennung der Mutation, fit $=$ Anfall). Die homozygoten Tiere hingegen, im Folgenden DNM 1A ${ }^{\mathrm{ftfl} / \mathrm{ftfl}}$ genannt, weisen schon nach Geburt eine erhebliche zerebelläre Ataxie und neben einem verzögerten Wachstum nach einigen Tagen ebenfalls Anfälle auf. Ihre Lebenserwartung liegt bei ca. drei Wochen.

Zur Zucht wurden heterozygote Tiere verpaart. Die Haltung fand in den Räumlichkeiten der Zentralen Tiereinrichtung (ZTE) der Universitätsklinik Göttingen statt. Bei identischen Lebensbedingungen wurden für die Versuche sowohl Wildtyp, Heterozygote als auch Homozygote verwendet. Sie wurden im Alter von ca. 14 Tagen und mit einem Gewicht von ca. 5-8 g durchgeführt, um das Überleben der homozygoten Tiere bis zu diesem Zeitpunkt sicher zu stellen. Die Genotypisierung fand mittels PCR anhand von Schwanzspitzenmaterial im Anschluss an die Versuche statt.

\subsection{Immunhistochemie}

\subsubsection{Präparation des Corti-Organes}

Nach der Dekapitation des Tieres und der Abpräparation der Schädelhaut wurde die Kalotte vom Foramen magnum ausgehend in zwei Hälften geschnitten. Diese wurden in eine mit eisgekühlter HEPES Hanks Lösung befüllte Petrischale verbracht.

Unter dem Mikroskop wurden die Hirnanteile entfernt und die Bulla zur Darstellung der Cochlea eröffnet. Die knöcherne Decke wurde vorsichtig mit einer feinen Pinzette an der Spitze eröffnet und anschließend so weit entfernt, dass die obere Windung des Corti-Organs 
entnommen werden konnte. Des Weiteren wurde darauf geachtet, dass die Stria vascularis nicht mehr an dem Präparat haftete und musste gegebenenfalls vorsichtig abgelöst werden.

\subsubsection{Färbung}

Im Anschluss an die Präparation wurde das Corti-Organ direkt mit einer Pasteurpipette in das Fixiermedium überführt. Dazu diente entsprechend der Färbung 4\%iges Formaldehyd oder 99,9\%iges Methanol (Merck). Methanolfixierungen fanden 20 Minuten lang bei $-20^{\circ} \mathrm{C}$ statt, Formaldehydfixierungen auf einem Eiselement gelagert wahlweise 10, 20 oder 60 Minuten lang.

Nach Auswaschen des Fixiermediums (3x10 Minuten in phosphate buffer solution (PBS) bei Raumtemperatur) erfolgte in einem feuchten Behältnis bei Raumtemperatur eine einstündige Inkubation in goat serum dilution buffer (GSDB). Die Inkubation mit den in GSDB gelösten Primärantikörpern erfolgte über Nacht bei $4^{\circ} \mathrm{C}$ ebenfalls in dem feuchten Behältnis.

Am nächsten Tag wurde das Präparat $3 \times 10$ Minuten mit Waschpuffer gewaschen und anschließend in einer feuchten, lichtgeschützten Box mit den Sekundärantikörpern inkubiert. Die folgenden Schritte fanden ebenfalls lichtgeschützt statt. Das Präparat wurde wiederum 3x10 Minuten mit dem Waschpuffer und ein weiteres Mal 10 Minuten lang mit $5 \mathrm{mM}$ Phosphatpuffer (PB) gewaschen. Anschließend wurde das Präparat in einem Tropfen mounting-oil auf einen Objektträger verbracht und mit einem Deckgläschen versehen.

Für die Färbungen wurden folgende Antikörper und Lösungen verwendet:

Primärantikörper:

Maus-anti-CtBP2 (C-terminal-binding protein)/RIBEYE(IgG1): BD Bioscience, 1:200, erkennt B-Domäne von RIBEYE und den Transkriptionsrepressor CtBP2 (Schmitz et al. 2000)

Kaninchen-anti-Glutamat Rezeptor 2 und 3: Chemicon, 1:200, polyklonaler Antikörper Kaninchen-anti-Dynamin1: Synaptic Systems, 1:200, polyklonaler Antikörper Kaninchen-anti-Calbindin D-28K: Swant, 1:1000, monoklonaler Antikörper Maus-anti-Calbindin: Swant, 1:500, monoklonaler Antikörper

Maus-anti-Clathrin leichte Kette, neuronenspezifisch: Synaptic Systems, 1:1000, monoklonaler Antikörper

Kaninchen-anti-Clathrin schwere Kette: Biozol, 1:400, polyklonaler Antikörper

Kaninchen-anti-Caveolin 1: Biozol , 1:500, polyklonaler Antikörper 
Sekundärantikörper:

Ziege-anti-Kaninchen Alexa Fluor 488: Molecular Probes, 1:200

Ziege-anti-Maus Alexa Fluor 568: Molecular Probes, 1:200

Kernfärbung:

Hoechst 34580: MolecularProbes, 1:1000

\section{Lösungen:}

HEPES HANKS (in mM): $141 \mathrm{NaCl}, 5,4 \mathrm{KCl}, 1 \mathrm{MgCl}_{2}, 0,5 \mathrm{MgSO}_{4}, 6$ L-Glutamin, 7 Glucose, $10 \mathrm{NaOH}-\mathrm{HEPES}$

Formaldehyd: 4\%ig in PBS

PBS (in mM): $140 \mathrm{NaCl}, 2,7 \mathrm{KCl}, 8 \mathrm{Na}_{2} \mathrm{HPO}_{4}, 1,5 \mathrm{KH}_{2} \mathrm{PO}_{4}$

GSDB: $16 \%$ iges Ziegenserum, 450mM NaCl, 0,3\%iges Triton X-100, $20 \mathrm{mM}$ Phosphatpuffer, $\mathrm{pH}=7,4$

Waschpuffer: $450 \mathrm{mM} \mathrm{NaCl}, 20 \mathrm{mM}$ Phosphatpuffer, 0,3\%iges Triton X-100

5 mM Phosphatpuffer: 4,17 mM Na $2 \mathrm{HPO}_{4}, 0,83 \mathrm{mM} \mathrm{NaH}_{2} \mathrm{PO}_{4}$

\subsection{Konfokale Lasermikroskopie}

Zur Analyse der fluoreszenzmarkierten Präparate wurde ein Leica TCS SP2 Mikroskop (Leica, Wetzlar, Deutschland) mit den Lasern Ar 488 und $\mathrm{Kr} 568$ verwendet. Wenn nicht anders gekennzeichnet, wurde standardmäßig mit 63 facher Vergrößerung in Öl gearbeitet. Um dreidimensionale Bilder zu erzeugen, wurde ein stack zweidimensionaler Bilder mit einer Schichtdicke von 0,5 $\mu \mathrm{m}$ entlang der Z-Achse aufgenommen. Die Anzahl der Pixel betrug 1024x1024. Die anschließende Auswertung der Aufnahmen erfolgte mit der Software ImageJ (NIH image, Bethesda, MD, USA).

\subsection{Synapsenzählung}

Um die Anzahl der Synapsen pro Haarzellen bestimmen zu können, wurden je Corti-Organ in zwei definierten Regionen der Basalmembran stacks aufgenommen. Dabei befand sich der erste Abschnitt in unmittelbarer Nähe zum Apex, der zweite Abschnitt visuell bemessen bei ca. 6-7 kHz. Anhand der Projektionen konnten die mit anti-CtBP2/RIBEYE und antiGluR2/3 gefärbten Prä- und Postsynapsen manuell mit Hilfe von ImageJ ausgezählt werden. 


\subsection{Audiologie}

\subsubsection{Allgemein}

Zur Messung der FAEP sowie der otoakustischen Signale wurden die Tiere mit einem Ketamin-Xylazingemisch der Dosis 0,0625 mg Ketamin/g KG und 0,125 $\mu$ g Xylazin/g KG mittels intraperitonealer Applikation narkotisiert. Auf diese Weise wurden Störsignale durch die Maus selbst minimiert, ohne die Antwort zu beeinträchtigen. Um eine durchgängige Narkose sicherzustellen, verblieb ein intraperitoneal gelegener Katheter, über den, wenn erforderlich, jederzeit Narkose nachgegeben werden konnte.

Alle Messungen fanden in einer schallgedämmten Kammer statt, die zur inneren Schalldämpfung dreidimensional mit ca. $80 \mathrm{~cm}$ langen, in den Raum hineinragenden Schaumstoffkeilen ausgekleidet war. Der Messplatz war mit einer Wärmematte (Hugo Sachs Elektronik-Harvard Apparatus) ausgestattet, die entsprechend der rektal gemessenen Temperatur diese konstant auf $37^{\circ} \mathrm{C}$ regelte.

\subsubsection{Messung der FAEP}

Die Messung mittels BERA erfolgte im Freifeld, die Maus befand sich dafür jeweils in 8,5cm Entfernung von dem Lautsprecher. Um die Reizantwort abzuleiten, dienten drei subkutan gestochene Nadelelektroden, siehe Abb. 3.1. Die Erdelektrode wurde in Schwanznähe, die Differenzelektrode am Vertex und die Referenzelektrode am Mastoid platziert. Die Impedanz zwischen den Ableitelektroden betrug weniger als $1 \mathrm{k} \Omega$.
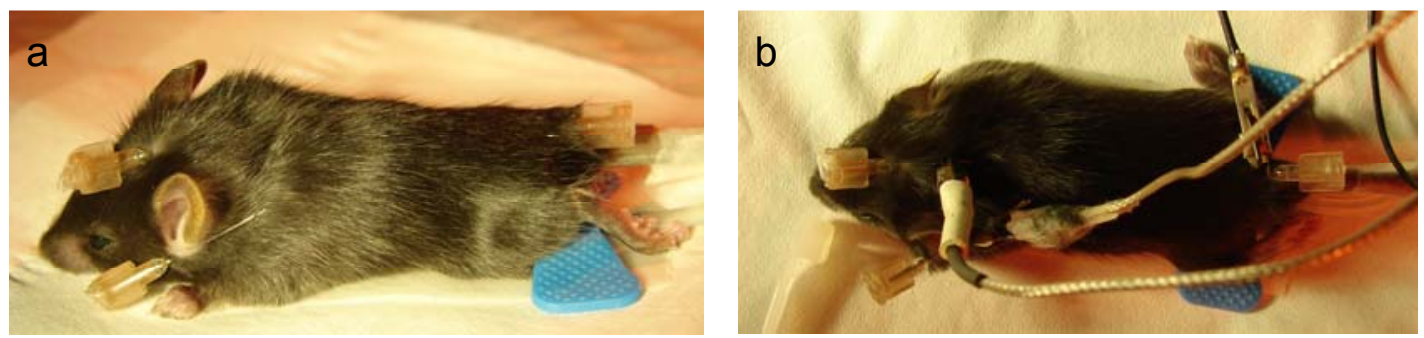

Abb. 3.1: Position der Nadelelektroden, (a) unverkabelt. (b) verkabelt. 


\section{Signal}

Die Messung der FAEP bestand aus zwei verschiedenen Anteilen - der frequenzspezifischen Tonschwellenbestimmung und der Klickmessung zur Erfassung von Amplituden und Latenzen der Reizantwort.

Erstere wurde mittels kurzer Tonimpulse durchgeführt. Diese Form von Stimulus kann in verschiedenen Frequenzen in Form von Sinusschwingungen dargeboten werden - im Zuge dieser Arbeit in 4, 8, 12, 16, 24 und $32 \mathrm{kHz}$. Die Stimuluslänge betrug $12 \mathrm{~ms}$ inklusive Anstiegs- und Abfallsflanken von jeweils $1 \mathrm{~ms}$. Das Interstimulusintervall belief sich auf $50 \mathrm{~ms}$ bei einer Stimulationsrate von $20 \mathrm{~Hz}$.

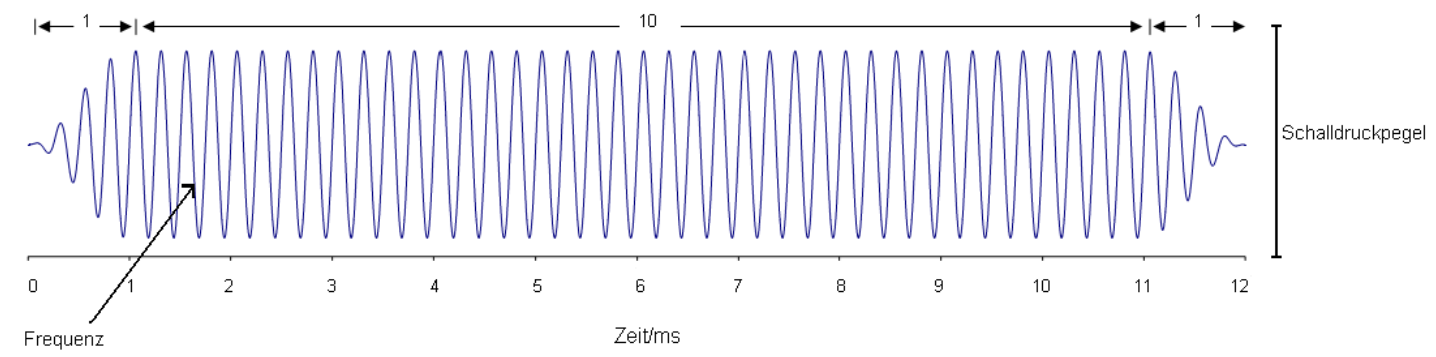

Abb. 3.2: Tonimpuls

Es wurde in $10 \mathrm{~dB}$ Schritten bis zur Hörschwelle gemessen. Die Schwelle wurde bei der niedrigsten Intensität, die noch eine reproduzierbare Wellenform hervorrief, festgelegt.

Der Stimulus für die Klickmessung bestand aus einem Rechteckimpuls mit einer Pulsdauer von $30 \mu \mathrm{s}$, der mit einer Repetitionsrate von 20 bzw. $90 \mathrm{~Hz}$ der Schallquelle zugeführt wurde. Diese Art von Stimulus erregt weite Teile der Basilarmembran. Appliziert wurde er ebenfalls in $10 \mathrm{~dB}$ Schritten.

Die Informationen für die verschiedenen Stimuli enthielt eine mit der Software SigGen (Tucker-Davis-Technologies, Ft Lauderdale, FL, USA) erstellte Konfigurationsdatei, in der die Reizparameter wie Form (Ton, Klick, Mischform), Dauer, Frequenz und Pegel definiert waren. Die beiden letzteren wurden als Variablen festgelegt und waren dadurch während der Messung über BioSig32 (Tucker-Davis-Technologies) veränderbar. 


\section{Aufbau}

Für die akustische Stimulation und die Aufnahme der auditorisch evozierten Potentiale wurde eine computergestützte Mess-Station (Tucker-Davis-Technologies, TDT System III) und die bereits erwähnte Software BioSig32 und SigGen verwendet. Dieses System mit seinen Komponenten bietet die Möglichkeit, sowohl psychoakustische als auch neurophysiologische und somit auch evozierte Potential-Messungen durchzuführen. Die Reizsignale können rechnergesteuert - über SigGen - erstellt und präsentiert sowie deren Antwort anschließend aufgezeichnet werden.

Abb. 3.3 stellt das Schaltbild zur Messung der FAEP dar. Die Signalgenerierung erfolgte über den real time processor (RP2.1), der außerdem den D/A-Wandler beinhaltete. Um Reizsignale mit genau definiertem Schalldruckpegel erzeugen zu können, bedurfte es einer kontrollierten Abschwächung des Signals, bevor es der Schallquelle zugeführt wurde. Dazu dienten die beiden hintereinander geschalteten Abschwächer programmable attenuator 5 (PA5). Durch sie kann in 0,1 dB Schritten der Schalldruckpegel von 0 bis $130 \mathrm{~dB}-$ allerdings abhängig von der jeweiligen Frequenz - angepasst werden. Bevor das Signal zu dem Lautsprecher geleitet wurde, durchlief es den Leistungsverstärker HB6. Der Lautsprecher (Monacor DT-119) war für beide Teile der Messung in 8,5 cm Entfernung von dem Tier platziert. 


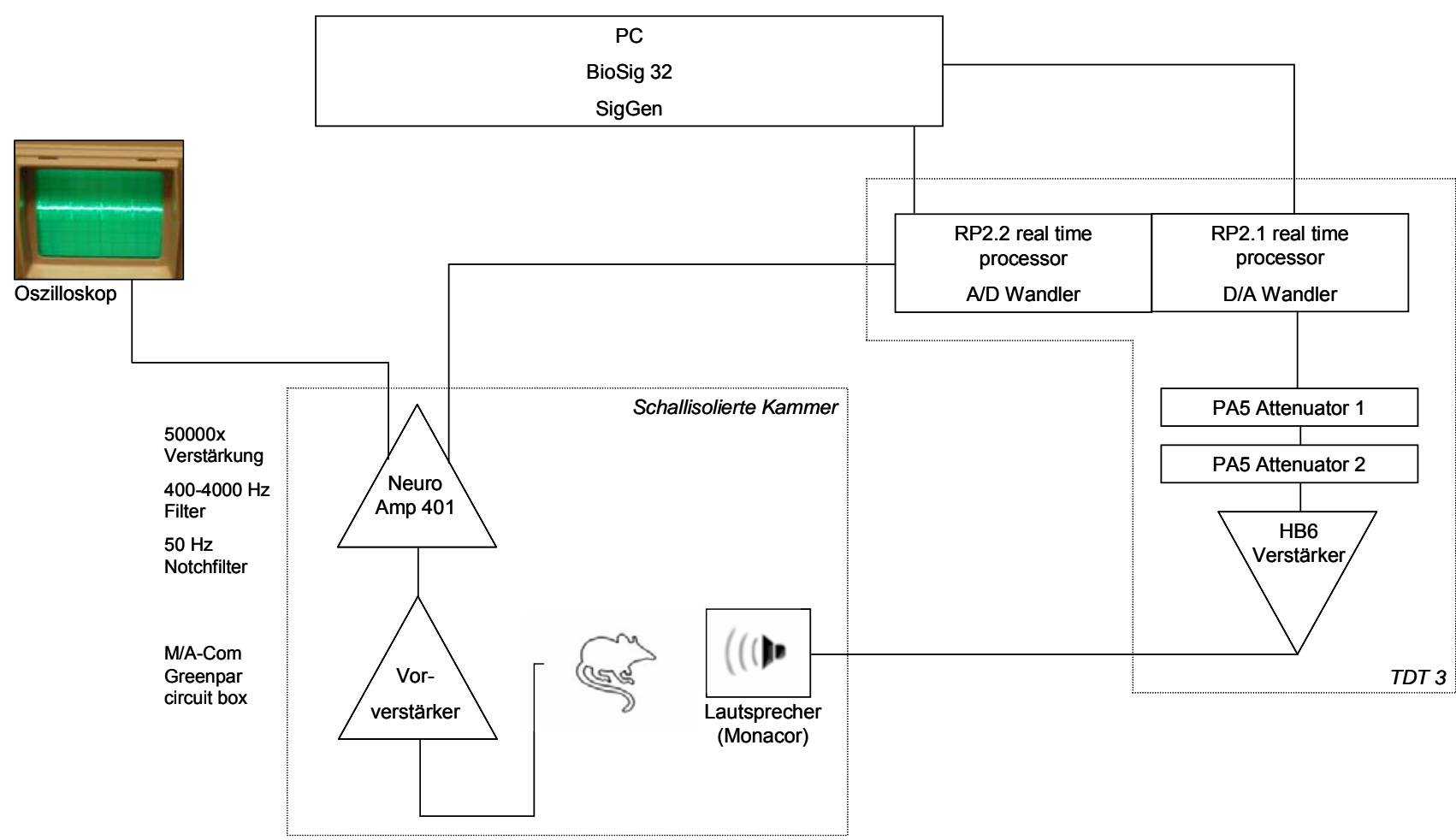

Abb. 3.3: Schaltbild zur Messung der FAEP.

Die durch den Schallreiz evozierten Potentiale wurden mit Hilfe der Nadelelektroden abgeleitet, siehe Abb. 3.1. Die Reizantwort in Form eines Differentialpotentials zwischen Referenz- und Aufnahmeelektrode wurde an einen Differenzverstärker, den Vorverstärker (M/A-Com Greenpar circuit box), in unmittelbarer Nähe zur Maus gegeben und von da aus an den Verstärker JHM NeuroAmp 401 weitergeleitet. Hier erfolgten eine 50.000fache Verstärkung und eine Bandpassfilterung von 400 - $4000 \mathrm{~Hz}$ des Messsignals. Außerdem filterte ein integrierter Notch-Filter die Störungen der Netzfrequenz bei $50 \mathrm{~Hz}$ heraus.

Die Datenaufnahme und die A/D-Umwandlung erfolgten in dem real time processor (RP2.2). Von hier aus wurde das Signal in BioSig32 eingespeist und aufgenommen.

Außerdem wurde das Signal von dem NeuroAmp aus ebenfalls dem Oszilloskop zur Überprüfung des physiologischen Status und der Narkosetiefe zugeleitet. Diese ließen sich anhand des EKG-Artefaktes beurteilen. 


\section{Aufzeichnung und Auswertung}

Jeder Stimulus wurde zweimal bis zu 2.000 Mal präsentiert und die Antworten gemittelt und mit Hilfe von BioSig32 aufgezeichnet. Durch die Mittlung wurden Hintergrundaktivitäten unterdrückt und außerdem wiederkehrende großamplitudige Signale, die nicht zu der gesuchten Antwort gehörten, als Artefakt erkannt und nicht in die Durchschnittsberechnung miteinbezogen (wie zum Beispiel der Herzschlag).

Zur Bestimmung der frequenzspezifischen Tonschwellen wurden die zwei gemittelten Spuren übereinander gelegt und visuell auf eine reproduzierbare Antwort hin geprüft.

Für die Ermittlung der Latenzen und Amplituden wurden die Ergebnisse der Klickmessung herangezogen. Die Amplitude wurde von dem jeweiligen Wellenpeak bis zum nächsten Tal gemessen. Die Latenzen der Wellen ergaben sich aus der Zeit vom akustischen Reizbeginn bis zum Auftreten der jeweiligen Potentialspitze.

\section{Kalibrierung}

Um sicherzustellen, dass die gewünschten Schalldruckpegel auch tatsächlich am Gehörgang des Tieres vorherrschten, wurde das System kalibriert. Dieser Vorgang wurde im Abstand von $8,5 \mathrm{~cm}$ vom Lautsprecher, den Experimentbedingungen entsprechend, durchgeführt. Das dargebotene Signal wurde mit einem Kalibriermikrophon mit integriertem Vorverstärker (B\&K Typ 4939, Brüel\&Kjaer GmbH, Bremen, Deutschland) aufgenommen und an den Measuring Amplifier (B\&K 2610, Brüel\&Kjaer GmbH, Bremen, Deutschland) weitergeleitet. Die ermittelten Werte wurden zur Berechnung der Abschwächerwerte (PA5) herangezogen.

\subsubsection{Messung der DPOAE}

\section{Signal}

Wie in dem Einleitungskapitel 2.4.2 erläutert, werden Distorsionsprodukte otoakustischer Emissionen mittels Stimulation mit zwei Tönen ausgelöst. Dazu wurden zwei Primärtöne in Form von Sinustönen unterschiedlicher Frequenz gleichzeitig erzeugt. Das Verhältnis der Frequenzen betrug $f_{2} / f_{1}=1,2$, der Schalldruckpegel von $f_{2}$ bemaß dabei $10 \mathrm{~dB}$ weniger als der von $\mathrm{f}_{1}$. 
Zuerst wurde ein so genanntes DP-Gramm erstellt, indem die Töne mit steigender Frequenz, siehe Tab. 3.1, aber gleichbleibendem Schalldruckpegel von $\mathrm{f}_{1}=60 \mathrm{~dB}$ appliziert wurden. Die Emissionsdruckpegel der DPOAE wurden als Funktion der Primärtonfrequenz $\mathrm{f}_{2}$ aufgetragen.

Tab. 3.1: Verwendete Frequenzen für das DP-Gramm bei $\mathrm{f}_{1}=60 \mathrm{~dB}$

\begin{tabular}{|l|l|l|l|l|l|}
\hline $\mathbf{f}_{\mathbf{1}}(\mathbf{k H z})$ & 5 & 6,667 & 10 & 13,333 & 16,667 \\
\hline $\mathbf{f}_{\mathbf{2}}(\mathbf{k H z})$ & 6 & 8 & 12 & 16 & 20 \\
\hline
\end{tabular}

Im Anschluss daran wurde eine Wachstumsfunktion erstellt, indem bei gleichbleibender Frequenz $-\mathrm{f}_{2}=16 \mathrm{kHz}-$ Pegel von 10 bis $70 \mathrm{~dB}$ in $10 \mathrm{~dB}$ Schritten dargeboten wurden. Die Schalldruckpegel der DPOAE wurden dabei als Funktion des Primärtones $\mathrm{L}_{2}$ aufgetragen.

\section{Aufbau}

Abb. 3.4 zeigt das Schaltbild zur Messung der DPOAE. Die akustische Stimulation mit den Primärtönen erfolgte mittels eines CD-Players. Die von dort ausgehenden Signale der beiden Frequenzen wurden getrennt über zwei Abschwächer PA4 (TDT System II) geleitet. Zu ihrer Steuerung diente die Software BioSig32.

Die Signale liefen zu zwei getrennten elektrostatischen Lautsprechern, EC1 (TDT), denen entsprechend die Treiber ED1 (electrostatic speaker driver) vorgeschaltet waren. 


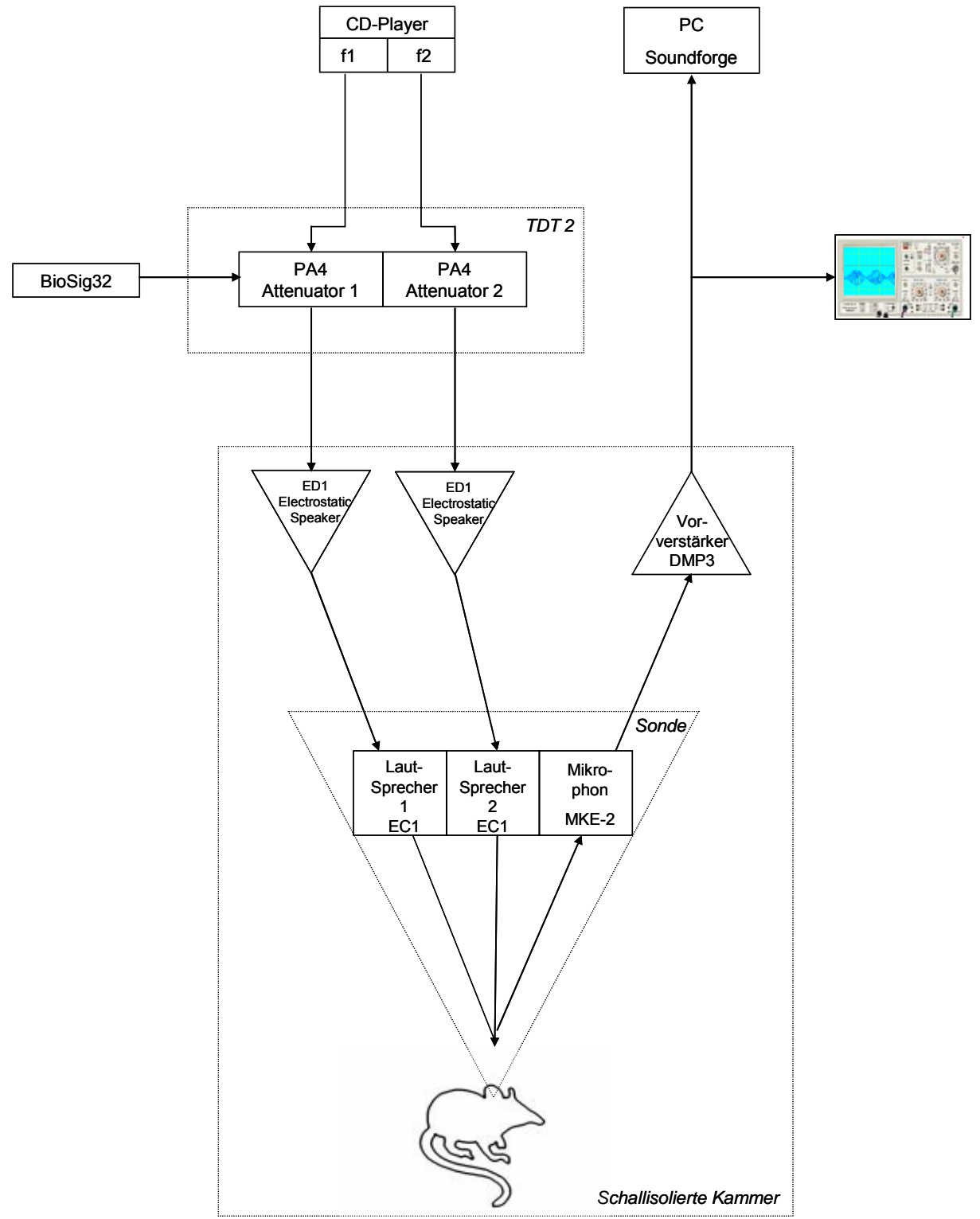

Abb. 3.4: Schaltbild zur Messung der DPOAE

Da es sich im Gegensatz zur Freifeld-Messung der BERA um eine Messung im geschlossenen Schallfeld handelte, wurden die applizierten Signale über zwei Silikonschläuche einer Ohrsonde zugeführt. Diese Sonde wurde mit Hilfe eines Mikromanipulators in den äußeren Gehörgang der Versuchstiere luftdicht eingepasst. Erst an dieser Stelle überlagerten sich die beiden Sinustöne mit Ausbildung einer Schwebung, siehe Abb. 3.5. 


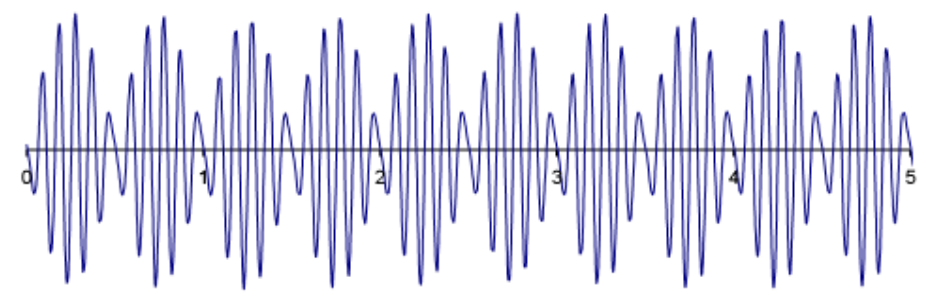

Zeit'ms

Abb. 3.5: Schwebung durch Überlagerung von $f_{1}=10 \mathrm{kHz}$ und $f_{2}=12 \mathrm{kHz}$

Als dritte Komponente enthielt die Sonde ein Mikrophon (MKE 2, Sennheiser, Hannover, Deutschland) zur Registrierung des entstehenden Distorsionsproduktes.

Das durch den Mikrophonvorverstärker DMP3 (dual microphone preamplifier, MIDIMAN, CA, USA) verstärkte Signal wurde sowohl an das Oszilloskop als auch an den PC weitergeleitet. Hier diente die Software Soundforge (Sony Creative Software, WI, USA) zur Aufnahme des eingehenden Signals. Das Oszilloskop wurde zur Optimierung der Sondenposition genutzt, da nur bei entsprechender Überlagerung der Töne die in Abb. 3.5 gezeigte Schwebung entsteht.

Neben dem eigentlichen Nutzsignal, den otoakustischen Emissionen, das eher geringer Intensität ist, enthielt das registrierte Signal weitere Störanteile. Diese waren, da die Messung synchron mit der Stimulation erfolgte, vor allem durch die Reiztöne selbst, aber auch durch das Umgebungs- und Körperrauschen durch Atmung, Blutzirkulation und Muskelarbeit bedingt. Um jene Störanteile herauszumitteln, wurden die Stimulation und simultane Messung je Frequenz und Schalldruckpegel über den Zeitraum von einer Minute hinweg durchgeführt. Zusätzlich wurde eine Minute lang eine Leeraufnahme ohne jeglichen zugeführten Reiz erstellt. 
Zur letztendlichen Auswertung fand eine Spektrumanalyse mit Hilfe von MATLAB (The Mathworks, Natick, MA, USA) anhand der Fast Fourier Transformation statt, wobei die Frequenz der ausgelösten DPOAE sich bei $2 \mathrm{f}_{1}-\mathrm{f}_{2}$ findet, siehe Abb. 3.6.

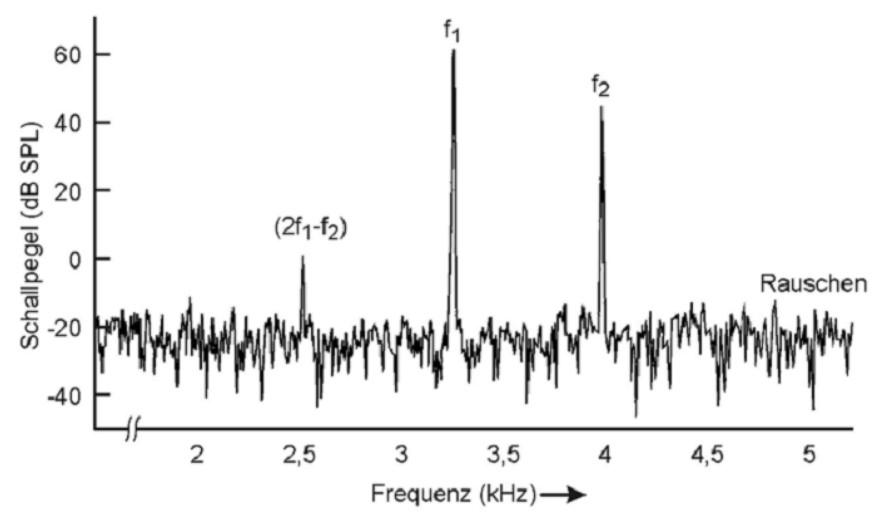

Abb. 3.6: Spektrale Darstellung der Primärtöne und der DPOAE. Entnommen aus Janssen (2001), S.83.

\section{Kalibrierung}

Die Kalibrierung fand mit Hilfe eines Modell-Ohres aus Teflon mit nachgebildetem Volumen statt. Das Signal wurde über die auch bei den Versuchen verwendete Sonde zugeführt und auf der anderen Seite des Modells mit dem Kalibrierungsmikrophon aufgezeichnet und wiederum an den measuring amplifier weitergeleitet. 


\section{$4 \quad$ Ergebnisse}

\subsection{Nachweis endozytotischer Proteine der IHZ}

Vor dem Hintergrund, dass bis $\mathrm{zu}$ dem jetzigen Zeitpunkt kaum Daten bezüglich der verschiedenen Endozytoseformen und deren beteiligten Proteinen an der IHZ existieren, wurde im Rahmen dieser Arbeit die IHZ mittels immunhistochemischer Färbung auf die Expression einzelner endozytotischer Proteine hin untersucht.

Für den klassischen Clathrin-vermittelten Weg ist die molekulare Grundlage gut beschrieben, siehe Kapitel 2.2.1, so dass dessen Anwesenheit anhand der Präsenz bestimmter Proteine angenommen werden kann.

Zunächst wurde dabei die Expression Clathrins untersucht. Wie in Kapitel 2.2.2 beschrieben, existieren neuronale Isoformen und Splicing-Varianten diverser Proteine, derart auch von Clathrin. Unter der Vorstellung, dass die IHZ als Transmitter-ausschüttende Zelle Neuronen-vergleichbare Leistungen erfüllen muss und ebenso Synapsen ausbildet, wurde in einem ersten Schritt geprüft, ob die ZNS-spezifische Splicing-Variante Clathrins vorliegt. Zu diesem Zweck wurde ein Antikörper gegen die neuronenspezifische Variante der leichten Kette Clathrins (rot) verwandt, siehe Abb. 4.1 (a). Wie auch in folgenden Färbungen diente zur Markierung des Zytosols der IHZ zusätzlich ein Antikörper gegen Calbindin D-28K (grün), ein Kalzium-bindendes Protein. Als Ergebnis ergibt sich eine Clathrin-spezifische Anfärbung im basalen Bereich der Haarzelle, bzw. unterhalb von ihr, in Form einer netzartigen Struktur. Dabei ist nicht sicher zu sagen, ob eine Überlagerung von Zytosol und Clathrin stattfindet oder Clathrin sich ausschließlich außerhalb der Haarzelle und damit im angrenzenden Nervengeflecht befindet. 


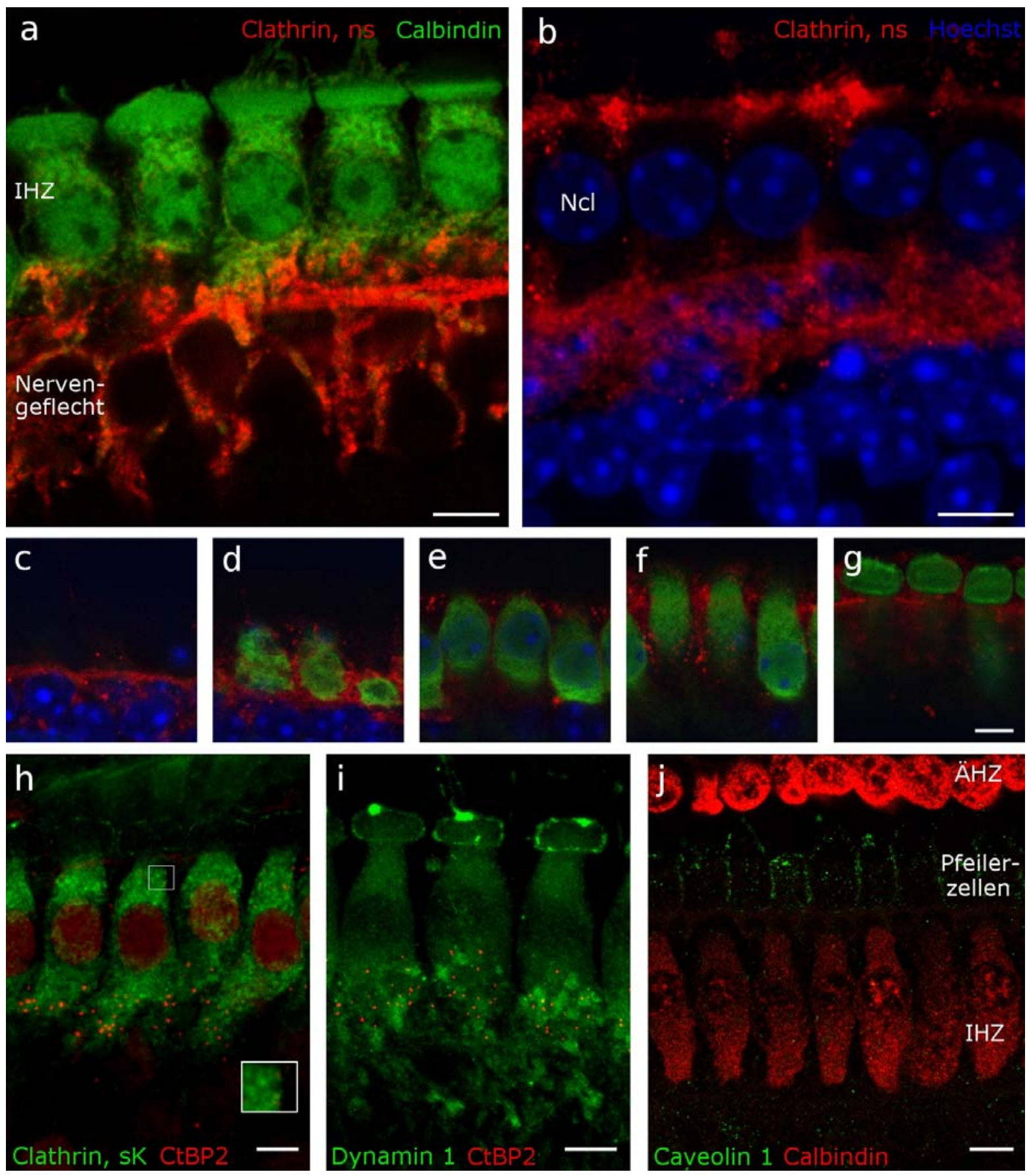

Abb. 4.1: Immunhistochemische Darstellung enodozytotischer Proteine in der IHZ. Wenn nicht anders bezeichnet, Projektion eines dreidimensionalen stacks, 63 fache Vergößerung, Maßstab jeweils $5 \mu \mathrm{m}$, für Verdünnungen siehe Kapitel 3.2.2.

(a) Anti-Clathrin, neuronenspezifisch (ns), und Anti-Calbindin. (b) Anti-Clathrin, neuronenspezifisch, und Kernfärbung mit Hoechst 34580, Nucleus (Ncl). (c-g) Einzelschichten von 0,5 $\mu \mathrm{m}$ eines stacks, Anti-Calbindin (grün), Anti-Clathrin, neuronenspezifisch (rot), und Kernfärbung mit Hoechst 34580 (blau), n=8 (für neuronenspezifisches Clathrin). (h) Anti-Clathrin, schwere Kette (sK) und damit ubiquitär und Anti-CtBP2/RIBEYE, n=7, Einsatz - vermutlich vesikuläre/ membranöse Strukturen. (i) Anti-Dynamin 1 und Anti-CtBP2/RIBEYE, n=12. (j) Anti-Caveolin 1 und Anti-Calbindin, IHZ im unteren, ÄHZ im oberen Bildbereich zu sehen, zentrale Einzelschicht, $\mathrm{n}=4$. 
Die Abb. 4.1 (b) zeigt eine Färbung gegen die neuronenspezifische leichte Kette Clathrins, mit Hilfe von Hoechst 34580 (blau) sind zusätzlich die Kerne (Ncl) dargestellt. Das Auslassen der Calbindin-Färbung vermeidet eine mögliche unspezifische Mitanregung des Zytosols. Clathrin (rot) ist mit einem regelmäßigen Abstand zum Zellkern lokalisiert und umrahmt die IHZ. In Abb. 4.1 (c-g) sind einzelne konfokale Schichten dargestellt. Die Färbung besteht in diesem Fall aus Calbindin, Clathrin und Hoechst, um genau nachvollziehen zu können, ob der gezeigte Clathrin-Rahmen sich ausschließlich extrazellulär befindet. Es ist ersichtlich, dass die neuronenspezifische Form Clathrins in der dreidimensionalen Entwicklung zu keinem Zeitpunkt innerhalb der Zelle liegt.

Aus diesem Grund wurde in einem nächsten Schritt untersucht, ob anstatt dessen die ubiquitäre Clathrin-Isoform exprimiert wird. Dazu wurde eine Färbung mit einem Antikörper gegen die schwere Kette Clathrins, nicht neuronenspezifisch, vorgenommen (grün), siehe Abb. 4.1 (h). Zusätzlich wurden die Nuclei mittels Hoechst und die synaptischen Bänder mittels eines Antikörpers gegen CtBP2, ein Transkriptionsrepressor, und die B-Domäne von RIBEYE, Hauptbestandteil der synaptischen Bänder, angefärbt (rot). Es zeigt sich deutlich, dass das gesamte Zytosol ausgenommen der Region der Kutikularplatte eine Clathrin-spezifische Anfärbung aufweist. Im apikalen Bereich sind gefärbte zytosolische Strukturen zu erkennen, siehe Einsatz, bei denen es sich vermutlich um Membranen handelt.

Als ein weiterer wesentlicher Faktor innerhalb der Clathrin-abhängigen aber auch Clathrinunabhängigen Endozytose wurde die Färbung von Dynamin vorgenommen. Es wurde ein Antikörper gegen Dynamin 1 verwandt (grün) und außerdem, wie in Abb. 4.1 (h) zuvor, die synaptischen Bänder zur Lokalisation der Synapsen mit angefärbt (rot), siehe Abb. 4.1 (i). Es findet sich eine homogene Anfärbung des gesamten Zytosols mit einer Akzentuierung der Kutikularplatte durch den Dynamin-1-Antikörper. Des Weiteren fallen im basalen Bereich 1-2 $\mu \mathrm{m}$ große patches auf, die sich dem Kompartiment der Synapsen zuordnen lassen.

Der letzte Punkt der Expressionsanalyse behandelt den Caveolin-abhängigen Weg, der ebenfalls in Abhängigkeit von Dynamin stattfindet. Um die Relevanz desselben zu prüfen, wurde das Präparat mit Antikörpern gegen Caveolin 1 (grün) sowie gegen Calbindin (rot) gefärbt. Abb. 4.1 (j) demonstriert als Resultat ein Fehlen von Caveolin innerhalb der IHZ (untere Zellreihe). Apikal der Zellen sind die Konturen anderer Zellen mit angefärbt. Hierbei 
könnte es sich aufgrund ihrer Lokalisation zwischen IHZ und ÄHZ um die so genannten Pfeilerzellen handeln. Ferner zeigten sich in anderen Schnittebenen Caveolin-Anfärbungen der umliegenden Zellen in Form gitterartiger Muster (hier nicht dargestellt).

Zusammenfassend konnte festgestellt werden, dass sowohl Clathrin als auch Dynamin, im Speziellen die ubiquitäre Form Clathrins und die neuronale Isoform Dynamin 1, in der IHZ vorhanden sind, Caveolin 1 sich dagegen nicht darstellen lässt.

\subsection{Dynamin-Mutante: DNM $1 A^{f f l / f t l l}$}

Im Folgenden wurde der Fokus auf das endozytotische Protein Dynamin und im Besonderen auf die Isoform Dynamin 1 gelegt. Um dessen Bedeutung und Funktion genauer analysieren zu können, wurde eine Maus-Mutante für Dynamin 1A, siehe Kapitel 3.1, eingesetzt. Zunächst wurden Daten bezüglich der Morphologie und molekularen Ausstattung gewonnen. Nachfolgend wurden audiologische Testverfahren vorgenommen, um den Einfluss von Dynamin 1A auf die Funktion des Innenohres zu untersuchen.

Generell wurden bei den Versuchen ebenfalls stets Heterozygote mit Wildtypen verglichen, allerdings fanden sich keine visuellen und statistischen Unterschiede, so dass sie als ein Pool behandelt wurden und im Folgenden als DNM 1A $\mathrm{A}^{+/ \mathrm{fffl} /+/+}$ bezeichnet werden.

\subsubsection{Morphologische Analyse}

\subsubsection{Anatomie des Corti-Organs}

Zur Charakterisierung der DNM-1A ${ }^{\text {ftfl/ftfl }}$-Maus wurde zunächst ein Überblick darüber gewonnen, ob die Anatomie des Corti-Organes Auffälligkeiten aufweist. Zu diesem Zweck wurden eine Übersichtsaufnahme, siehe Abb. 4.2 (a), sowie eine Vergrößerung der Haarzellen, siehe Abb. 4.2 (b) und eine DIC (differential interference contrast) Aufnahme am lebenden Präparat, siehe Abb. 4.2 (c), angefertigt. 

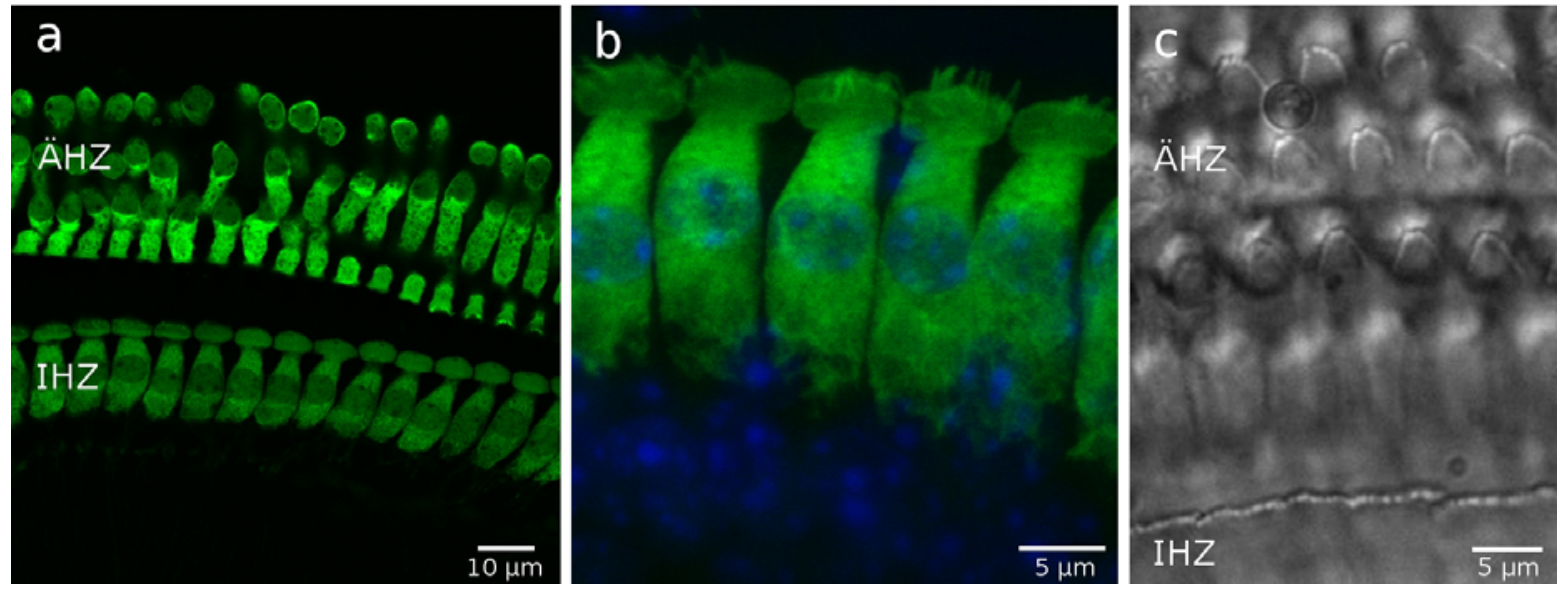

Abb. 4.2: (a) Übersichtsaufnahme eines Abschnitts des Corti-Organs von DNM 1A fttl/ftll, Calbindin (grün), zentrale Einzelschicht. Oben drei Reihen ÄHZ, unten IHZ. (b) Vergrößerte Darstellung der IHZ von DNM 1A ${ }^{\text {fttl/ftrl }}$, Calbindin (grün), Hoechst 34580 (blau), Projektion eines stacks. (c) Mikroskopische DIC-Aufnahme des Corti-Organs. Zilien der ÄHZ und IHZ.

In Abb. 4.2 (a) sind mittels Calbindinfärbung (grün) sowohl eine regelmäßig angeordnete Reihe IHZ im unteren Bildbereich als auch das Vorhandensein der drei Reihen ÄHZ apikal davon zu sehen. Abb. 4.2 (b) zeigt die Existenz der Zilien und der Kutikularplatte der IHZ. Abb. 4.2 (c) belegt dies am lebenden Präparat, zusätzlich sind die Zilien der ÄHZ zu erkennen.

\subsubsection{Synapsen}

Boumil et al. (2010) konnten morphologische Auffälligkeiten an Primärkulturen von Neuronen der DNM-1A ${ }^{\text {fttl/ftl }}$-Mäuse beobachten - die Axone der homozygoten Tiere stellten sich als kürzer und mit Filapodien-ähnlichen Protusionen versehen dar. Außerdem wiesen sie nach, dass im Wildtyp mit Beginn der Synaptogenese ein Wechsel der überwiegenden Isoform von Dynamin 1B zu Dynamin 1A stattfindet. Vor diesem Hintergrund wurde die quantitative Synapsenausbildung auf einen potentiellen Effekt der Mutation hin untersucht.

Dazu wurden immunhistochemische Färbungen des Corti-Organes sowohl der präsynaptischen Bänder (anti-CtBP2/RIBEYE, rot) als auch postsynaptischer Cluster an Glutamatrezeptoren (anti-GluR 2/3, grün) vorgenommen. Auf diese Weise konnte die Zuordnung von Band (= Präsynapse) und Postsynapse sichergestellt werden. 
Abb. 4.3 zeigt exemplarisch ein Präparat der ersten Windung des Corti-Organes mit beschriebener Färbung. Da sich die Synapsenanzahl entlang der tonotopischen Achse verändert (Meyer AC et al. 2009), wurden zwei Bereiche zur Zählung der Synapsen herangezogen. Der erste Abschnitt findet sich in unmittelbarer Nähe zum Apex, der zweite bei ca. $6-7 \mathrm{kHz}$.

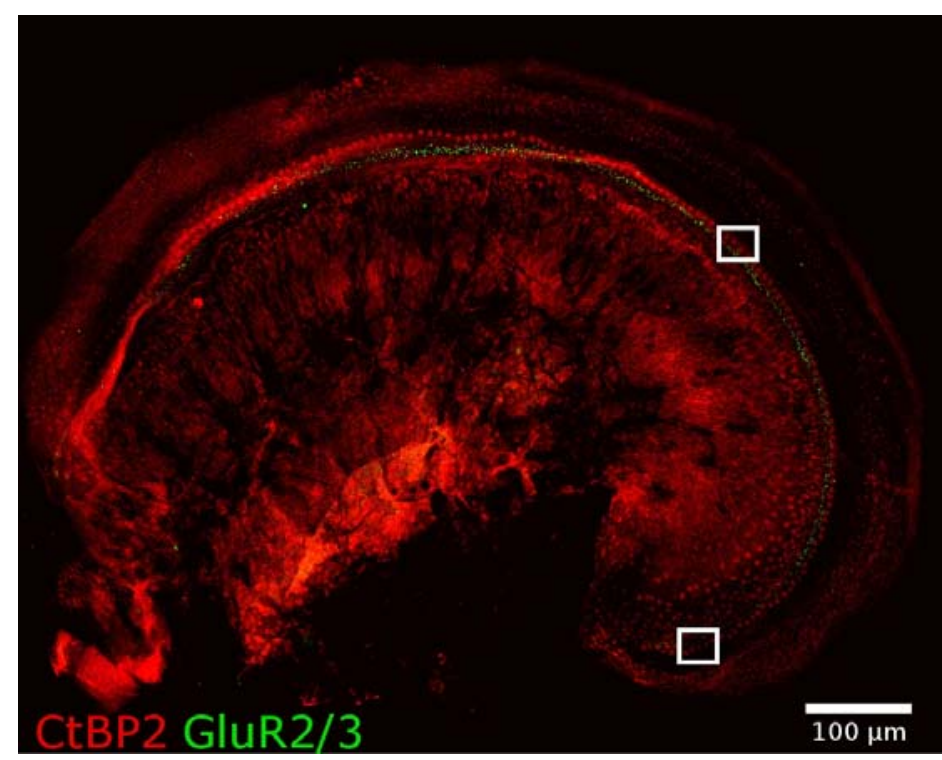

Abb. 4.3: Immunhistochemische Darstellung der oberen Windung eines Corti-Organes mit 10facher Vergrößerung, zentrale Einzelschicht. Färbung mit Anti-CtBP2/RIBEYE (rot) und Anti-GluR 2/3 (grün). Die Ausschnitte entlang der Reihe der IHZ entsprechen den Bereichen, von denen aus die Synapsen gezählt wurden.

Zur Zählung wurden mit Hilfe von konfokaler Mikroskopie dreidimensionale stacks produziert, deren Projektionen für die Auswertung genutzt wurden.

Abb. 4.4 zeigt Ausschnitte dieser Projektionen für DNM 1A ${ }^{+/ f f f l /+/+}$ und DNM 1A ${ }^{\text {ftfl/ftfl }}$ jeweils für beide Bereiche. Die hinzugefügten Linien markieren den schwach angefärbten Zellkern.

Bereits visuell ist kein ausgeprägter Unterschied in Bezug auf die Synapsenanzahl festzustellen. Die Aufnahmen bestätigen die ortsabhängige Variabilität der Synapsenanzahl. Sie nimmt vom Apex aus zu, um im Bereich des schärfsten Hörens ein Maximum zu erreichen und dann wieder abzunehmen (Meyer AC et al. 2009). 

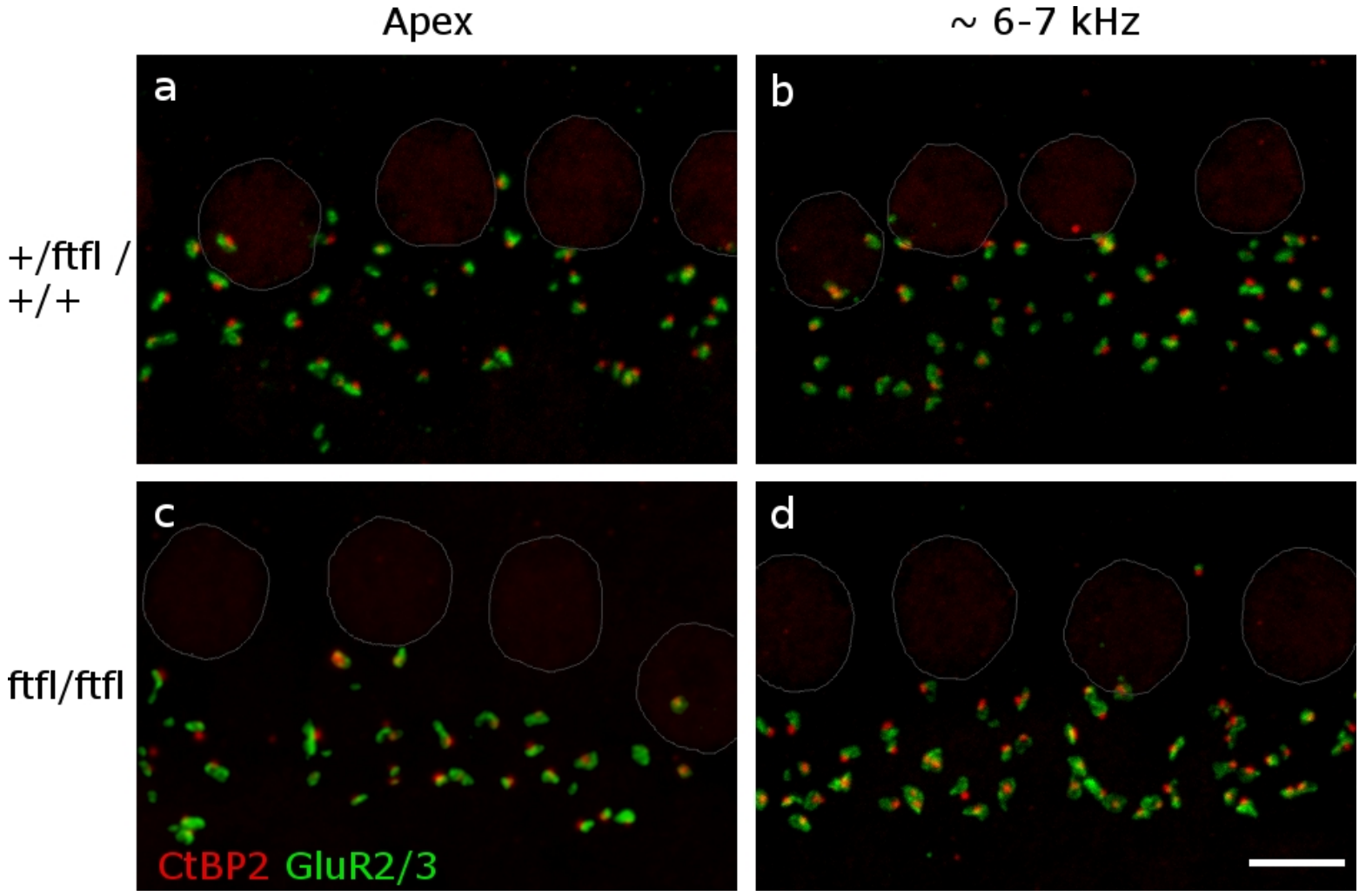

Abb. 4.4: Projektionen dreidimensionaler stacks von IHZ von DNM 1A ${ }^{\mathrm{ftfl} / \mathrm{ftfl}}$ und DNM 1A ${ }^{+/ \mathrm{ftfl} / /^{+/+}} \mathrm{mit}^{\mathrm{t}}$ Darstellung der Synapsen im Apexbereich und bei 6-7 kHz. Färbung der synaptischen Bänder (Präsynapse) mittels Anti-CtBP2/RIBEYE (rot) und der Glutamatrezeptoren (Postsynapse) mittels Anti-GluR2/3 (grün). Umrandung der Nuclei zur exakten Zählung, Maßstab $5 \mu \mathrm{m}$.

Abb. 4.5 stellt die Auswertung der Zählung dar. Es fand sich eine Tendenz zu weniger Synapsen in den Mutanten, die jedoch keine statistische Signifikanz erreichte (Mittelwert \pm Standardabweichung des Mittelwertes: DNM 1A ${ }^{\mathrm{ftfl} / \mathrm{ftfl}}$ Apex 9,39 \pm 0,74, 6-7 kHz 12,66 \pm 1,26, DNM 1A $\mathrm{A}^{+/ \mathrm{fffl} /+/+}$ Apex 10,64 $\pm 0,42,6-7 \mathrm{kHz} 14,68 \pm 0,42$ bei $\left.\mathrm{n}(\mathrm{IHZ})=120\right)$. 


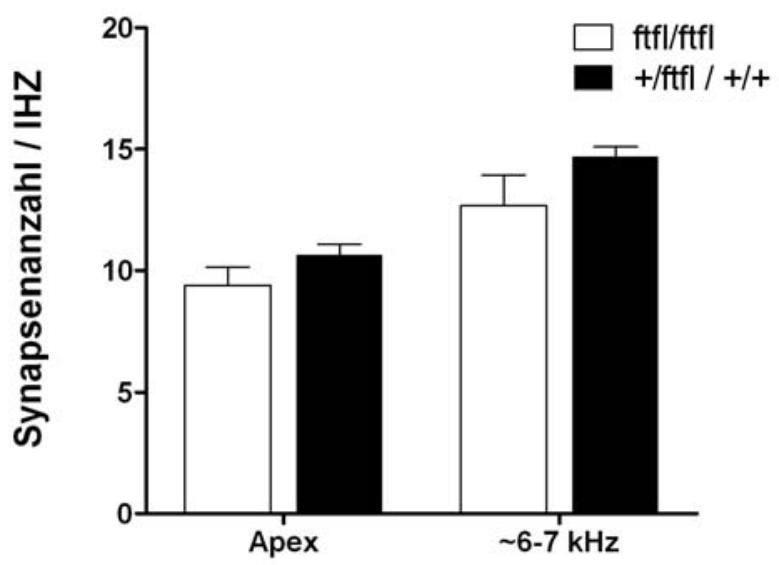

Abb. 4.5: Synapsenanzahl/IHZ + Standardabweichung des Mittelwertes im jeweiligen Bereich für DNM 1A fftl/fftl und DNM $1 \mathrm{~A}^{+/ \text {fftl } /+/+} . \mathrm{n}=$ mind. 7, entsprechend $\mathrm{n}(\mathrm{IHZ})=120$ pro Bereich und Pool. $\mathrm{p}$-Wert Apex $=0,15,4-6 \mathrm{kHz}=0,13$.

Als eine Synapse wurden ausschließlich diejenigen angesehen, bei denen sich die immunfluoreszierenden spots des synaptischen Bandes und der Postsynapse in unmittelbarer Nähe zueinander befanden. Alleinstehende Prä- und Postsynapsen wurden ebenfalls gezählt, es ergaben sich diesbezüglich keine Unterschiede zwischen den beiden Gruppen (Daten nicht gezeigt).

\subsubsection{Subzelluläre Verteilung endozytotischer Proteine}

Nach der morphologischen Analyse wurde die Expression einzelner endozytotischer Proteine in IHZ der DNM-1A ${ }^{\text {fttl/ftfl }}$-Maus untersucht. Mit Dynamin als einem der Hauptakteure in diesem molekularen Ablauf ist im Rahmen der Mutation nicht nur dessen Expression und Distribution innerhalb der Haarzelle von Interesse, sondern auch jene interagierender Proteine.

In Abb. 4.6 ist eine Gegenüberstellung von Homozygoten und Wildtyp/Heterozygoten für drei endozytotische Proteine dargestellt. Zunächst wurde eine Färbung mit Anti-Dynamin-1 (grün) und Anti-CtBP2/RIBEYE zur Synapsendarstellung (rot) durchgeführt, siehe Abb. 4.6 (a) und (b). Es zeigt sich, dass trotz Mutation die Verteilung inklusive der patches im basalen Bereich und der Betonung der Kutikularplatte erhalten bleibt. Dabei ist zu beachten, dass die Färbung nicht zwischen Dynamin 1A und 1B unterscheidet, sondern Dynamin 1 in seiner Gesamtheit angefärbt wird. Dabei können Unterschiede in Quantität und Lokalisation zwischen den Isoformen nicht beurteilt werden. 

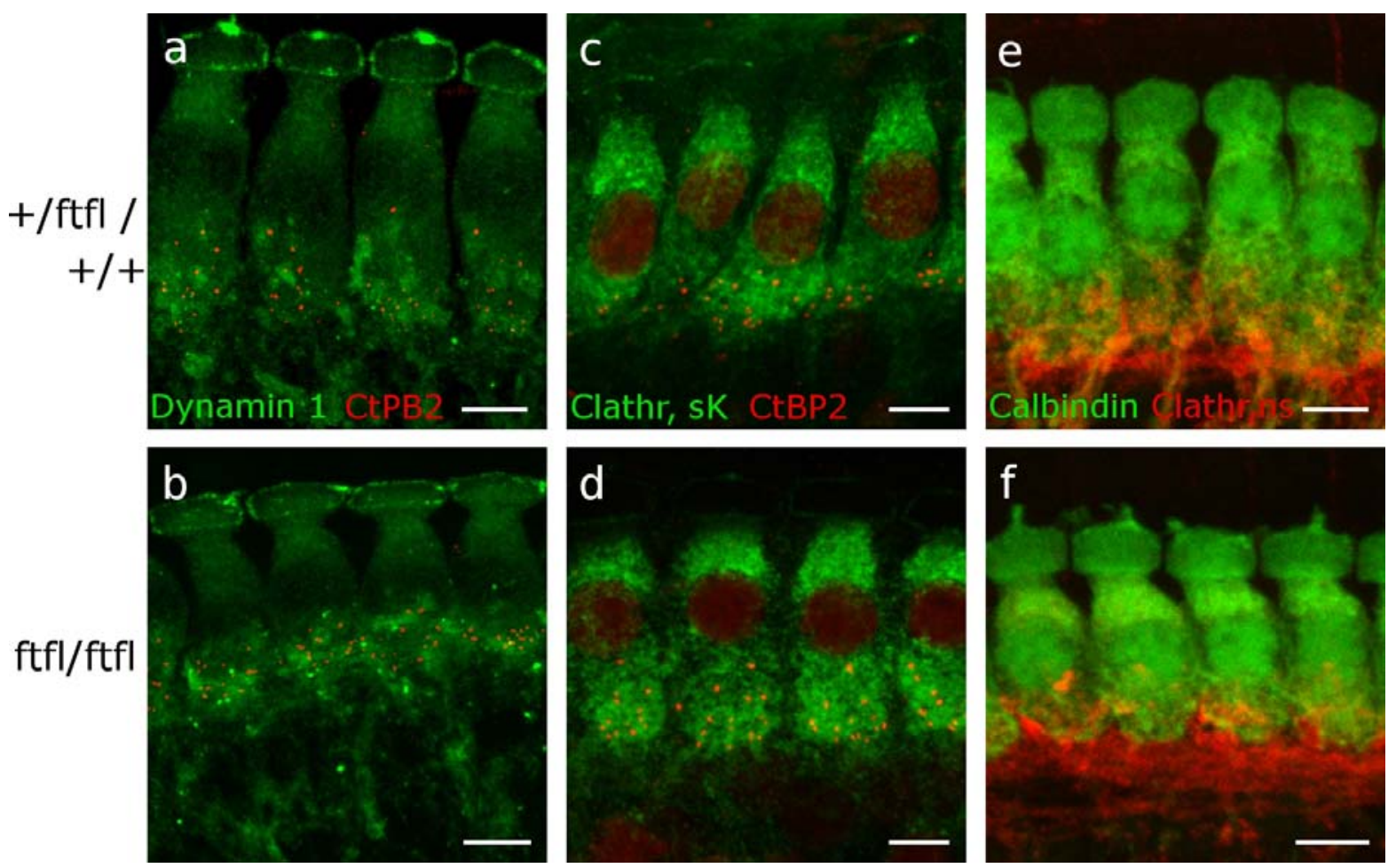

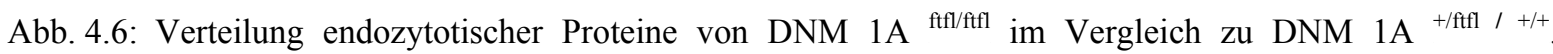
(a) und (b) Anti-Dynamin-1 und Anti-CtBP2/RIBEYE, n=7. (c) und (d) Anti-Clathrin, schwere Kette (Clathr, sK) und Anti-CtBP2/RIBEYE, n=5. (e) und ( $f$ ) Anti-Clathrin, neuronenspezifisch (Clathr, ns) und Anti-Calbindin, $\mathrm{n}=8$.

An Neuronen-Kulturen von Dynamin-1-knock-out-Mäusen konnte mittels Immunfluoreszenz gezeigt werden, dass sich eine Reihe endozytotischer Proteine intensiver und punktuierter als im Wildtyp darstellt (Hayashi et al. 2008).

Dieses Ergebnis konnte für die DNM-1A ${ }^{\text {fttl/ftfl }}$-Mäuse weder für das ubiquitäre Clathrin im Bereich der Haarzellen, siehe Abb. 4.6 (c) und (d), noch für das neuronenspezifische Clathrin im basalen Nervengeflecht, siehe Abb. 4.6 (e) und ( $f$ ), bestätigt werden. Beide Färbungen sind mit der des Wildtyp/Heterozygoten identisch. 


\subsubsection{Funktionelle Analyse}

\subsubsection{Schwellenunterschiede in frequenzspezifischer BERA}

Um den Einfluss der fitful-Mutation auf das Hörvermögen zu testen, wurde zunächst eine frequenzspezifische BERA unter Verwendung von Tonimpulsen durchgeführt. Bei einem Frequenzbereich des Hörens der Maus von 1-100 kHz wurden Tonimpulse mit Frequenzen von 4 bis $32 \mathrm{kHz}$ eingesetzt und mit einer Frequenz von $20 \mathrm{~Hz}$ dargeboten. Für weitere Informationen bezüglich Stimulus und Aufbau siehe Abb. 3.2 und Abb. 3.3. Es wurden jeweils 14 Tiere für den pool der Homozygoten sowie für den der Heterozygoten und Wildtypen herangezogen. Letzterer bestand aus 9 Heterozygoten und 5 Wildtypen, die nach Ausschluss von Unterschieden in der BERA einer gemeinsamen Gruppe zugeordnet wurden und im Folgenden auch für die funktionelle Analyse als eine solche behandelt werden. Das Durchschnittsalter von 15,5 Tagen garantierte einerseits ein bereits bestehendes Hörvermögen (Mikaelian und Ruben 1965; Ehret 1985) und andererseits das Überleben der homozygoten Tiere. Abb. 4.7 zeigt die Ergebnisse in Form der Schwellenkurven für beide Gruppen.

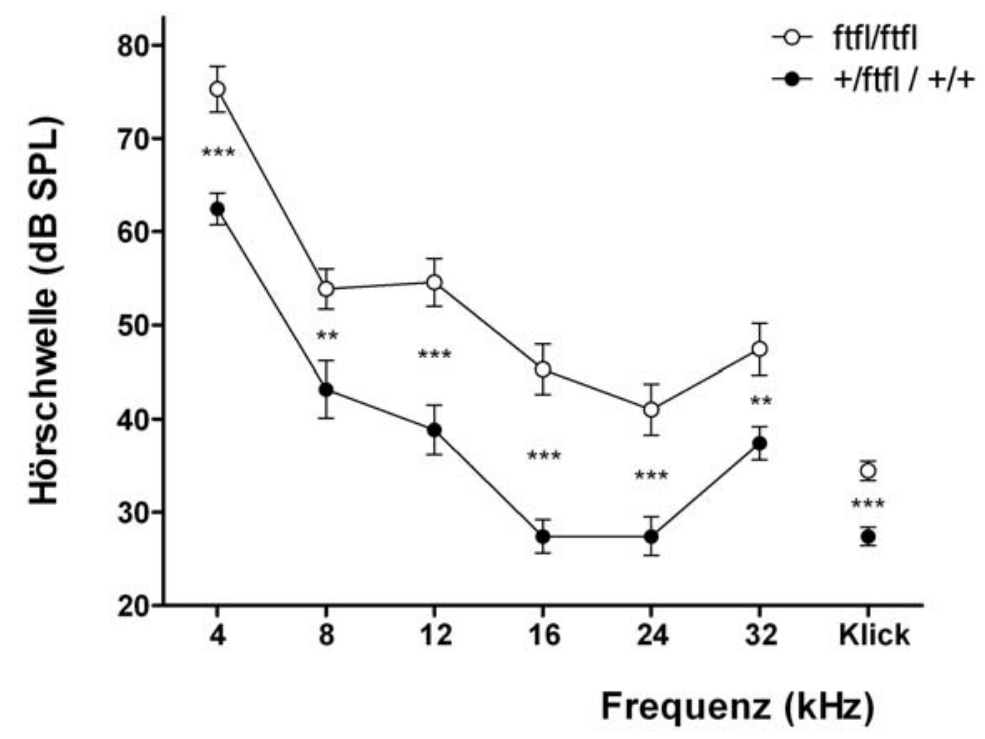

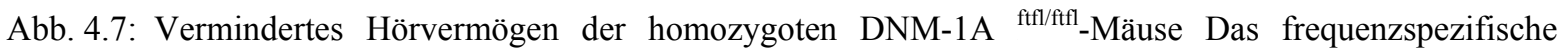
BERA-Audiogramm zeigt die gemittelten Schwellen \pm Standardabweichung des Mittelwertes der DNM 1A ${ }^{\text {ftfl/ftfl }}$ (unausgefüllte Symbole) und der DNM 1A ${ }^{+/ f t f l /+/+}$ (ausgefüllte Symbole) Mäuse. Signifikanzniveaus bei $\mathrm{p}<=0,001=* * *, \mathrm{p}<0,01=* *, \mathrm{p}<0,05=*$, $\mathrm{t}$-Test für unverbundene Stichproben. 
Über den gesamten Bereich der getesteten Frequenzen ist ein signifikanter Schwellenunterschied zwischen den beiden Gruppen zu verzeichnen. Der größte Unterschied findet sich im Bereich der mittleren Frequenzen von 12 und $16 \mathrm{kHz}$ mit bis zu $18 \mathrm{~dB}$. Ebenfalls der zuletzt aufgeführte Klick-Stimulus weist einen signifikanten Schwellenunterschied auf.

\subsubsection{Stimulation mit Klickreizen - Latenzen, Amplituden}

Im Gegensatz zu den durch Tonimpulse ausgelösten Potentialen entsteht bei Stimulation mit Klickreizen klarer erkennbar die in Kapitel 2.4.1 dargestellte charakteristische Wellenform. Anhand ihrer kann ebenfalls die Hörschwelle bestimmt werden, siehe Abb. 4.7. Die bessere Synchronisierung erlaubt überdies eine vereinfachte Ermittlung von Latenzen und Amplituden sowie eine annähernde Zuordnung zu anatomischen Strukturen. Dabei ist unter Latenz die Zeitspanne von Stimulusdarbietung bis zum Eintreten des jeweiligen Wellenpeaks zu verstehen. Die Amplitude wird vom Wellenpeak bis zum nächsten Tal vermessen

Neben der Standardreizfrequenz von $20 \mathrm{~Hz}$ (Pauli-Magnus et al. 2007) wurden die Tiere zusätzlich mit $90 \mathrm{~Hz}$ gereizt. Durch Ferguson et al. (2007) konnte gezeigt werden, dass der Phänotyp der Dynamin-1-knock-out-Mäuse aktivitätsabhängig ausprägt ist, so dass es Ziel der Versuchsplanung war, eventuelle frequenzabhängige Defizite zu detektieren.

Die in Abb. 4.8 und Abb. 4.9 gezeigten Diagramme stellen als Übersicht die Antworten auf einen überschwelligen Reiz von $86 \mathrm{~dB}$ bei 20 und $90 \mathrm{~Hz}$ dar.

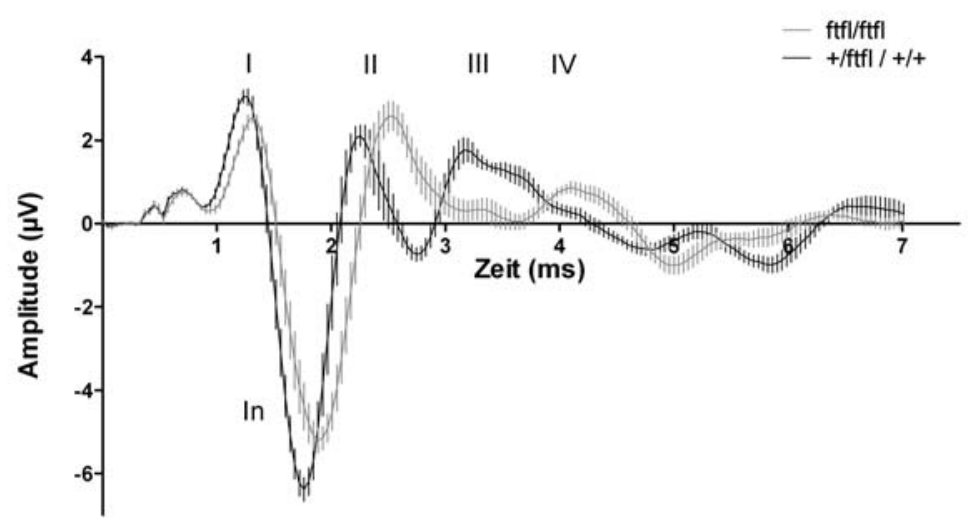

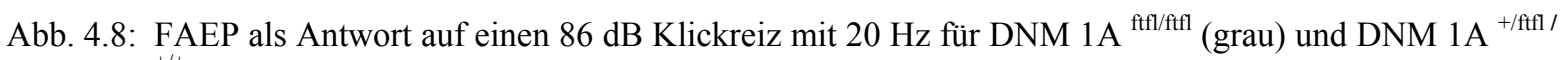
${ }^{+/+}$(schwarz), $\mathrm{n}=9$. 


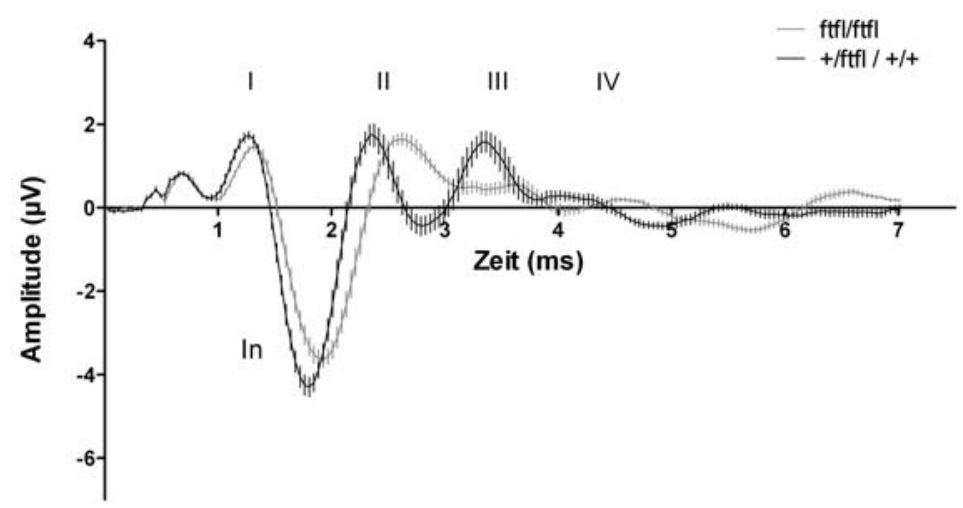

Abb. 4.9: FAEP als Antwort auf einen $86 \mathrm{~dB}$ Klickreiz mit $90 \mathrm{~Hz}$ für DNM 1A ${ }^{\mathrm{fttl} / \mathrm{ftfl}}$ (grau) und DNM 1A ${ }^{+/ \mathrm{fttl} /}$ ${ }^{+/+}$(schwarz), $\mathrm{n}=9$.

Auffallend sind die unterschiedlichen Latenzen zwischen den beiden untersuchten Gruppen. Dieser Unterschied setzt sich von Welle I aus fort und besteht in beiden Messreihen. Im Gegensatz zu den FAEP des Menschen, bei dem die Welle V das wichtigste Kriterium darstellt, ist bei der Maus die Welle I mit der höchsten Amplitude am prominentesten. Bei Betrachtung dieser ist eine eindeutige Amplitudendifferenz zwischen DNM 1A ${ }^{\mathrm{ftt} l / f t l}$ und DNM 1 $\mathrm{A}^{+/ \mathrm{ftfl} /+/+}$ auszumachen. Als bekanntes Phänomen ist den Diagrammen außerdem zu entnehmen, dass die Amplituden bei steigender Frequenz grundsätzlich abnehmen und die Latenzen sich verlängern.

Die folgenden Abschnitte beinhalten eine detailliertere Betrachtung von Latenzen und Amplituden bei Reizpegeln von $86 \mathrm{~dB}$ in 10-dB-Schritten abnehmend bis zur Hörschwelle.

\section{Latenzunterschiede zwischen DNM $1 \mathrm{~A}^{\mathrm{ftfl} / \mathrm{ftfl}}$ und DNM 1A $\mathrm{A}^{+/ \mathrm{fffl} /+/+}$}

Die Abb. 4.10 zeigt so genannte Latenz-Pegeldiagramme bei Stimulationsfrequenzen von 20 und $90 \mathrm{~Hz}$. Diese werden aus den einzelnen Potentialkurven bei steigenden Reizpegeln erstellt.

Die leichte negative Steigung der Latenzkurven für die jeweiligen Wellen bringt die Abhängigkeit der Latenzen von dem Reizpegel zum Ausdruck - bei Abnahme des Pegels verlängern sich die Latenzen. Außerdem ist wie zuvor in der Übersicht bei $86 \mathrm{~dB} z u$ erkennen, dass eine höhere Frequenz von $90 \mathrm{~Hz}$ längere Latenzen in beiden Gruppen bewirkt (Don et al. 1977). 
$20 \mathrm{~Hz}$

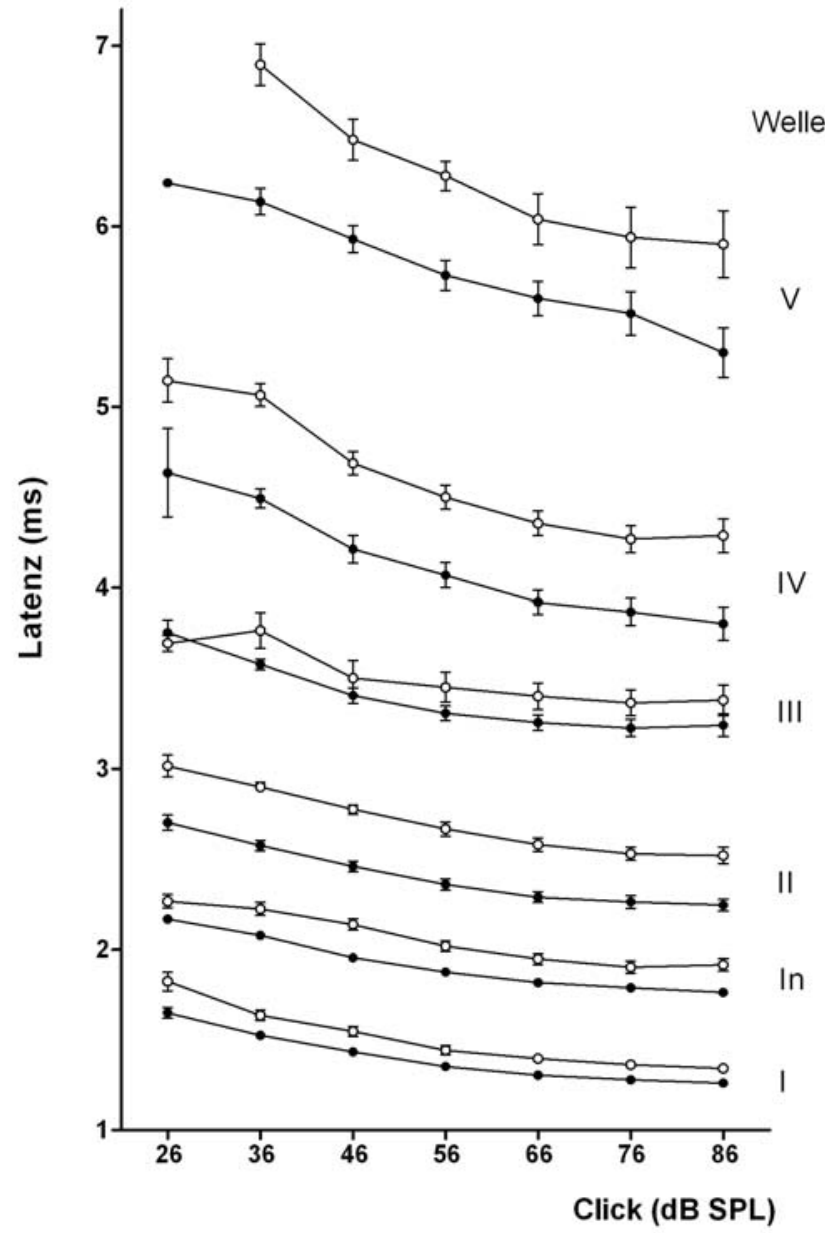

$90 \mathrm{~Hz} \quad-0-\mathrm{ftfl} / \mathrm{ftfl}$

$\rightarrow+/ f \mathrm{ffl} /+/+$

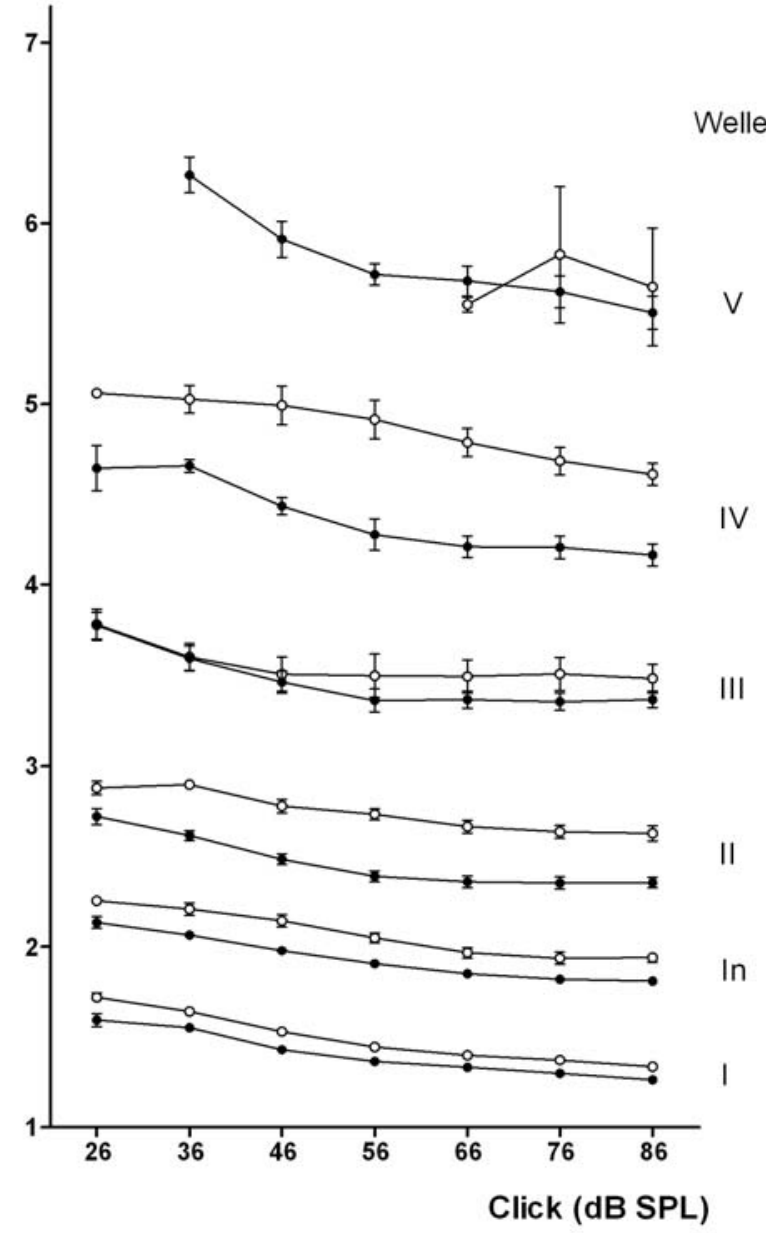

Abb. 4.10: Latenz-Pegeldiagramm für Welle I-V bei $20 \mathrm{~Hz}$ (links) und $90 \mathrm{~Hz}$ (rechts) mit Standardabweichung

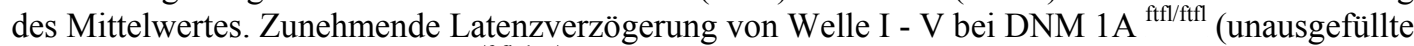
Symbole) gegenüber DNM 1A ${ }^{+/ f f f l /+/}$ (ausgefüllte Symbole). Keine Zunahme des Unterschiedes von 20 nach $90 \mathrm{~Hz} . \mathrm{n}=9$.

Im Vergleich der beiden Gruppen ist deutlich zu sehen, dass sich die ebenfalls in Abb. 4.8 und Abb. 4.9 bei $86 \mathrm{~dB}$ dargestellte Latenzverzögerung der DNM-1A ${ }^{\mathrm{fttl} / \mathrm{ftfl}}$-Mäuse über den gesamten Pegelbereich und nahezu alle Wellen fortsetzt. Mit Ausnahme der Welle III ist dieser Unterschied durchgehend signifikant, zumeist mit $\mathrm{p}$-Werten von $<0,01$ und $<0,001$. Als Beispiel für Absolutwerte bei $86 \mathrm{~dB}$ siehe auch Tab. 4.1.

Die Welle V der DNM-1A ${ }^{\text {ftfl/ftfl }}$-Mäuse ist bei $90 \mathrm{~Hz}$ nicht mehr sicher zu vermessen, da sich bei steigender Frequenz und abnehmendem Pegel die Amplitude derart verringert, dass sie in Schwellennähe nicht mehr zu detektieren ist. 
Tab. 4.1: Latenzen mit Standardabweichung des Mittelwertes der einzelnen Wellen von DNM 1A ${ }^{\mathrm{ftfl} / \mathrm{ftfl}}$ und DNM $1 \mathrm{~A}^{+/ \mathrm{ftfl} /+/+}$ bei $86 \mathrm{~dB}$ und $20 \mathrm{~Hz}$.

\begin{tabular}{c|c|c|c} 
Welle & $\begin{array}{c}\mathbf{f t f l} / \mathbf{f t f l} \\
\mathbf{( m s )}\end{array}$ & $\begin{array}{c}+/ \mathbf{f t f l} /+/+ \\
\mathbf{( m s )}\end{array}$ & $\mathbf{p}$-Wert \\
\hline $\mathbf{I}$ & $1,34 \pm 0,02$ & $1,26 \pm 0,02$ & 0,0165 \\
\hline In & $1,92 \pm 0,03$ & $1,76 \pm 0,02$ & 0,0013 \\
\hline II & $2,52 \pm 0,05$ & $2,25 \pm 0,03$ & 0,0002 \\
\hline III & $3,38 \pm 0,09$ & $3,24 \pm 0,06$ & 0,2156 \\
\hline IV & $4,29 \pm 0,09$ & $3,80 \pm 0,09$ & 0,0020 \\
\hline $\mathbf{V}$ & $5,90 \pm 0,18$ & $5,30 \pm 0,14$ & 0,0184
\end{tabular}

Die Auftragung der Latenzen der einzelnen Wellen liefert den wichtigen Nachweis, dass es sich nicht um eine zu Beginn entstehende einmalige Verzögerung der Fortleitung handelt, die sich anschließend konstant fortsetzt. Stattdessen weist der größer werdende Abstand zwischen den einzelnen Kurven von Homozygoten und Wildtyp/Heterozygoten darauf hin, dass diese Verzögerung bei jeder weiteren Welle zunimmt, so dass sich analog der anatomischen Zuordnung nicht nur eine gestörte Funktion der ersten auditorischen Synapse vermuten lässt, sondern auch nachfolgender Strukturen.

Wie visuell aus den beiden Diagrammen zu erwarten, ergab die statistische Auswertung keine signifikante Zunahme des Unterschiedes bei $90 \mathrm{~Hz}$ (hier nicht gezeigt) und somit keinen Anhalt auf einen Einfluss der Reizfrequenz auf die vorliegende Latenzverlängerung. Als möglichen Erklärungsansatz für die Latenzverzögerung ist im Rahmen der DynaminMutation eine Erschöpfung der synaptischen Übertragung in Betracht zu ziehen. Unter der Vorstellung, dass bei potentiell gestörter Endozytose die Exozytose nicht über einen entsprechenden Zeitraum aufrechterhalten werden kann, entstünde die Latenzverzögerung erst über die Zeit der 2000 Spuren. Um dieser Theorie auf den Grund zu gehen, wurde im Abstand von jeweils 500 Spuren die Latenz immer wieder erneut bestimmt. Dabei konnten jedoch keine signifikanten Unterschiede im zeitlichen Verlauf festgestellt werden (Daten nicht gezeigt). 


\section{Amplitudenunterschiede bei hoher Reizrate}

Bei den in Abb. 4.8 und Abb. 4.9 gezeigten Potentialkurven als Antwort auf einen überschwelligen Reiz entsteht der Eindruck verminderter Amplituden der homozygoten Tiere.

In der Einzelanalyse der Amplituden bei einer Reizrate von $20 \mathrm{~Hz}$ erweist sich dieser Unterschied zwar für die Welle I besonders bei niedrigen und sehr hohen Pegeln als signifikant (Daten nicht gezeigt). Für die restlichen Wellen jedoch ist dieser Unterschied nur vereinzelt und nicht über den gesamten Pegelbereich hinweg vorhanden. Trägt man die aus den 5 Wellen summierten Amplituden bei $20 \mathrm{~Hz}$ gegen den Reizpegel auf, siehe Abb. 4.11 links, bestätigt sich dies. Der Abbildung ist zu entnehmen, dass lediglich bei zwei verschiedenen Reizpegeln ein Amplitudenunterschied - im Besonderen bedingt durch die Welle I - besteht.

Die Einzelanalyse der Amplituden bei einer Reizfrequenz von $90 \mathrm{~Hz}$ dagegen ergibt durchweg das Überwiegen einzelner Wellen bei bestimmten Reizpegeln. Entsprechend ist über den gesamten Messbereich hinweg ein signifikanter Unterschied der summierten Amplituden festzustellen, siehe Abb. 4.11 rechts.
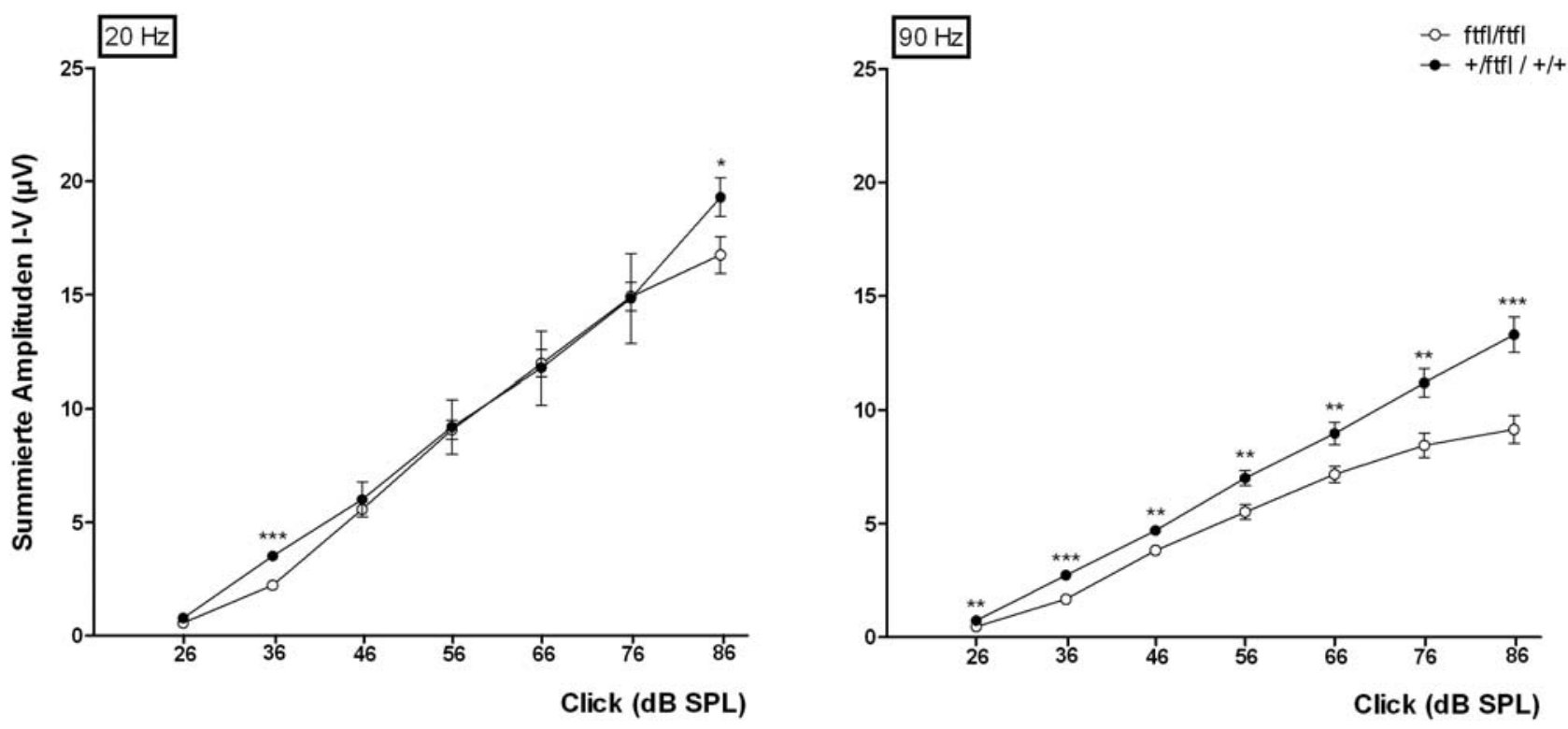

Abb. 4.11: Summierte Amplituden \pm Standardabweichung des Mittelwertes bei 20 und $90 \mathrm{~Hz}$ von DNM 1A $\mathrm{ftfl} / \mathrm{ftfl}$ (unausgefüllte Symbole) und DNM 1A ${ }^{+/ \mathrm{fffl}} /^{+/+}$(ausgefüllte Symbole). Signifikanter Unterschied bei $90 \mathrm{~Hz}$ im Gegensatz zu 20 Hz. Signifikanzniveaus wie in Abb. 4.7 beschrieben. 
Diese Daten zeigen, dass das Amplitudendefizit der DNM-1A ${ }^{\text {fttl/ftfl }}$-Mäuse im Gegensatz zu der Latenzverzögerung erst bei höherer Reizfrequenz deutlich zum Tragen kommt.

Aus der Graphik geht nicht eindeutig hervor, ob der Unterschied zwischen den beiden Gruppen ebenfalls mit zunehmendem Reizpegel wächst. Dazu zeigt

Abb. 4.12 die zueinander ins Verhältnis gesetzten summierten Amplituden bei $90 \mathrm{~Hz}$.

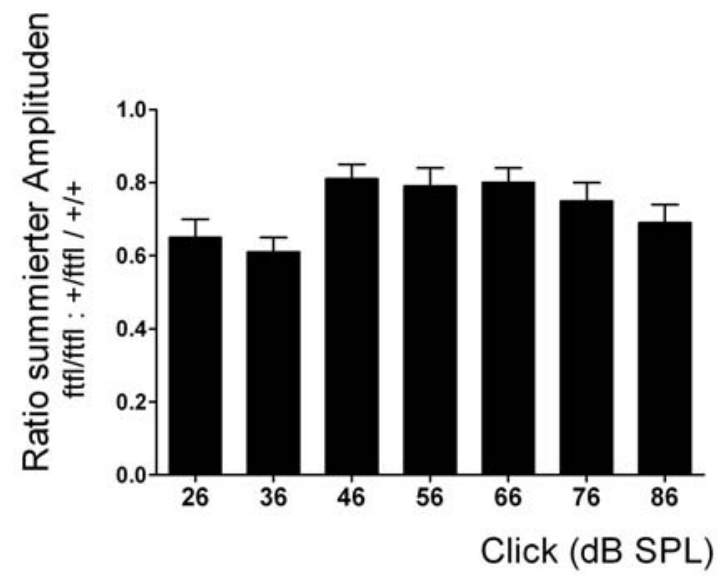

Abb. 4.12: Verhältnis der summierten Amplituden von DNM 1A $\mathrm{A}^{\mathrm{fft} / \mathrm{ftfl} l} \mathrm{zu} \mathrm{DNM} 1 \mathrm{~A}^{+/ \text {fftl } /+/+}$ bei $90 \mathrm{~Hz}$.

Der Wert bewegt sich zwischen 0,6 und 0,8 und folgt keiner Gesetzmäßigkeit bezüglich des Pegels. Der Unterschied besteht demnach lediglich in Abhängigkeit der Reizfrequenz.

Auch hier wurde geprüft, ob der Amplitudendifferenz eine zeitliche Entwicklung zu Grunde liegt. Abb. 4.13 stellt die summierten Amplituden bei $86 \mathrm{~dB}$ über die Dauer der Aufnahme dar. Es zeigt sich eine signifikante Abnahme der summierten Amplituden der DNM-1A ${ }^{\mathrm{ftfl} / \mathrm{ftfl}}$ -Gruppe im zeitlichen Verlauf. Nach Aufnahme von 500 Spuren beträgt der Durchschnitt der summierten Amplituden 12,07 $\pm 0,6 \mu \mathrm{V}$, wohingegen er nach 4000 Spuren bei 9,12 \pm $0,6 \mu \mathrm{V}$ liegt. Für die DNM $1 \mathrm{~A}^{+/ \mathrm{ftfl} /{ }^{+/+}}$ergibt sich keine signifikante Änderung der summierten Amplituden im Laufe der Aufnahmezeit. 


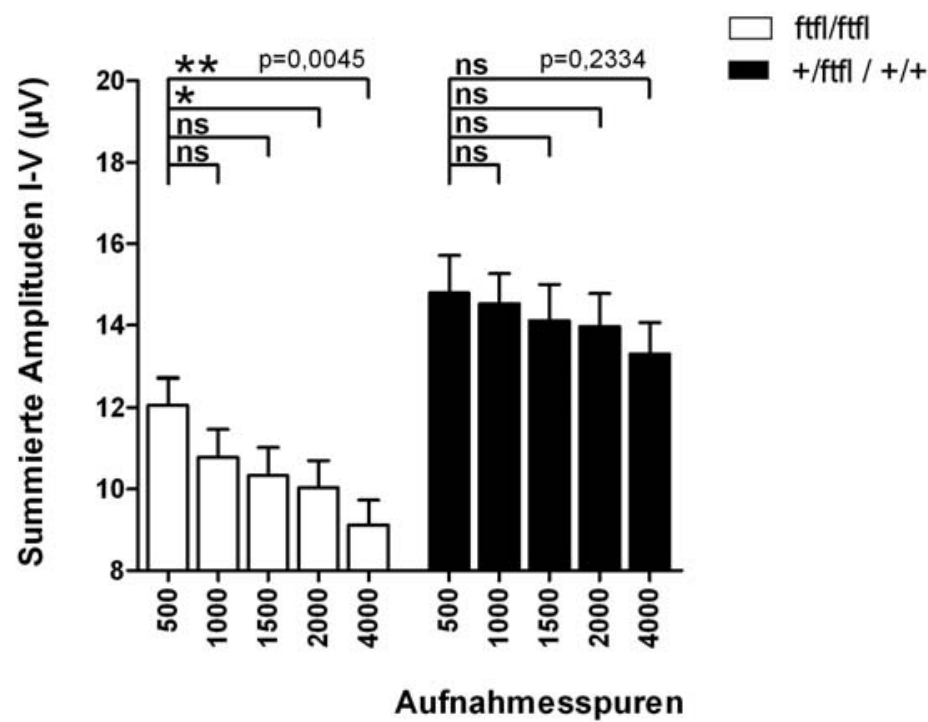

Abb. 4.13: Summierte Amplituden bei $86 \mathrm{~dB}$ von DNM 1A $\mathrm{A}^{\mathrm{ftfl} / \mathrm{ftfl}}$ und DNM 1A ${ }^{+/ \mathrm{fffl} /+/+}$ im zeitlichen Verlauf der Aufnahme. Signifikanzniveaus wie oben beschrieben, ns=nicht signifikant.

\subsubsection{Unveränderte DPOAE}

Die angeführten Ergebnisse zeigen eindeutig, dass das Hörvermögen der DNM-1A ftfl/ftfl Mäuse beeinträchtigt ist. Ursächlich kann ein Defekt der Schallverarbeitung bis hin zur aktiven cochleären Mechanik zugrunde liegen. Um eine dieser Schnittstellen auszuschließen, bedient man sich der Testung der DPOAE. Wie in Kapitel 2.4.2 erläutert, dient sie der Überprüfung der Funktionsfähigkeit der ÄHZ. Darüber hinaus setzt die Entstehung von DPOAE eine intakte Schallleitung und damit ein funktionsfähiges Mittelohr voraus.

Die in Abb. 4.14 links gezeigte Kurve stellt das DP-Gramm bei steigender Frequenz und gleichbleibendem Pegel von $\mathrm{f}_{1}=60 \mathrm{~dB}$ zur frequenzspezifischen Lokalisation möglicher Schäden dar. Rechts ist die so genannte Wachstumsfunktion mit steigendem Pegel und $\mathrm{f}_{2}=$ $16 \mathrm{kHz}$ dargestellt. Aus beiden Diagrammen geht hervor, dass kein Unterschied zwischen den beiden Gruppen besteht. 

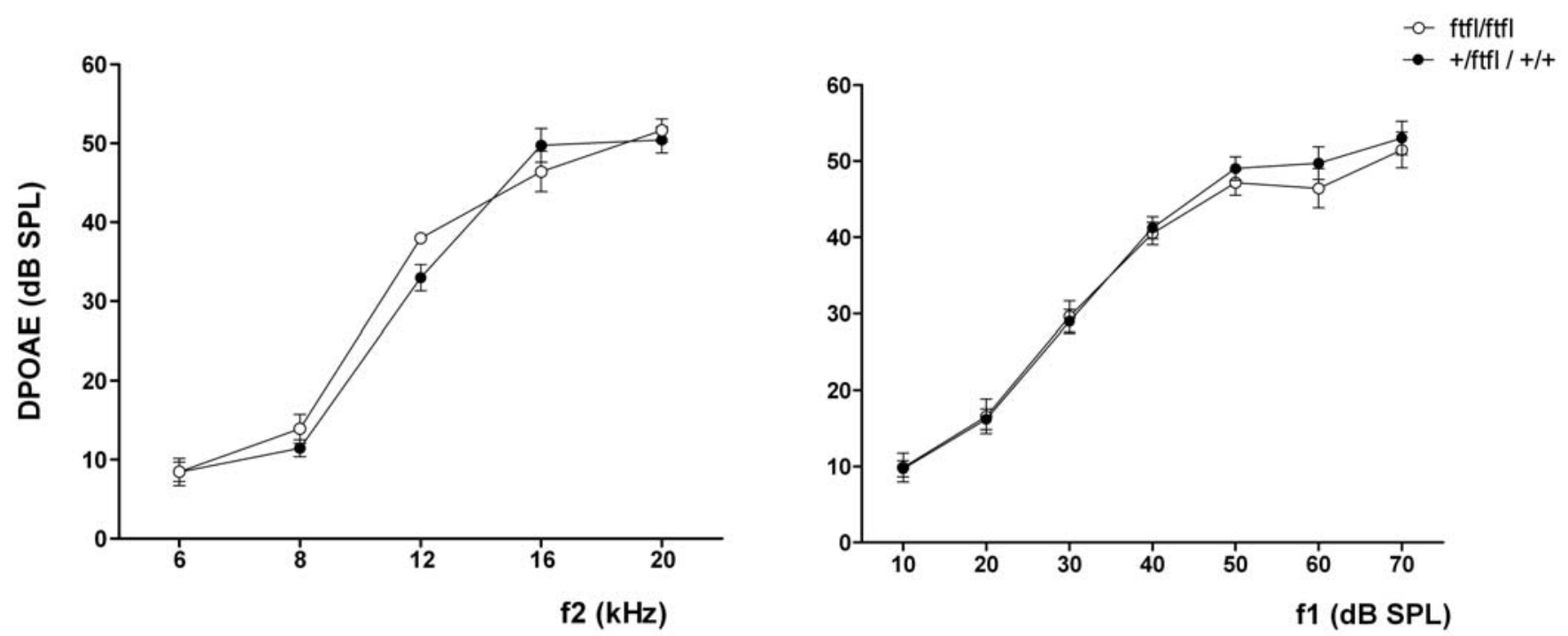

Abb. 4.14: DPOAE relativ zum Rauschen von DNM 1A $\mathrm{ftfl} / \mathrm{ftfl}_{\text {(unausgefüllte Symbole) und DNM 1A }}^{+/ \mathrm{ftfl} /+/+}$ (ausgefüllte Symbole) \pm Standardabweichung des Mittelwertes. Links: DP-Gramm bei $60 \mathrm{~dB}$, rechts: Wachstumsfunktion bei $16 \mathrm{kHz}$.

Die intakten DPOAE über alle Frequenzen und den gesamten Pegelbereich hinweg schließen daher einen defizitären mechanischen Verstärkerprozess als Auslöser für die Hörminderung bzw. Latenzverzögerung und Amplitudenreduktion aus. Ein Schaden der ÄHZ hätte einen veränderten Kurvenverlauf der Wachstumsfunktion zur Folge. Hier liegt ein physiologischer Kurvenverlauf mit einer nicht-linearen Steigung vor. Eine Dysfunktion der ÄHZ zöge eine lineare Steigung nach sich, da eine Verstärkung der niedrigen Pegel sowie eine Dämpfung der hohen Pegel ausblieben.

Ein Schaden des Mittelohres als Ursache der verlängerten Latenzen der FAEP konnte ebenfalls ausgeschlossen werden. Bei Vorliegen eines solchen wäre die Kurve der Wachstumsfunktion der DNM 1A ${ }^{\mathrm{ftfl} / \mathrm{ftfl}}$ als Ausdruck einer verminderten Anregung der ÄHZ horizontal nach unten verschoben.

Insgesamt demonstrieren die Daten, dass der Defekt unterhalb der Schallleitung sowie der mechanoelektrischen Transduktion und Verstärkung zu suchen ist. 


\section{Diskussion}

\subsection{Expressionsanalyse endozytotischer Proteine}

\subsubsection{Endozytoseformen der IHZ}

Im Gegensatz zu der Bänder-Synapse der Retina existierte bislang keine molekulare Analyse der Endozytose an IHZ und der ersten Synapse des auditorischen Weges. Analog der Arbeit von Sherry und Heidelberger (2005) an retinalen Zellen wurden im Rahmen dieser Arbeit mittels immunhistochemischer Färbung die Expression, Lokalisation und Ausprägung einzelner endozytotischer Proteine in IHZ untersucht.

Dabei konnte gezeigt werden, dass IHZ Clathrin und Dynamin exprimieren, siehe Abb. 4.1 (h) und (i).

Die Clathrin-Anfärbung wirft die Frage nach der Rolle des klassischen Weges der Clathrinvermittelten Endozytose an Bänder-Synapsen auf. Es handelt sich dabei um einen kontrovers diskutierten Aspekt - im Gegensatz zu konventionellen Synapsen ist die Existenz des Clathrin-abhängigen Weges an Bänder-Synapsen bereits mehrfach in Frage gestellt worden.

So zeigten Paillart et al. (2003) für retinale Bipolarzellen des Goldfisches, dass sowohl nach kurzer als auch nach repetitiver Stimulation keinerlei Clathrin-umhüllte Vesikel zu beobachten sind und statt dessen die kompensatorische Endozytose in Form von bulk retrieval stattfindet. Diese Beobachtung geht einher mit früheren Arbeiten von Heidelberger et al. (2002) bzw. Heidelberger (2001), in denen die Applikation von GTPase Inhibitoren $(\mathrm{GTP} \gamma \mathrm{S})$ im Gegensatz zu ATPase Inhibitoren (ATP $\gamma \mathrm{S})$ keine Blockade der Endozytose an Bänder-Synapsen von Bipolarzellen des Goldfisches hervorrufen konnte. Bei Vorliegen eines Clathrin-vermittelten Mechanismus allerdings - mit der GTPase Dynamin als fundamentalem Bestandteil - hätte es zu einer Inhibition der Endozytose kommen müssen. Ergänzend ergaben spätere Experimente mittels Immunhistochemie an Bipolarzellen nur eine leichte Anfärbung der Bipolarzellen für Dynamin im Gegensatz zu konventionellen Synapsen (Sherry und Heidelberger 2005).

Konträr zu den initialen Resultaten von Heidelberger et al. konnte mit vergleichbaren Methoden eine Dynamin-Abhängigkeit der langsamen sowie der schnellen Endozytose an 
Bipolarzellen des Goldfisches demonstriert werden (Jockusch et al. 2005). Weiterführend ergab die Inhibition von Interaktionen zwischen Clathrin und akzessorischen Proteinen eine selektive Unterbindung der langsamen Komponente. Durch diesen Nachweis ist das Bestehen eines Clathrin-basierten Mechanismus in IHZ wahrscheinlich, wobei zu berücksichtigen ist, dass die Persistenz der schnellen Komponente als Anhalt auf die Existenz Clathrin-unabhängiger Wege gesehen werden muss.

In einer kürzlich veröffentlichten Arbeit konnten an Bipolarzellen der Maus im Gegensatz zu denen des Goldfisches ausschließlich Clathrin-abhängige Reinternalisierungen beobachtet werden (LoGiudice et al. 2009).

Die zunächst widersprüchlich erscheinenden Ergebnisse wurden im Rahmen dieser Studie auf die unterschiedliche Größe des synaptischen Terminals und damit gleichzeitig des Reservepools zurückgeführt. Demnach bedingte die Größe des Terminals die Wahl des jeweiligen Endozytoseweges - die beträchtlich kleineren Bipolarzellen der Maus könnten aufgrund des entsprechend kleineren Reservepools viel stärker auf einen direkten Weg des Recyclings, das heißt ohne Umweg über Endosomen-große Vorläuferstrukturen im Rahmen des bulk retrievals, angewiesen sein.

Im Gegensatz zur Retina liegen bezüglich der Existenz eines Clathrin-vermittelten Weges in IHZ bedeutend weniger Studien dieser Differenziertheit vor.

Für ein Überwiegen der langsamen Clathrin-vermittelten Endozytose in IHZ sprechen im Besonderen Kapazitätsmessungen (Moser und Beutner 2000; Beutner et al. 2001; Khimich et al. 2005). Nach Stimulation durch Kalzium-Einstrom werden dabei für die Membranwiedergewinnung Zeitkonstanten im Clathrin-charakteristischen Bereich gemessen. Anhalt für die Anwesenheit dieser Endozytose-Form gibt außerdem die Beobachtung Clathrinummantelter Vesikel (ungezeigte elektronenmikroskopische Beobachtungen im Rahmen dieser Arbeit sowie Siegel und Brownell (1986), Leake und Snyder (1987), Nadol (1990), Sendin et al. (2007), Meyer AC et al. (2009), Neef et al. (2009)). Experimente unter Durchführung von FM1-43 imaging an IHZ dagegen konnten keinen Hinweis einer Clathrin-abhängigen Form der Endozytose erbringen, sondern lediglich einen schnellen, aufgrund der Zeitkonstante vermutlich davon unabhängigen Weg darstellen (Seiler und Nicolson 1999; Griesinger et al. 2002; 2005). Es ist jedoch fraglich, ob es sich dabei tatsächlich um einen alternativen Endozytose-Mechanismus handelt oder vielmehr eine 
unspezifische Aufnahme des Farbstoffes über Ionenkanäle erfolgt. Meyers et al. (2003) sowie Gale et al. (2001) konnten zeigen, dass die Blockade von Mechanotransduktionskanälen zu einer Inhibition der Farbstoffaufnahme führt, so dass diese Methode zur Darstellung von Endozytose entsprechend kritisch zu sehen ist.

Die Tatsache, dass es in dieser Arbeit gelungen ist, die IHZ der Maus spezifisch für Clathrin anzufärben, unterstützt die Hypothese, dass Clathrin-vermittelte Endozytose in IHZ stattfindet. In diesem Zusammenhang ist auf das bereits erwähnte Charakteristikum zurückzukommen, das die Arbeitsgruppe Logiudice et al. (2009) für Zellen entwirft, die elementar einer Clathrin-vermittelten Endozytoseform unterliegen. Es handelt sich dabei um Zellen mit einem aufgrund ihrer Größe geringeren Reservepool und einem besonders hohen Umsatz an Vesikeln, so dass ein direkter Nachschub dieser essentiell ist. Dies trifft auch auf die hier untersuchte IHZ der Maus zu. Ihre Größe entspricht mit 5-7 $\mu \mathrm{m}$ im Durchmesser der der Bipolarzelle der Maus und auch der Umsatz der Zelle mit 40.000 Vesikeln auf einen Stimulus hin ist immens (Beutner et al. 2001). Unterstützend konnten Cheung et al. (2010) zeigen, dass im Besonderen die Clathrin-vermittelte Endozytose für die Wiederherstellung des ready releasable pools (RRP), der in IHZ eine zentrale Rolle einnimmt, stattfindet.

Die Kombination aus dieser Theorie, bisherigen Kapazitätsmessungen und der hier gezeigten spezifischen Clathrinfärbung macht das Vorliegen der Clathrin-vermittelten Endozytose in der IHZ sehr wahrscheinlich.

Die in dieser Arbeit ebenfalls nachgewiesene Existenz von Dynamin in IHZ ist Voraussetzung für den Ablauf des Clathrin-vermittelten Weges. Umgekehrt sind bei Vorliegen von Dynamin jedoch auch alternative - Clathrin-unabhängige - Wege der Endozytose in IHZ in Betracht zu ziehen. Diese sollen im Folgenden diskutiert werden.

Dynamin ist im Gegensatz zu Clathrin nicht nur für die langsame, sondern auch für eine schnelle Form der Endozytose zuständig (Artalejo et al. 1995; Jockusch et al. 2005). Deren Existenz an Haarzellen ist nicht nur anhand von FM1-43 imaging detektiert (Griesinger et al. 2002; Griesinger et al. 2005), sondern ebenfalls bei Kapazitätsmessungen beobachtet worden (Beutner et al. 2001). Im Unterschied zur langsamen Endozytose wird diese allerdings durch Stimulation in Form von Kalzium-Photolyse hervorgerufen, so dass ihre Existenz unter physiologischen Bedingungen noch nachzuweisen ist. 
Grundsätzlich ermöglicht die Anwesenheit von Dynamin neben dem in Kapitel 5.2.2 besprochenen bulk retrieval außerdem den Caveolin-abhängigen Weg (Oh et al. 1998), siehe auch Kapitel 2.2.1. Aufgrund dessen wurde der Frage nachgegangen, ob die IHZ eine Caveolin-Expression aufweist. Das Fehlen einer Anfärbung spricht jedoch gegen eine relevante Rolle dieses Weges, siehe Abb. 4.1 (j). Einerseits scheint dieses Ergebnis überraschend, da IHZ entwicklungstechnisch dem Ektoderm entstammen (Streit 2001) und für Zellen epithelialen Ursprungs eine Caveolin-Expression nachgewiesen werden konnte (Scheiffele et al. 1998; Verkade et al. 2000). Andererseits steht dieses Resultat im Einklang mit der Neuronen-ähnlichen Funktion der IHZ. Trotz neuerer Ergebnisse, die belegen, dass Caveolin beispielsweise in die Internalisierung postsynaptischer Rezeptoren involviert ist (Francesconi et al. 2009), besteht nach wie vor die gängige Auffassung, dass Neuronen nicht grundsätzlich Caveolin exprimieren (Shogomori und Futerman 2001; Doherty und McMahon 2009). Der Caveolin-abhängige Weg scheint die Aufgabe der an die Exozytose gekoppelten und damit kompensatorischen Endozytose nicht $\mathrm{zu}$ erfüllen. Dies wird verständlich, wenn man bedenkt, dass es sich um einen sehr langsamen Prozess handelt sogar nach Aktivierung des Weges beträgt die Halbwertszeit mehr als 20 min (Conner und Schmid 2003). Vor diesem Hintergrund wird das Fehlen Caveolins in der IHZ nachvollziehbar.

\subsubsection{Isoformen endozytotischer Proteine der IHZ}

Der zuletzt angeführte Punkt sowie die Zusammenschau der weiteren Ergebnisse im Bereich der immunhistochemischen Färbungen machen eine Diskrepanz zwischen Ursprung und Funktion der IHZ deutlich.

Interessanterweise lässt sich die Haarzelle für die neuronenspezifische Isoform von Dynamin - Dynamin 1 - anfärben. Dadurch wird die Vorstellung gestützt, dass die Funktion für die molekulare Ausstattung der Zelle entscheidend ist. Dieses Ergebnis ist kompatibel mit der fehlenden Epithel-typischen Caveolin-Expression, da Dynamin 1 im Gegensatz zu Dynamin 2 nicht an der Caveolin-abhängigen Endozytose beteiligt ist (Yao et al. 2005).

Der Nachweis jedoch, dass die IHZ ausschließlich die ubiquitäre Form Clathrins anstatt der neuronenspezifischen Form exprimiert, steht dem gegenüber. Dieser Aspekt verdeutlicht, dass durchaus Unterschiede zu Neuronen existieren und die IHZ als sekundäre Sinneszelle eine Sonderstellung einnimmt. Die neuronenspezifische Variante der leichten Kette Clathrins besitzt ein zusätzliches Exon (Jackson et al. 1987), das im Gegensatz zur 
ubiquitären Form für eine vereinfachte Bindung des in Triskelien vorliegenden Clathrins an Calmodulin sorgt (Pley et al. 1995). Die daraus resultierende erhöhte Kalziumsensitivität könnte in Abhängigkeit neuronaler Aktivität zur Plastizität des ZNS beitragen (Daoud et al. 1999). Neben den neuronalen Isoformen der leichten Kette Clathrins existieren grundsätzlich zwei Formen der leichten Kette $-\mathrm{LC}_{\mathrm{a}}$ und $\mathrm{LC}_{\mathrm{b}}$. Deren Verteilung variiert entsprechend der jeweiligen Funktion auch unter den verschiedenen nicht-neuronalen Zellen. So ist für sekretorische Zellen sowie für das ZNS ein Überwiegen von $\mathrm{LC}_{\mathrm{b}}$ festgestellt worden (Acton und Brodsky 1990). In dieser Form könnte auch ohne Expression der neuronalen Variante der Funktion der IHZ entsprochen werden.

\subsubsection{Lokalisation der Endozytose}

Neben den verschiedenen Endozytoseformen und der Expression bestimmter Isoformen endozytotischer Proteine wurde ein Schwerpunkt auf die Verteilung der einzelnen Proteine gelegt. In dem Zusammenhang besteht ein Konflikt hinsichtlich der Lokalisation der Endozytose in IHZ, apikal versus basal, siehe auch Kapitel 2.2.3. Anhand der erhobenen Ergebnisse fällt die deutliche Akzentuierung Dynamins im basalen Kompartiment auf, siehe Abb. 4.1 (i). Die Größe der patches von ca. $1 \mu \mathrm{m}$ übersteigt die einer Postsynapse, so dass die Lokalisation am ehesten der Präsynapse zuzuordnen ist. Dieser Befund entspricht zudem der gängigen Meinung über die Verteilung von Dynamin 1 (Powell und Robinson 1995; Gray et al. 2003). Die überwiegend basale Präsenz von Dynamin 1 spräche für das Recycling von Membran in unmittelbarer Nähe zum synaptischen Spalt und damit dem Fusionsort von Vesikeln, so dass eine räumlich enge Kopplung von Exo- und Endozytose möglich wäre, siehe auch LoGiudice et al. (2009). Die Anfärbung für Clathrin dagegen wirkt eher homogen über die gesamte Zelle verteilt mit vesikulären Strukturen im apikalen Bereich, siehe Abb. 4.1 (h). Diese könnten eventuell dem apikal gelegenen Golgi-Apparat entsprechen und die Beteiligung Clathrins am intrazellulären Vesikeltransport demonstrieren (McNiven und Thompson 2006).

Zusammenfassend kann auf Grundlage der Expressionsanalyse die Anwesenheit des Clathrin-vermittelten Endozytoseweges in der IHZ angenommen werden. Durch den Nachweis einer Dynamin-1-Expression sind außerdem das Vorliegen alternativer Endozytoseformen wie eine schnelle Form und bulk retrieval in IHZ in Betracht zu ziehen. Eine Caveolin-vermittelte Endozytose dagegen konnte ausgeschlossen werden. Insgesamt 
entspricht die Kombination der exprimierten endozytotischen Proteine bzw. ihrer Isoformen weder einheitlich dem Muster einer epithelialen noch dem einer neuronalen Zelle, demonstriert jedoch die Sonderstellung der IHZ als sekundäre Sinneszelle.

\subsection{Intaktes Dynamin 1A ist wesentlich für den Hörvorgang}

Durch die vorliegende spontan aufgetretene Mutation für die Isoform 1A des Dynamin-Gens ist es erstmals möglich geworden, Isoform-spezifische Untersuchungen vorzunehmen. Sie bot im Rahmen dieser Arbeit die Gelegenheit, etwaige Auswirkungen auf das auditorische System festzustellen.

Obwohl es sich bei dem betroffenen Genprodukt nur um eine der beiden Splicing-Varianten des Dynamin-1-Gens handelt, präsentiert sich bereits der neurologische Phänotyp als eindrücklich. Die homozygoten Tiere zeigen eine erhebliche Ataxie sowie epileptische Anfälle, die die Lebenserwartung auf ca. 3 Wochen reduzieren. Alleinig diese Beobachtung verdeutlicht die gravierenden Folgen eines Ausfalls bzw. einer Dysfunktion und damit die wichtige Rolle von Dynamin 1A.

Eine Untersuchung des Innenohres der DNM-1A fttl/ftl -Mäuse ergab eine regelrechte Morphologie der drei Reihen ÄHZ und der einzelnen Reihe IHZ, siehe Abb. 4.2. Im Gegensatz zu den Resultaten von Hayashi et al. (2008) an Dynamin-1-knock-out-Mäusen stellten sich für DNM 1A ${ }^{\mathrm{ftfl} / \mathrm{ftfl}}$ nicht nur Dynamin 1, sondern auch beide Varianten Clathrins als unverändert gegenüber dem Wildtyp/Heterozygoten dar, siehe Abb. 4.6. Dieses Resultat lässt sich vermutlich auf die Tatsache zurückführen, dass lediglich eine der beiden Isoformen von Dynamin 1 in mutierter Form vorliegt und Interaktionen dadurch nicht vollständig unterbunden zu sein scheinen.

Darüber hinaus war die quantitative Ausprägung der Synapsen unbeeinträchtigt, siehe Abb. 4.4, Abb. 4.5, und entsprach analog der jeweiligen Lokalisation zuvor erhobener Daten (Meyer AC et al. 2009). Vor dem Hintergrund, dass Boumil et al. (2010) zeigen konnten, dass Dynamin 1A im Gegensatz zu Dynamin 1B insbesondere mit Einsetzen der Synaptogenese ansteigt, wäre eine Minderung der Synapsenanzahl nicht unerwartet gewesen. Eine mögliche Erklärung für den dennoch regulären Befund könnten Ergebnisse der selben Arbeit von Boumil et al. (2010) bieten. Sie fanden bei der DNM-1A ${ }^{\text {ftfl/ftfl }}$-Maus eine erhöhte mRNA Expression der intakten Isoform Dynamin 1B im Verhältnis zu der 
mutierten Isoform Dynamin 1A. Vorstellbar wäre eine partielle Kompensation durch Dynamin 1B, die ein Sistieren der Synapsenausbildung verhinderte. Bei dieser Art von Kompensation würde es sich lediglich um einen quantitativen Erhalt handeln, da bei DNM 1A ftfl/ftfl qualitative Unterschiede im Rahmen der Neuritenausbildung primärer Neuronenkulturen festgestellt werden konnten (Boumil et al. 2010). Zu berücksichtigen ist überdies, dass die durchschnittliche Lebenserwartung von 3 Wochen auch durch einen knock-out beider Isoformen mit 2 Wochen nicht wesentlich unterschritten wird (Ferguson et al. 2007), so dass die nachgewiesen erhöhte Expression von Dynamin 1B im Falle von DNM $1 \mathrm{~A}^{\mathrm{ftfl} / \mathrm{ftfl}}$ kein bedeutend verbessertes outcome zu bewirken scheint.

Damit stellt Dynamin 1A zwar keine Voraussetzung für die embryonale Entwicklung sowie direktes perinatales Überleben dar, das Fehlen einer Isoform jedoch bedingt bereits eine gestörte weitere postnatale Entwicklung mit konsekutiv deutlich reduzierter Lebenserwartung.

Im Kontext dieser Arbeit konnte als ein wesentlicher Defekt gezeigt werden, dass das Hörvermögen der DNM-1A ${ }^{\mathrm{ftfl} / \mathrm{ftfl}}$-Mäuse, das in der zweiten Woche postnatalen Lebens einsetzt, signifikant beeinträchtigt ist. Im Audiogramm ist eine Anhebung der Hörschwelle um ca. $15 \mathrm{~dB}$ über den gesamten Frequenzbereich zu verzeichnen, darüber hinaus zeigen sich die Latenzen der FAEP verlängert sowie die Amplituden bei starker Stimulation reduziert.

Die Kombination aus Expression von Dynamin 1 in IHZ, siehe Kapitel 5.1.1, und dem funktionellen Phänotyp der DNM-1A ${ }^{\mathrm{fttl} / \mathrm{ftfl}}$-Mäuse spricht somit für eine wichtige Rolle von Dynamin 1 und $1 \mathrm{~A}$ im Hörvorgang.

\subsubsection{Lokalisation und Grundlage des Defektes}

Um einen Zusammenhang zwischen der Dynamin-1-Expression in IHZ und dem audiologischen Phänotyp herstellen zu können, ist es entscheidend, dem Defekt ein anatomisches Korrelat zuzuordnen.

Die FAEP mit der Zuordnung der fünf Wellen zu anatomischen Strukturen ermöglichen es, Aussagen zur Lokalisation des Defektes zu treffen. Die Tatsache, dass bereits die erste Welle mit signifikant verzögerter Latenz auftritt, siehe Abb. 4.10, spricht für einen Defekt in der ersten auditorischen Synapse. Dies belegt, dass Dynamin 1A nicht nur generell wesentlich für den Hörvorgang ist, sondern als funktionell relevant an der Bänder-Synapse 
gesehen werden kann - entgegen der These von Heidelberger et al. (2002) bzw. Heidelberger (2001), siehe oben.

Um nachzuweisen, dass Dynamin in Form von Endozytosebeteiligung in IHZ vorhanden und essentiell für deren Funktion ist, ist zeigen, dass dem verminderten Hörvermögen ein Defekt der Endozytose zugrunde liegt. Dass eine Dysfunktion von Dynamin 1A eine verminderte Endozytose nach sich zieht, konnte bereits an COS-7 Zellen, die DNM-1A ${ }^{\text {fft/fffl }}$ -Form des Dynamin 1A exprimieren, sowie an neuronalen Primärzellen der Mutante gezeigt werden (Boumil et al. 2010).

Innerhalb unserer Arbeitsgruppe ist es darüber hinaus unter Durchführung von Kapazitätsmessungen mittels patchclamp-Technik gelungen, sowohl die Lokalisation des Defektes als auch die Art der Dysfunktion nachzuweisen. Bei Stimulation der IHZ mit Depolarisationspulsen von 20 und $200 \mathrm{~ms}$ Dauer zeigte sich an denen der DNM-1A ${ }^{\text {fftl/ftrl }}$-Mäuse ein gering, jedoch signifikant verminderter Abfall der Kapazität als Zeichen reduzierter Rückgewinnung von Membran nach exozytotischer Aktivität. (Neef, Jakob, unveröffentlichte Ergebnisse).

Somit kann die These komplettiert werden, dass Dynamin 1 in der IHZ vorhanden ist, dort die Isoform 1A an der Endozytose mitwirkt und bei Inhibition derselben der Hörvorgang gestört wird.

Daraus ist nicht abzuleiten, dass der Defekt ausschließlich in der IHZ zu finden ist. Im Folgenden soll kurz auf weitere Strukturen eingegangen werden, die betroffen sein und dadurch die Hörminderung mit bewirken könnten.

Wie in Kapitel 4.2.3.3 dargestellt, ist eine unbeeinträchtigte Funktion der ÄHZ der DNM-1 $\mathrm{A}^{\mathrm{fffl} / \mathrm{ftfl}}$-Mäuse festgestellt worden. Dieses Ergebnis wird durch die Aufgabe der ÄHZ als verstärkendes Element nachvollziehbar, da diese mechanische Funktion nicht im direkten Zusammenhang mit dem Prozess der Endozytose steht. Überdies enden im Gegensatz zu den IHZ weniger als 10\% der afferenten Ganglienzellen an den ÄHZ. Die daraus resultierende geringere Synapsenausbildung hat eine untergeordnetere Rolle des Vesikelrecyclings zur Folge. In diesem Sinne konnte bereits früh nachgewiesen werden, dass an den überwiegend efferent innervierten ÄHZ erheblich weniger Endozytose stattfindet (Siegel und Brownell 1986; Leake und Snyder 1987), so dass ein Defekt von Dynamin 1A hier nicht zum Tragen kommt. 
Im Gegensatz zu den ÄHZ erfüllen nachgeschaltete Strukturen als fortleitende Instanzen eine mit den IHZ vergleichbare Aufgabe. Aufgrund dessen ist die zusätzliche Ausprägung des Defizits durch die Mutation an dieser Stelle wahrscheinlich.

Die Ergebnisse der Latenzbestimmungen bestätigen diese Annahme. Wie in Kapitel 4.2.3.2 erläutert, nehmen die Latenzunterschiede zwischen DNM 1A fft/fffl und DNM $1 \mathrm{~A}^{+/ f f f l /+/+}$ von Welle I bis Welle V kontinuierlich zu, so dass nicht nur initial einmalig eine sich fortsetzende Verzögerung auftritt, sondern ebenfalls die Interpeaklatenz verlängert ist. Analog der anatomischen Zuordnung weist dies auf eine Störung entlang der gesamten auditorischen Fortleitung - wahrscheinlich im Sinne einer defekten synaptischen Transmission - hin. Im Gegensatz dazu läge bei einem isolierten Innenohrschaden eine normwertige Interpeaklatenz und aufgrund des Lautheitsausgleiches tendenziell eine Normalisierung der Latenzen bei hohen Pegeln vor. Das Ergebnis geht mit den zuvor beschriebenen Resultaten einer verminderten Endozytose auch in neuronalen Primärkulturen einher (Boumil et al. 2010).

Auf Grundlage der elektrophysiologischen Ergebnisse mit Untersuchung der Präsynapse ist hinsichtlich des Defektes von einer Minderung des Membran - und damit des Vesikelrecyclings auszugehen.

Eine kürzlich veröffentliche Arbeit stellt die Rolle der Endozytose an der Postsynapse in den Mittelpunkt der Untersuchungen (Chen Z et al. 2009). Dabei kam ein inhibitorisches Peptid, dyn-myr (myristoylated peptide), zum Einsatz, um die Rekrutierung Dynamins zur Membran und damit endozytotische Vorgänge zu blockieren (Marks und McMahon 1998). Die damit behandelten Mäuse präsentierten nach Lärmexposition dauerhaft erhöhte Hörschwellen, die auf eine defiziente Endozytose an der Postsynapse zurückgeführt wurde. Aufgrund einer gestörten Inkorporation postsynaptischer AMPA-Rezeptoren sind diese dem Stimulus ungeschützt ausgesetzt, so dass es zu exitotoxischen Folgen kommt, die auf Grundlage einer Denervation (Kujawa und Liberman 2006) eine irreversible Erhöhung der Schwellen nach sich ziehen (Chen $Z$ et al. 2009).

Für diese Arbeit ist entscheidend, dass sich der von Chen $\mathrm{Z}$ et al. verwendete Stimulus unterhalb der exitotoxischen Grenze befindet. So ist es denkbar, dass auch geringere Pegel in entsprechend reduziertem Maße einen Effekt mit sich bringen. Konsistent damit zeigte die 
Arbeitsgruppe, dass sich die Hörschwellen der mit dyn-myr behandelten Tiere auch ohne Lärmapplikation bereits um ca. $5 \mathrm{~dB}$ nach oben verschieben.

Aufgrund der Tatsache, dass sich ein Defekt der Endozytose nicht nur an der Prä- sondern auch an der Postsynapse niederzuschlagen scheint, könnten die audiologischen Befunde der DNM-1A ${ }^{\mathrm{ftfl} / \mathrm{ftfl}}$-Mäuse auf diese Kombination aus defizitärem Membranrecycling an der Präsynapse und der beschriebenen Störung an der Postsynapse zurück zu führen sein.

Die bisher diskutierten Aspekte betreffen die Lokalisation des Defektes - eine Zuordnung zu den IHZ und den fortleitenden Strukturen konnte gezeigt werden, eine Beteiligung der Postsynapse ist wahrscheinlich. Zudem haben sie gezeigt, dass dem Defekt eine verringerte Endozytose zugrunde liegt. Weiterführend ist zu klären, in welcher Form die Mutation zu einer Dysfunktion von Dynamin 1A innerhalb der Endozytose führt. Rückschlüsse auf den entsprechenden Mechanismus bietet der Ort der Mutation.

Die Mitteldomäne, in der die Mutation fitful lokalisiert ist, spielt eine wichtige Rolle in der Oligomerisation Dynamins (Okamoto et al. 1999; Smirnova et al. 1999). Es wurde nachgewiesen, dass bei Vorliegen von Mutationen in der Mitteldomäne die Ausbildung tetramerischer Strukturen gestört ist (Ramachandran et al. 2007), wodurch wiederum die Fähigkeit, an die Membran zu binden sowie höhergradige Strukturen wie Ringe oder Spiralen zu formieren, unterbunden wird. Für die hier behandelte Mutation konnte Entsprechendes gezeigt werden - die mutierte Isoform Dynamin 1A war zwar in der Lage, Dimere, nicht jedoch höhergradige Strukturen zu bilden (Boumil et al. 2010). Das bedeutet, dass es sich, wie erwartet, nicht um einen Totalausfall des Proteins handelt, es sich allerdings in seiner Konformation beeinträchtigt zeigt.

In diesem Kontext ist die Hypothese von Bedeutung, nach der Dynamin sowohl im polymeren und gebundenen Zustand, aber auch im ungebundenen Zustand Funktionen erfüllt (Narayanan et al. 2005; Loerke et al. 2009; Mettlen et al. 2009):

Das ungebundene Dynamin soll in einer frühen Phase der Endozytose eine Art molekularen Kontrollpunkt darstellen, in dessen Abhängigkeit es zu einer Reifung oder zu einem Abbruch der bestehenden Clathrin-beschichteten Invaginate kommt.

Die Oligomerisation Dynamins führt dagegen zu einer $>50$ fachen Stimulation der GTPaseAktivität (Warnock et al. 1996; Stowell et al. 1999), so dass der Hypothese nach dem polymeren Zustand die Aufgabe der letztendlichen Abschnürung der Vesikel zufällt. 
Analog konnte gezeigt werden, dass Zellen, die die mutierte Form des Dynamin 1A exprimieren, lediglich membranverbundene tubuläre Strukturen ohne eine vollständige Abschnürung aufweisen (Boumil et al. 2010).

So könnte die gestörte Polymerisierung und damit fehlende Stimulation der GTPaseAktivität zur Vesikelabspaltung eine direkte Erklärung für die vorliegende Dysfunktion bieten.

\subsubsection{Aktivitäts-abhängig erhöhter Bedarf an Dynamin 1 bzw. 1A?}

Um einen Hinweis darauf zu gewinnen, an welchen Wegen der Endozytose Dynamin 1 bzw. 1A mitwirkt, ist in einem abschließenden Punkt ist zu klären, unter welchen Bedingungen der Bedarf an Dynamin 1A besonders entscheidend ist.

Aus den audiologischen Resultaten lassen sich hinsichtlich dessen zwei Aussagen hervorheben.

(I) Einerseits demonstriert die Erhöhung der Hörschwellen, dass die Dysfunktion bereits bei einer Stimulation mit der Standardfrequenz von $20 \mathrm{~Hz}$ zum Tragen kommt. Entsprechend verhält es sich mit den Latenzen, die bei $20 \mathrm{~Hz}$ durchgehend verlängert sind. Bei physiologischer und milder Stimulation ist vor allem von dem Vorherrschen einer Clathrinvermittelten Endozytose auszugehen (Granseth et al. 2006). Insbesondere dieser Weg wurde durch Inhibition der GTPase-Aktivität mittels dynasore blockiert (Macia et al. 2006). Aufgrund der dargestellten Beeinträchtigung der Konformation Dynamins ist im Fall der DNM-1 $\mathrm{A}^{\mathrm{fttl} / \mathrm{ftfl}}$-Mäuse von einer beträchtlich eingeschränkten GTPase-Aktivität auszugehen. Aus dieser Konstellation heraus erklärt sich, warum bereits bei milder Stimulation ein Defizit vorliegt und stützt die These, dass der Clathrin-vermittelte Weg in IHZ entscheidend ist.

(II) Andererseits ist bezüglich der Amplituden der FAEP festzustellen, dass es bei einer höheren Stimulationsfrequenz sowie zusätzlich bei längerer Stimulation zu einer Aggravation des Defektes kommt. Die bei $20 \mathrm{~Hz}$ nur vereinzelt reduzierten Amplituden der DNM$1 \mathrm{~A}^{\mathrm{fttl} / \mathrm{ftfl}}$-Mäuse zeigen sich bei $90 \mathrm{~Hz}$ in der Summe durchgehend als hochsignifikant vermindert und nehmen bei dieser Frequenz zusätzlich noch über die Dauer der Stimulation ab. 
Ähnliche Daten konnten an neuronalen Primärkulturen von Dynamin-1-knock-out-Mäusen erhoben werden (Ferguson et al. 2007). Bei Stimulation mit steigender Frequenz kam es im Vergleich zum Wildtypen zu signifikant reduzierten endozytotischen Ereignissen. Auch der endozytotische Defekt der DNM-1A ${ }^{\text {fftl/ftll }}$-Mäuse konnte erst nach zweifacher Stimulation dargestellt werden (Boumil et al. 2010). Unstimulierte sowie einmalig stimulierte kortikale Primärzellkulturen der DNM-1A ${ }^{\text {fftl/ffl }}$-Mäuse dagegen wiesen das gleiche Maß endozytotischer Aktivität auf wie die des Wildtypen.

Als Erklärungsansatz für diese Ergebnisse kommen folgende Überlegungen in Betracht. Ferguson et al. (2007) wiesen an DNM-1-knock-out-Mäusen für die Stimulation mit niedrigeren Frequenzen eine unvollständige Kompensation des Defekts durch überexprimiertes Dynamin 2 und eine vollständige Kompensation durch überexprimiertes Dynamin 3 nach. Es ist vorstellbar, dass bei geringeren Anforderungen das Defizit der knock-out- und DNM$1 \mathrm{~A}^{\mathrm{fffl} / \mathrm{ftrl}}$-Mäuse durch die physiologisch exprimierten Isoformen (DNM 2, 3, 1B) zumindest anteilig ausgeglichen werden kann. Im Fall der DNM-1A fffl/ftl -Mäuse ist in diesem Zusammenhang erneut an das hochregulierte Dynamin 1B als kompensierendes Element zu denken. Bei hoher und anhaltender Stimulation dagegen wäre dieser Ausgleich in einem höheren Maße unzureichend und führte so zu stärkeren Defiziten. Dieser ungenügende Ausgleich könnte einerseits quantitativ bedingt sein, insofern als bei stärkerer Stimulation ein höherer Gehalt an Dynamin 1A benötigt würde und so die Kompensation nicht mehr greift.

Denkbar ist andererseits - oder zusätzlich - aber auch ein qualitativer Unterschied, nach dem Dynamin 1 bzw. 1A aufgrund einer spezifischen Beschaffenheit im Gegensatz zu den anderen Formen eher bei stärkerer Stimulation rekrutiert wird.

Diesbezüglich könnte eine einzelne Endozytoseform bei starker Stimulation im Besonderen auf Dynamin 1A angewiesen sein. Dabei ist zu diskutieren, ob einer der drei Hauptvertreter der synaptischen Endozytosewege - Clathrin-vermittelt, „,kiss-and-run“ oder bulk retrieval dafür in Frage kommt.

Die Arbeit von Lou et al. (2008) zeigt, dass unter starker Stimulation die langsame Komponente der Endozytose an der Held'schen Calyx von Dynamin-1-knock-out-Mäusen beeinträchtigt ist, wodurch der Clathrin-vermittelte Weg in Betracht zu ziehen wäre. Gerade die Eigenschaft einer relativ langsamen Form, für die kontinuierlich Zeitkonstanten von 10- 
15 sec gemessen werden (Granseth et al. 2006; Balaji und Ryan 2007), spricht jedoch eher gegen diesen Weg. Es ist schwer vorstellbar, dass über den langsamen Clathrin-abhängigen Weg eine ausreichende Reaktion auf gesteigerten Bedarf einsetzt (Cheung et al. 2010).

Da die Form „kiss-and-run“ auf einen starken Reiz hin beobachtet werden konnte (Zhang et al. 2009), wäre es möglich, dass sie bei hoher Stimulation Dynamin-1-abhängig mit einer gesteigerten Rate abläuft und so immerhin über eine kurze Dauer dem Bedarf gerecht wird. Bei der Interpretation der vorliegenden Daten ist allerdings zu bedenken, dass bisher kein Nachweis für „,kiss-and-run“ an Bänder-Synapsen erbracht werden konnte, siehe Kapitel 2.2.3, und dieser Weg nur in wenigen Arbeiten mit Dynamin in Zusammenhang gebracht wurde (Newton et al. 2006), so dass er ebenfalls wenig wahrscheinlich erscheint.

Grundsätzlich bieten die beiden genannten Formen lediglich die Möglichkeit der Internalisierung einzelner Vesikel. Mit Endozytose als Antwort auf eine starke Stimulation wird dagegen mittlerweile gemeinhin die kompensatorische Form des bulk retrievals verbunden (Lenzi et al. 2002; Wu LG et al. 2007; Clayton et al. 2008; Clayton und Cousin 2009; Cheung et al. 2010). Dieser Weg kann aufgrund des enormen Umfangs an endozytierter Oberfläche prompt auf einen gesteigerten Bedarf an Vesikelnachschub reagieren. Dementsprechend könnte analog der Stimulationsstärke ein Wechsel des Endozytoseweges unter Einbeziehung von Dynamin 1 bzw. 1A zu bulk retrieval stattfinden.

Hinsichtlich dessen existieren zwar durchaus divergente Ansichten - neben einer Studie, die eine Dynamin-1-Abhängigkeit der bulk-Endozytose negiert (Hayashi et al. 2008), spricht die Zusammenschau der bisherigen Erkenntnisse aber für eine Involvierung von Dynamin 1 in diesen endozytotischen Mechanismus.

Bereits die zuvor geschilderten Arbeiten, innerhalb derer der endozytotische Defekt der Dynamin-1-knock-out bzw. Mutante besonders bei hoher Stimulation detektiert werden konnte, deuteten auf diese Abhängigkeit hin (Ferguson et al. 2007; Boumil et al. 2010). Besonders jedoch eine kürzlich erschienene Arbeit von Clayton et al. (2009) konnte zeigen, dass die aktivitätsabhängige bulk-Endozytose in Abhängigkeit von der Dephosphorylierung von Dynamin 1 stattfindet. In dem Zusammenhang ist es evident, dass die Phosphatase Calcineurin als Kalziumsensor aktivitätsabhängig die bulk-Endozytose triggert (Evans und Cousin 2007; Clayton und Cousin 2008). Dynamin 1 als eines der Schlüsselsubstrate dieser Phosphatase wird dabei oberhalb derselben Aktivitätsschwelle, die bulk retrieval auslöst, 
dephosphoryliert (Clayton et al. 2009), um anschließend eine Phosphorylierung durch GSK3 (Glycogen Synthase Kinase 3) zu erfahren (Clayton et al. 2010). Darüber hinaus konnte die Arbeitsgruppe unter Einsatz von dynasore zur Inhibition der GTPase-Aktivität nicht nur eine Blockade der Clathrin-vermittelten Endozytose, sondern auch des bulk retrieval nachweisen (Clayton et al. 2009).

Aus den präsentierten Ergebnissen wird ersichtlich, dass für den Prozess des bulk retrievals sowohl spezifisch die Dephosphorylierung Dynamin 1 als auch generell dessen GTPase Aktivität Voraussetzung zu sein scheint.

Angewandt auf die audiologischen Ergebnisse der DNM-1A ${ }^{\mathrm{ftfl} / \mathrm{ftfl}}$-Mäuse erscheint es plausibel, dass die Mutation zwei voneinander unabhängige Defizite mit folgenden Auswirkungen bedingen kann:

(I) Einerseits ist aufgrund der gestörten Konformation Dynamins von einer eingeschränkten Stimulation der GTPase-Aktivität auszugehen. Dies erklärte nicht nur die Inhibition des Clathrin-vermittelten Weges bei milderer Stimulation, sondern ebenfalls des bulk retrievals bei stärkerer Stimulation, da beide Wege auf die GTPase-Aktivität angewiesen sind.

(II) Zusätzlich ist eine Störung der spezifischen Dephosphorylierung Dynamins wahrscheinlich, da die Mitteldomäne interessanterweise mehrere Phosphorylierungsstellen enthält (Graham et al. 2007). Eine Mutation in diesem Bereich könnte demnach spezifisch für eine Dysfunktion der bulk-Endozytose bei stärkerer Stimulation verantwortlich sein.

Ein entscheidender Unterschied im Gegensatz zu bisherigen Arbeiten, die eine Beteiligung von Dynamin 1 in bulk retrieval nachweisen, besteht in der Tatsache, dass keine Unterscheidung der Isoformen von Dynamin 1 vorgenommen wurde. Unter Einsatz der DNM-1A ftfl/ftfl -Mäuse jedoch kann erstmalig angenommen werden, dass die spezifische Isoform Dynamin $1 \mathrm{~A}$ in diese Form der Endozytose involviert ist.

Insgesamt deuten die Ergebnisse darauf hin, dass die fitful Mutation sowohl den Clathrinvermittelten Weg besonders bei milder als auch eine Form des bulk retrievals bei stärkerer Stimulation zu stören scheint, so dass beide Wege im Zusammenhang mit Dynamin 1A sowie als wesentlich für die Fortleitung akustischer Stimuli zu sehen sind. 


\section{$6 \quad$ Zusammenfassung}

Endozytose stellt einen elementaren Prozess einer jeden funktionierenden Zelle dar. Jedoch ergeben sich in Abhängigkeit vom jeweiligen Zelltyp - neuronal versus nicht-neuronal sowie der verschiedenen Synapsenformen Unterschiede bezüglich der heterogenen Internalisierungswege. Innerhalb dieser sind zudem unterschiedliche Proteine beteiligt, deren exakte Funktionen und Zusammenspiel nicht vollständig geklärt sind.

Die innere Haarzelle (IHZ) des Innenohres bildet als sekundäre Sinneszelle so genannte Bänder-Synapsen aus. Neben der Exozytose ist hier zur Aufrechterhaltung der Stimulusfortleitung die Endozytose essentiell. Bisher jedoch existieren wenige Arbeiten, die den Fokus auf diesen Vorgang legen. Ziel dieser Arbeit war es daher, in Form einer Expressionsanalyse (Immunhistochemie) bestimmte Proteine als Vertreter der potentiellen Wege in der IHZ der Maus darzustellen. Des Weiteren wurde das Augenmerk auf ein bestimmtes endozytotisches Protein - Dynamin 1A (DNM 1A) - gelegt und sowohl morphologische als auch funktionelle Analysen an einer Mausmutante für DNM 1A (fitful) vorgenommen.

Immunhistochemisch gelang die Darstellung von Clathrin und Dynamin 1, Caveolin dagegen konnte nicht nachgewiesen werden. Auf dieser Grundlage kann sowohl der klassische Clathrin-vermittelte Weg als auch das Vorliegen alternativer Dynaminabhängiger Endozytoseformen wie eine schnelle Endozytose und bulk retrieval in IHZ vermutet werden. Der Caveolin-vermittelte Weg jedoch scheint der Funktion der IHZ nicht gerecht $\mathrm{zu}$ werden. Insgesamt zeigte sich darüber hinaus eine uneinheitliche Expression neuronaler und nicht-neuronaler Proteine, welche die Sonderstellung der IHZ als sekundäre Sinneszelle demonstriert.

Die DNM-1A-Mausmutante fitful präsentierte neben einem eindrücklichen neurologischen Phänotyp mit epileptischen Anfällen ein signifikant gemindertes Hörvermögen in der BERA (brainstem electric response audiometry). Es zeigte sich nicht nur eine herabgesetzte Hörschwelle, sondern ebenfalls eine Verlängerung der Latenzen und bei hoher Reizrate eine Reduktion der Amplituden der FAEP (frühe auditorisch evozierte Potentiale). Dabei scheint sich der Defekt nicht auf die erste auditorische Synapse zu beschränken, sondern sich entlang der weiteren Verschaltung fortzusetzen. Die Aggravation des Defizits bei stärkerer und anhaltender Stimulation im Bereich der Amplituden weist auf eine Beteiligung von Dynamin 1A nicht nur an dem klassischen Clathrin-vermittelten Weg, sondern auch an dem 
endozytotischen Weg bulk retrieval hin, der charakteristischerweise bei starken Stimuli beobachtet wird.

Zusammenfassend wurde erstmals die molekulare Ausstattung endozytotischer Proteine der IHZ untersucht. Außerdem bot die fitful-Mutation die bisher einmalige Gelegenheit, Funktionen der Isoform Dynamin $1 \mathrm{~A} \mathrm{zu}$ analysieren. Sie übernimmt entscheidende Aufgaben im Hörvorgang und scheint im Speziellen nicht nur an der klassischen Clathrinvermittelten Endozytose, sondern auch am bulk retrieval mitzuwirken.

Weitere Studien sind in Zukunft notwendig, um genauere Einsicht in endozytotische Wege der IHZ zu gewinnen sowie differenzierte Aussagen bezüglich Isoform-spezifischer Funktionen von Dynamin 1 treffen zu können. 


\section{Abbildungs- und Tabellenverzeichnis}

\section{Abbildungen}

Abb. 2.1 Querschnitt durch das Corti-Organ 3

Abb. 2.2 Elektronenmikroskopische Darstellung einer Bänder-Synapse 5

Abb. 2.3 Einteilung der Endozytoseformen 7

Abb. 2.4 Formation eines Clathrin-beschichteten Vesikels, elektronenmikroskopisch

Abb. 2.5 (a) Clathrin-Triskelion (b) AP2 (c) Schema der Clathrin-vermittelten Endozytose $\quad 9$

Abb. 2.6 Wege der Reinternalisierung von Vesikeln an der Synapse 11

$\begin{array}{lll}\text { Abb. } 2.7 & \text { Architektur von Dynamin } 1 & 16\end{array}$

Abb. 2.8 Modell potentieller Funktionsweisen von Dynamin 17

Abb. 2.9 Registrierung akustisch evozierter Potentiale 19

Abb. 2.10 Schematische Darstellung der Hörbahn 20

Abb. $3.1 \quad$ Position der Nadelelektroden $\quad 25$

Abb. 3.2 Tonimpuls 26

$\begin{array}{lll}\text { Abb. } 3.3 & \text { Schaltbild zur Messung der FAEP } & 28\end{array}$

Abb. 3.4 Schaltbild zur Messung der DPOAE 31

Abb. 3.5 Schwebung durch Überlagerung von $\mathrm{f}_{1}=10 \mathrm{kHz}$ und $\mathrm{f}_{2}=12 \mathrm{kHz}$

Abb. 3.6 Spektrale Darstellung der Primärtöne und der DPOAE 33

Abb. 4.1 Immunhistochemische Darstellung endozytotischer

Proteine in der IHZ 35

Abb. 4.2 (a) Übersichtsaufnahme von IHZ und ÄHZ und

(b) Vergrößerte Darstellung der IHZ von DNM-1A ${ }^{\mathrm{ftfl} / \mathrm{ftfl}}$-Mutanten

(c) DIC Aufnahme des Corti-Organs

Abb. 4.3 Immunhistochemische Darstellung der oberen Windung des Corti-Organes

Abb. 4.4 Projektionen von IHZ mit Darstellung der Synapsen im Apexbereich und bei 4-6 kHz für DNM 1A ${ }^{\mathrm{ftfl} / \mathrm{ftfl}}$ im Vergleich zu DNM $1 \mathrm{~A}^{+/ \mathrm{ftfl} /+/+}$ 
Abb. 4.6 Verteilung endozytotischer Proteine von DNM 1A ${ }^{\mathrm{ftfl} / \mathrm{ftfl}}$

im Vergleich zu DNM 1A ${ }^{+/ f t f l /+/+}$

Abb. 4.7 Vermindertes Hörvermögen der DNM-1A ${ }^{\mathrm{ftfl} / \mathrm{ftfl}}$-Mäuse im

Audiogramm, aufgenommen mit frequenzspezifischer BERA

Abb. 4.8 FAEP als Antwort auf einen $86 \mathrm{~dB}$ Klickreiz mit $20 \mathrm{~Hz}$

Abb. 4.9 FAEP als Antwort auf einen $86 \mathrm{~dB}$ Klickreiz mit $90 \mathrm{~Hz}$

Abb. 4.10 Latenzpegeldiagramm bei 20 und $90 \mathrm{~Hz}$

Abb. 4.11 Summierte Amplituden bei 20 und $90 \mathrm{~Hz}$

Abb. 4.12 Verhältnis summierter Amplituden von DNM 1A $\mathrm{Attl}^{\mathrm{ftftl}}$ zu DNM 1A $\mathrm{A}^{+/ \mathrm{fffl} /+/+}$ bei $90 \mathrm{HZ}$

Abb. 4.13 Summierte Amplituden bei $90 \mathrm{HZ}$

Abb. 4.14 DPOAE von DNM 1A $\mathrm{ftfl} / \mathrm{fffl}^{\mathrm{f}}$ und DNM 1A $\mathrm{A}^{+/ \mathrm{ftfl} /+/+}$, DP-Gramm, Wachstumsfunktion

\section{Tabellen}

Tab. 3.1 Verwendete Frequenzen für das DP-Gramm

Tab. 4.1 Latenzen der einzelnen Wellen von DNM $1 \mathrm{~A}^{\mathrm{ftfl} / \mathrm{ftfl}}$ und DNM $1 \mathrm{~A}^{+/ \mathrm{ftfl} /+/+}$ bei $86 \mathrm{~dB}$ und $20 \mathrm{~Hz}$ 


\section{$8 \quad$ Literaturverzeichnis}

Acton SL, Brodsky FM (1990): Predominance of clathrin light chain LCb correlates with the presence of a regulated secretory pathway. J Cell Biol 111(4): 1419-26

Ales E, Tabares L, Poyato JM, Valero V, Lindau M, Alvarez de Toledo G (1999): High calcium concentrations shift the mode of exocytosis to the kiss-and-run mechanism. Nat Cell Biol 1(1): 40-4

Altstiel L, Branton D (1983): Fusion of coated vesicles with lysosomes: measurement with a fluorescence assay. Cell 32(3): 921-9

Aravanis AM, Pyle JL, Tsien RW (2003): Single synaptic vesicles fusing transiently and successively without loss of identity. Nature 423(6940): 643-7

Artalejo CR, Henley JR, McNiven MA, Palfrey HC (1995): Rapid endocytosis coupled to exocytosis in adrenal chromaffin cells involves $\mathrm{Ca} 2+, \mathrm{GTP}$, and dynamin but not clathrin. Proc Natl Acad Sci U S A 92(18): 8328-32

Ashmore J (2008): Cochlear outer hair cell motility. Physiol Rev $\underline{88(1)}$ : 173-210

Balaji J, Ryan TA (2007): Single-vesicle imaging reveals that synaptic vesicle exocytosis and endocytosis are coupled by a single stochastic mode. Proc Natl Acad Sci U S A 104(51): 20576-81

Beutner D, Voets T, Neher E, Moser T (2001): Calcium dependence of exocytosis and endocytosis at the cochlear inner hair cell afferent synapse. Neuron 29(3): 681-90

Biacabe B, Chevallier JM, Avan P, Bonfils P (2001): Functional anatomy of auditory brainstem nuclei: application to the anatomical basis of brainstem auditory evoked potentials. Auris Nasus Larynx 28(1): 85-94

Boumil RM, Letts VA, Roberts MC, Lenz C, Mahaffey CL, Zhang ZW, Moser T, Frankel WN (2010): A missense mutation in a highly conserved alternate exon of dynamin-1 causes epilepsy in fitful mice. PLoS Genet 6(8): e1001046

Cao H, Garcia F, McNiven MA (1998): Differential distribution of dynamin isoforms in mammalian cells. Mol Biol Cell 9(9): 2595-609

Ceccarelli B, Hurlbut WP, Mauro A (1972): Depletion of vesicles from frog neuromuscular junctions by prolonged tetanic stimulation. J Cell Biol 54(1): 30-8

Ceccarelli B, Hurlbut WP, Mauro A (1973): Turnover of transmitter and synaptic vesicles at the frog neuromuscular junction. J Cell Biol 57(2): 499-524

Chen YJ, Zhang P, Egelman EH, Hinshaw JE (2004): The stalk region of dynamin drives the constriction of dynamin tubes. Nat Struct Mol Biol 11(6): 574-5 
Chen Z, Kujawa SG, Sewell WF (2007): Auditory sensitivity regulation via rapid changes in expression of surface AMPA receptors. Nat Neurosci 10(10): 1238-40

Chen Z, Peppi M, Kujawa SG, Sewell WF (2009): Regulated expression of surface AMPA receptors reduces excitotoxicity in auditory neurons. J Neurophysiol 102(2): 1152-9

Cheung G, Jupp OJ, Cousin MA (2010): Activity-dependent bulk endocytosis and clathrindependent endocytosis replenish specific synaptic vesicle pools in central nerve terminals. J Neurosci 30(24): 8151-61

Clayton EL, Cousin MA (2008): Differential labelling of bulk endocytosis in nerve terminals by FM dyes. Neurochem Int 53(3-4): 51-5

Clayton EL, Cousin MA (2009): The molecular physiology of activity-dependent bulk endocytosis of synaptic vesicles. J Neurochem 111(4): 901-14

Clayton EL, Evans GJ, Cousin MA (2008): Bulk synaptic vesicle endocytosis is rapidly triggered during strong stimulation. J Neurosci 28(26): 6627-32

Clayton EL, Anggono V, Smillie KJ, Chau N, Robinson PJ, Cousin MA (2009): The phospho-dependent dynamin-syndapin interaction triggers activity-dependent bulk endocytosis of synaptic vesicles. J Neurosci 29(24): 7706-17

Clayton EL, Sue N, Smillie KJ, O'Leary T, Bache N, Cheung G, Cole AR, Wyllie DJ, Sutherland C, Robinson PJ, et al. (2010): Dynamin I phosphorylation by GSK3 controls activity-dependent bulk endocytosis of synaptic vesicles. Nat Neurosci 13(7): 845-51

Conner SD, Schmid SL (2003): Regulated portals of entry into the cell. Nature $\underline{422(6927)}$ : $37-44$

Cook TA, Urrutia R, McNiven MA (1994): Identification of dynamin 2, an isoform ubiquitously expressed in rat tissues. Proc Natl Acad Sci U S A 91(2): 644-8

Cook TA, Mesa K, Urrutia R (1996): Three dynamin-encoding genes are differentially expressed in developing rat brain. J Neurochem 67(3): 927-31

Cousin MA, Robinson PJ (2001): The dephosphins: dephosphorylation by calcineurin triggers synaptic vesicle endocytosis. Trends Neurosci 24(11): 659-65

Creutz CE, Harrison JR (1984): Clathrin light chains and secretory vesicle binding proteins are distinct. Nature 308(5955): 208-10

Dallos P, Fakler B (2002): Prestin, a new type of motor protein. Nat Rev Mol Cell Biol 3(2): 104-11

Damke H, Baba T, Warnock DE, Schmid SL (1994): Induction of mutant dynamin specifically blocks endocytic coated vesicle formation. J Cell Biol 127(4): 915-34 
Damke H, Baba T, van der Bliek AM, Schmid SL (1995): Clathrin-independent pinocytosis is induced in cells overexpressing a temperature-sensitive mutant of dynamin. J Cell Biol 131(1): 69-80

Danino D, Moon KH, Hinshaw JE (2004): Rapid constriction of lipid bilayers by the mechanochemical enzyme dynamin. J Struct Biol 147(3): 259-67

Daoud R, Da Penha Berzaghi M, Siedler F, Hubener M, Stamm S (1999): Activitydependent regulation of alternative splicing patterns in the rat brain. Eur J Neurosci 11(3): 788-802

de Lange RP, de Roos AD, Borst JG (2003): Two modes of vesicle recycling in the rat calyx of Held. J Neurosci 23(31): 10164-73

Doherty GJ, McMahon HT (2009): Mechanisms of endocytosis. Annu Rev Biochem $\underline{78}$ : $857-902$

Don M, Allen AR, Starr A (1977): Effect of click rate on the latency of auditory brain stem responses in humans. Ann Otol Rhinol Laryngol 86(2 pt. 1): 186-95

Ehret G (1985): Behavioural studies on auditory development in mammals in relation to higher nervous system functioning. Acta Otolaryngol Suppl 421: 31-40

Eisenberg E, Greene LE (2007): Multiple roles of auxilin and hsc70 in clathrin-mediated endocytosis. Traffic $\underline{8(6)}:$ 640-6

Evans GJ, Cousin MA (2007): Activity-dependent control of slow synaptic vesicle endocytosis by cyclin-dependent kinase 5. J Neurosci 27(2): 401-11

Ferguson SM, Brasnjo G, Hayashi M, Wolfel M, Collesi C, Giovedi S, Raimondi A, Gong LW, Ariel P, Paradise S, et al. (2007): A selective activity-dependent requirement for dynamin 1 in synaptic vesicle endocytosis. Science 316(5824): 570-4

Francesconi A, Kumari R, Zukin RS (2009): Regulation of group I metabotropic glutamate receptor trafficking and signaling by the caveolar/lipid raft pathway. J Neurosci 29(11): 3590-602

Gad H, Low P, Zotova E, Brodin L, Shupliakov O (1998): Dissociation between Ca2+triggered synaptic vesicle exocytosis and clathrin-mediated endocytosis at a central synapse. Neuron 21(3): 607-16

Gale JE, Marcotti W, Kennedy HJ, Kros CJ, Richardson GP (2001): FM1-43 dye behaves as a permeant blocker of the hair-cell mechanotransducer channel. J Neurosci 21(18): $7013-25$

Galletta BJ, Cooper JA (2009): Actin and endocytosis: mechanisms and phylogeny. Curr Opin Cell Biol 21(1): 20-7 
Gandhi SP, Stevens CF (2003): Three modes of synaptic vesicular recycling revealed by single-vesicle imaging. Nature 423(6940): 607-13

Glowatzki E, Fuchs PA (2002): Transmitter release at the hair cell ribbon synapse. Nat Neurosci $\underline{5(2)}$ : 147-54

Grabowski PJ (1998): Splicing regulation in neurons: tinkering with cell-specific control. Cell 92(6): 709-12

Graham ME, Anggono V, Bache N, Larsen MR, Craft GE, Robinson PJ (2007): The in vivo phosphorylation sites of rat brain dynamin I. J Biol Chem 282(20): 14695-707

Granseth B, Odermatt B, Royle SJ, Lagnado L (2006): Clathrin-mediated endocytosis is the dominant mechanism of vesicle retrieval at hippocampal synapses. Neuron 51(6): 773-86

Gray NW, Fourgeaud L, Huang B, Chen J, Cao H, Oswald BJ, Hemar A, McNiven MA (2003): Dynamin 3 is a component of the postsynapse, where it interacts with mGluR5 and Homer. Curr Biol 13(6): 510-5

Griesinger CB, Richards CD, Ashmore JF (2002): Fm1-43 reveals membrane recycling in adult inner hair cells of the mammalian cochlea. J Neurosci 22(10): 3939-52

Griesinger CB, Richards CD, Ashmore JF (2005): Fast vesicle replenishment allows indefatigable signalling at the first auditory synapse. Nature 435(7039): 212-5

Guha A, Sriram V, Krishnan KS, Mayor S (2003): Shibire mutations reveal distinct dynamin-independent and -dependent endocytic pathways in primary cultures of Drosophila hemocytes. J Cell Sci 116(Pt 16): 3373-86

Guth PS, Aubert A, Ricci AJ, Norris CH (1991): Differential modulation of spontaneous and evoked neurotransmitter release from hair cells: some novel hypotheses. Hear Res 56(1-2): $69-78$

Hama K, Saito K (1977): Fine structure of the afferent synapse of the hair cells in the saccular macula of the goldfish, with special reference to the anastomosing tubules. J Neurocytol 6(4): 361-73

Hansen CG, Nichols BJ (2009): Molecular mechanisms of clathrin-independent endocytosis. J Cell Sci 122(Pt 11): 1713-21

Hayashi M, Raimondi A, O'Toole E, Paradise S, Collesi C, Cremona O, Ferguson SM, De Camilli P (2008): Cell- and stimulus-dependent heterogeneity of synaptic vesicle endocytic recycling mechanisms revealed by studies of dynamin 1-null neurons. Proc Natl Acad Sci U S A 105(6): 2175-80 
He L, Wu LG (2007): The debate on the kiss-and-run fusion at synapses. Trends Neurosci 30(9): 447-55

He L, Wu XS, Mohan R, Wu LG (2006): Two modes of fusion pore opening revealed by cell-attached recordings at a synapse. Nature 444(7115): 102-5

Heidelberger R (2001): ATP is required at an early step in compensatory endocytosis in synaptic terminals. J Neurosci 21(17): 6467-74

Heidelberger R, Sterling P, Matthews G (2002): Roles of ATP in depletion and replenishment of the releasable pool of synaptic vesicles. J Neurophysiol 88(1): 98106

Herskovits JS, Burgess CC, Obar RA, Vallee RB (1993): Effects of mutant rat dynamin on endocytosis. J Cell Biol 122(3): 565-78

Hinshaw JE (2000): Dynamin and its role in membrane fission. Annu Rev Cell Dev Biol 16: 483-519

Hinshaw JE, Schmid SL (1995): Dynamin self-assembles into rings suggesting a mechanism for coated vesicle budding. Nature 374(6518): 190-2

Hudspeth AJ: Hearing; in: Principles of Neural Science; hrsg. v. Kandel ER, Schwartz JH,Jessell TM; McGraw-Hill, USA 2000, 590-624

Itoh T, De Camilli P (2006): BAR, F-BAR (EFC) and ENTH/ANTH domains in the regulation of membrane-cytosol interfaces and membrane curvature. Biochim Biophys Acta 1761(8): 897-912

Jackson AP, Seow HF, Holmes N, Drickamer K, Parham P (1987): Clathrin light chains contain brain-specific insertion sequences and a region of homology with intermediate filaments. Nature 326(6109): 154-9

Janssen T: Otoakustische Emissionen (OAE); in: Praxis der Audiometrie; hrsg. v. Lehnhardt E,Laszig R; Georg Thieme Verlag, Stuttgart 2001, 79-107

Jewett DL (1970): Volume-conducted potentials in response to auditory stimuli as detected by averaging in the cat. Electroencephalogr Clin Neurophysiol 28(6): 609-18

Jockusch WJ, Praefcke GJ, McMahon HT, Lagnado L (2005): Clathrin-dependent and clathrin-independent retrieval of synaptic vesicles in retinal bipolar cells. Neuron 46(6): 869-78

Kachar B, Battaglia A, Fex J (1997): Compartmentalized vesicular traffic around the hair cell cuticular plate. Hear Res 107(1-2): 102-12

Keen JH (1987): Clathrin assembly proteins: affinity purification and a model for coat assembly. J Cell Biol 105(5): 1989-98 
Kemp DT (2002): Otoacoustic emissions, their origin in cochlear function, and use. Br Med Bull 63: 223-41

Khimich D, Nouvian R, Pujol R, Tom Dieck S, Egner A, Gundelfinger ED, Moser T (2005): Hair cell synaptic ribbons are essential for synchronous auditory signalling. Nature 434(7035): 889-94

Kiang NY, Rho JM, Northrop CC, Liberman MC, Ryugo DK (1982): Hair-cell innervation by spiral ganglion cells in adult cats. Science 217(4555): 175-7

Kim Y, Chang S (2006): Ever-expanding network of dynamin-interacting proteins. Mol Neurobiol 34(2): 129-36

Kirchhausen T, Harrison SC, Chow EP, Mattaliano RJ, Ramachandran KL, Smart J, Brosius J (1987): Clathrin heavy chain: molecular cloning and complete primary structure.

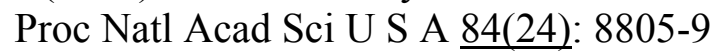

Kirkham M, Fujita A, Chadda R, Nixon SJ, Kurzchalia TV, Sharma DK, Pagano RE, Hancock JF, Mayor S, Parton RG (2005): Ultrastructural identification of uncoated caveolin-independent early endocytic vehicles. J Cell Biol 168(3): 465-76

Klinke R: Hören und Sprechen: Kommunikation des Menschen; in: Physiologie; hrsg. v. Klinke R, Pape HC,Silbernagel S; Georg Thieme Verlag, Stuttgart 2005, 657-674

Koenig JH, Ikeda K (1989): Disappearance and reformation of synaptic vesicle membrane upon transmitter release observed under reversible blockage of membrane retrieval. J Neurosci 9(11): 3844-60

Kujawa SG, Liberman MC (2006): Acceleration of age-related hearing loss by early noise exposure: evidence of a misspent youth. J Neurosci 26(7): 2115-23

Leake PA, Snyder RL (1987): Uptake of horseradish peroxidase from perilymph by cochlear hair cells. Hear Res 25(2-3): 153-71

Lenzi D, Runyeon JW, Crum J, Ellisman MH, Roberts WM (1999): Synaptic vesicle populations in saccular hair cells reconstructed by electron tomography. J Neurosci 19(1): 119-32

Lenzi D, Crum J, Ellisman MH, Roberts WM (2002): Depolarization redistributes synaptic membrane and creates a gradient of vesicles on the synaptic body at a ribbon synapse. Neuron $\underline{36(4)}$ : 649-59

Liberman MC (1978): Auditory-nerve response from cats raised in a low-noise chamber. $\mathrm{J}$ Acoust Soc Am 63(2): 442-55

Llobet A, Beaumont V, Lagnado L (2003): Real-time measurement of exocytosis and endocytosis using interference of light. Neuron $\underline{40(6)}$ : 1075-86 
Loerke D, Mettlen M, Yarar D, Jaqaman K, Jaqaman H, Danuser G, Schmid SL (2009): Cargo and dynamin regulate clathrin-coated pit maturation. PLoS Biol 7(3): e57

LoGiudice L, Matthews G (2009): The role of ribbons at sensory synapses. Neuroscientist 15(4): $380-91$

LoGiudice L, Sterling P, Matthews G (2009): Vesicle recycling at ribbon synapses in the finely branched axon terminals of mouse retinal bipolar neurons. Neuroscience 164(4): 1546-56

Lou X, Paradise S, Ferguson SM, De Camilli P (2008): Selective saturation of slow endocytosis at a giant glutamatergic central synapse lacking dynamin 1. Proc Natl Acad Sci U S A 105(45): 17555-60

Lu J, Helton TD, Blanpied TA, Racz B, Newpher TM, Weinberg RJ, Ehlers MD (2007): Postsynaptic positioning of endocytic zones and AMPA receptor cycling by physical coupling of dynamin-3 to Homer. Neuron 55(6): 874-89

Macia E, Ehrlich M, Massol R, Boucrot E, Brunner C, Kirchhausen T (2006): Dynasore, a cell-permeable inhibitor of dynamin. Dev Cell 10(6): 839-50

Marks B, McMahon HT (1998): Calcium triggers calcineurin-dependent synaptic vesicle recycling in mammalian nerve terminals. Curr Biol 8(13): 740-9

Matsubara A, Laake JH, Davanger S, Usami S, Ottersen OP (1996): Organization of AMPA receptor subunits at a glutamate synapse: a quantitative immunogold analysis of hair cell synapses in the rat organ of Corti. J Neurosci 16(14): 4457-67

Mayor S, Pagano RE (2007): Pathways of clathrin-independent endocytosis. Nat Rev Mol Cell Biol 8(8): 603-12

McMahon HT, Gallop JL (2005): Membrane curvature and mechanisms of dynamic cell membrane remodelling. Nature 438(7068): 590-6

McNiven MA, Thompson HM (2006): Vesicle formation at the plasma membrane and transGolgi network: the same but different. Science 313(5793): 1591-4

Melcher JR, Kiang NY (1996): Generators of the brainstem auditory evoked potential in cat. III: Identified cell populations. Hear Res 93(1-2): 52-71

Melcher JR, Guinan JJ, Jr., Knudson IM, Kiang NY (1996 a): Generators of the brainstem auditory evoked potential in cat. II. Correlating lesion sites with waveform changes. Hear Res 93(1-2): 28-51

Melcher JR, Knudson IM, Fullerton BC, Guinan JJ, Jr., Norris BE, Kiang NY (1996 b): Generators of the brainstem auditory evoked potential in cat. I. An experimental approach to their identification. Hear Res 93(1-2): 1-27 
Mettlen M, Pucadyil T, Ramachandran R, Schmid SL (2009): Dissecting dynamin's role in clathrin-mediated endocytosis. Biochem Soc Trans 37(Pt 5): 1022-6

Meyer AC, Moser T (2010): Structure and function of cochlear afferent innervation. Curr Opin Otolaryngol Head Neck Surg 18(5): 441-6

Meyer AC, Frank T, Khimich D, Hoch G, Riedel D, Chapochnikov NM, Yarin YM, Harke B, Hell SW, Egner A, et al. (2009): Tuning of synapse number, structure and function in the cochlea. Nat Neurosci 12(4): 444-53

Meyer J, Mack AF, Gummer AW (2001): Pronounced infracuticular endocytosis in mammalian outer hair cells. Hear Res 161(1-2): 10-22

Meyers JR, MacDonald RB, Duggan A, Lenzi D, Standaert DG, Corwin JT, Corey DP (2003): Lighting up the senses: FM1-43 loading of sensory cells through nonselective ion channels. J Neurosci 23(10): 4054-65

Mikaelian D, Ruben RJ (1965): Development of hearing in the normal CBA-J mouse. Acta Otolaryngol 59: 451-461

Moser T, Beutner D (2000): Kinetics of exocytosis and endocytosis at the cochlear inner hair cell afferent synapse of the mouse. Proc Natl Acad Sci U S A 97(2): 883-8

Mousavi SA, Malerod L, Berg T, Kjeken R (2004): Clathrin-dependent endocytosis. Biochem J 377(Pt 1): 1-16

Muhlberg AB, Warnock DE, Schmid SL (1997): Domain structure and intramolecular regulation of dynamin GTPase. EMBO J 16(22): 6676-83

Murata M, Peranen J, Schreiner R, Wieland F, Kurzchalia TV, Simons K (1995): VIP21/caveolin is a cholesterol-binding protein. Proc Natl Acad Sci U S A 92(22): $10339-43$

Nadol JB, Jr. (1990): Synaptic morphology of inner and outer hair cells of the human organ of Corti. J Electron Microsc Tech 15(2): 187-96

Nakata T, Takemura R, Hirokawa N (1993): A novel member of the dynamin family of GTP-binding proteins is expressed specifically in the testis. J Cell Sci 105 (Pt 1): 1-5

Narayanan R, Leonard M, Song BD, Schmid SL, Ramaswami M (2005): An internal GAP domain negatively regulates presynaptic dynamin in vivo: a two-step model for dynamin function. J Cell Biol 169(1): 117-26

Neef J, Gehrt A, Bulankina AV, Meyer AC, Riedel D, Gregg RG, Strenzke N, Moser T (2009): The $\mathrm{Ca} 2+$ channel subunit beta 2 regulates $\mathrm{Ca} 2+$ channel abundance and function in inner hair cells and is required for hearing. J Neurosci 29(34): 10730-40 
Newton AJ, Kirchhausen T, Murthy VN (2006): Inhibition of dynamin completely blocks compensatory synaptic vesicle endocytosis. Proc Natl Acad Sci U S A 103(47): $17955-60$

Nouvian R, Beutner D, Parsons TD, Moser T (2006): Structure and function of the hair cell ribbon synapse. J Membr Biol 209(2-3): 153-65

Obar RA, Collins CA, Hammarback JA, Shpetner HS, Vallee RB (1990): Molecular cloning of the microtubule-associated mechanochemical enzyme dynamin reveals homology with a new family of GTP-binding proteins. Nature 347(6290): 256-61

Oh P, McIntosh DP, Schnitzer JE (1998): Dynamin at the neck of caveolae mediates their budding to form transport vesicles by GTP-driven fission from the plasma membrane of endothelium. J Cell Biol 141(1): 101-14

Okamoto PM, Tripet B, Litowski J, Hodges RS, Vallee RB (1999): Multiple distinct coiledcoils are involved in dynamin self-assembly. J Biol Chem 274(15): 10277-86

Oliver D, Fakler B: Auditorisches System; in: Physiologie; hrsg. v. Deetjen P,Speckmann EJ; Urban und Fischer Verlag 2004, 135-158

Paillart C, Li J, Matthews G, Sterling P (2003): Endocytosis and vesicle recycling at a ribbon synapse. J Neurosci 23(10): 4092-9

Parsons TD, Lenzi D, Almers W, Roberts WM (1994): Calcium-triggered exocytosis and endocytosis in an isolated presynaptic cell: capacitance measurements in saccular hair cells. Neuron 13(4): 875-83

Parton RG, Simons K (2007): The multiple faces of caveolae. Nat Rev Mol Cell Biol $\underline{\text { (3): }}$ 185-94

Pauli-Magnus D, Hoch G, Strenzke N, Anderson S, Jentsch TJ, Moser T (2007): Detection and differentiation of sensorineural hearing loss in mice using auditory steady-state responses and transient auditory brainstem responses. Neuroscience 149(3): 673-84

Perry MM, Gilbert AB (1979): Yolk transport in the ovarian follicle of the hen (Gallus domesticus): lipoprotein-like particles at the periphery of the oocyte in the rapid growth phase. J Cell Sci 39: 257-72

Pley UM, Hill BL, Alibert C, Brodsky FM, Parham P (1995): The interaction of calmodulin with clathrin-coated vesicles, triskelions, and light chains. Localization of a binding site. J Biol Chem 270(5): 2395-402

Powell KA, Robinson PJ (1995): Dephosphin/dynamin is a neuronal phosphoprotein concentrated in nerve terminals: evidence from rat cerebellum. Neuroscience 64(3): 821-33 
Ramachandran R, Surka M, Chappie JS, Fowler DM, Foss TR, Song BD, Schmid SL (2007): The dynamin middle domain is critical for tetramerization and higher-order self-assembly. EMBO J 26(2): 559-66

Rea R, Li J, Dharia A, Levitan ES, Sterling P, Kramer RH (2004): Streamlined synaptic vesicle cycle in cone photoreceptor terminals. Neuron 41(5): 755-66

Richards DA, Guatimosim C, Betz WJ (2000): Two endocytic recycling routes selectively fill two vesicle pools in frog motor nerve terminals. Neuron 27(3): 551-9

Roberts WM, Jacobs RA, Hudspeth AJ (1990): Colocalization of ion channels involved in frequency selectivity and synaptic transmission at presynaptic active zones of hair cells. J Neurosci 10(11): 3664-84

Rose JE, Brugge JF, Anderson DJ, Hind JE (1967): Phase-locked response to low-frequency tones in single auditory nerve fibers of the squirrel monkey. J Neurophysiol 30(4): 769-93

Rothberg KG, Heuser JE, Donzell WC, Ying YS, Glenney JR, Anderson RG (1992): Caveolin, a protein component of caveolae membrane coats. Cell 68(4): 673-82

Roux A, Uyhazi K, Frost A, De Camilli P (2006): GTP-dependent twisting of dynamin implicates constriction and tension in membrane fission. Nature 441(7092): 528-31

Scheiffele P, Verkade P, Fra AM, Virta H, Simons K, Ikonen E (1998): Caveolin-1 and -2 in the exocytic pathway of MDCK cells. J Cell Biol 140(4): 795-806

Schmid EM, McMahon HT (2007): Integrating molecular and network biology to decode endocytosis. Nature 448(7156): 883-8

Schmitz F, Konigstorfer A, Sudhof TC (2000): RIBEYE, a component of synaptic ribbons: a protein's journey through evolution provides insight into synaptic ribbon function. Neuron 28(3): 857-72

Seiler C, Nicolson T (1999): Defective calmodulin-dependent rapid apical endocytosis in zebrafish sensory hair cell mutants. J Neurobiol 41(3): 424-34

Sendin G, Bulankina AV, Riedel D, Moser T (2007): Maturation of ribbon synapses in hair cells is driven by thyroid hormone. J Neurosci 27(12): 3163-73

Sever S, Muhlberg AB, Schmid SL (1999): Impairment of dynamin's GAP domain stimulates receptor-mediated endocytosis. Nature 398(6727): 481-6

Sever S, Damke H, Schmid SL (2000): Dynamin:GTP controls the formation of constricted coated pits, the rate limiting step in clathrin-mediated endocytosis. J Cell Biol 150(5): 1137-48 
Sewell WF (1984): The relation between the endocochlear potential and spontaneous activity in auditory nerve fibres of the cat. J Physiol 347: 685-96

Sharma DK, Brown JC, Choudhury A, Peterson TE, Holicky E, Marks DL, Simari R, Parton RG, Pagano RE (2004): Selective stimulation of caveolar endocytosis by glycosphingolipids and cholesterol. Mol Biol Cell 15(7): 3114-22

Sheng M, Kim MJ (2002): Postsynaptic signaling and plasticity mechanisms. Science 298(5594): 776-80

Sherry DM, Heidelberger R (2005): Distribution of proteins associated with synaptic vesicle endocytosis in the mouse and goldfish retina. J Comp Neurol 484(4): 440-57

Shogomori H, Futerman AH (2001): Cholera toxin is found in detergent-insoluble rafts/domains at the cell surface of hippocampal neurons but is internalized via a raftindependent mechanism. J Biol Chem 276(12): 9182-8

Shpetner HS, Vallee RB (1989): Identification of dynamin, a novel mechanochemical enzyme that mediates interactions between microtubules. Cell 59(3): 421-32

Siegel JH, Brownell WE (1986): Synaptic and Golgi membrane recycling in cochlear hair cells. J Neurocytol 15(3): 311-28

Slepnev VI, De Camilli P (2000): Accessory factors in clathrin-dependent synaptic vesicle endocytosis. Nat Rev Neurosci 1(3): 161-72

Smirnova E, Shurland DL, Newman-Smith ED, Pishvaee B, van der Bliek AM (1999): A model for dynamin self-assembly based on binding between three different protein domains. J Biol Chem 274(21): 14942-7

Smith SM, Renden R, von Gersdorff H (2008): Synaptic vesicle endocytosis: fast and slow modes of membrane retrieval. Trends Neurosci 31(11): 559-68

Spicer SS, Thomopoulos GN, Schulte BA (1999): Novel membranous structures in apical and basal compartments of inner hair cells. J Comp Neurol 409(3): 424-37

Stowell MH, Marks B, Wigge P, McMahon HT (1999): Nucleotide-dependent conformational changes in dynamin: evidence for a mechanochemical molecular spring. Nat Cell Biol 1(1): 27-32

Streit A (2001): Origin of the vertebrate inner ear: evolution and induction of the otic placode. J Anat 199(Pt 1-2): 99-103

Takei K, McPherson PS, Schmid SL, De Camilli P (1995): Tubular membrane invaginations coated by dynamin rings are induced by GTP-gamma $\mathrm{S}$ in nerve terminals. Nature 374(6518): $186-90$ 
Takei K, Mundigl O, Daniell L, De Camilli P (1996): The synaptic vesicle cycle: a single vesicle budding step involving clathrin and dynamin. J Cell Biol 133(6): 1237-50

Teng H, Wilkinson RS (2000): Clathrin-mediated endocytosis near active zones in snake motor boutons. J Neurosci 20(21): 7986-93

Thomsen P, Roepstorff K, Stahlhut M, van Deurs B (2002): Caveolae are highly immobile plasma membrane microdomains, which are not involved in constitutive endocytic trafficking. Mol Biol Cell 13(1): 238-50

Traub LM (2003): Sorting it out: AP-2 and alternate clathrin adaptors in endocytic cargo selection. J Cell Biol 163(2): 203-8

Traub LM (2009): Tickets to ride: selecting cargo for clathrin-regulated internalization. Nat Rev Mol Cell Biol 10(9): 583-96

Ungewickell E, Branton D (1981): Assembly units of clathrin coats. Nature 289(5796): 4202

Ungewickell EJ, Hinrichsen L (2007): Endocytosis: clathrin-mediated membrane budding. Curr Opin Cell Biol 19(4): 417-25

van der Bliek AM, Meyerowitz EM (1991): Dynamin-like protein encoded by the Drosophila shibire gene associated with vesicular traffic. Nature 351(6325): 411-4

van der Bliek AM, Redelmeier TE, Damke H, Tisdale EJ, Meyerowitz EM, Schmid SL (1993): Mutations in human dynamin block an intermediate stage in coated vesicle formation. J Cell Biol 122(3): 553-63

Verkade P, Harder T, Lafont F, Simons K (2000): Induction of caveolae in the apical plasma membrane of Madin-Darby canine kidney cells. J Cell Biol 148(4): 727-39

Verstreken P, Koh TW, Schulze KL, Zhai RG, Hiesinger PR, Zhou Y, Mehta SQ, Cao Y, Roos J, Bellen HJ (2003): Synaptojanin is recruited by endophilin to promote synaptic vesicle uncoating. Neuron $\underline{40(4)}$ : 733-48

von Gersdorff H, Matthews G (1994): Dynamics of synaptic vesicle fusion and membrane retrieval in synaptic terminals. Nature 367(6465): 735-9

Wang CT, Lu JC, Bai J, Chang PY, Martin TF, Chapman ER, Jackson MB (2003): Different domains of synaptotagmin control the choice between kiss-and-run and full fusion. Nature 424(6951): 943-7

Warnock DE, Hinshaw JE, Schmid SL (1996): Dynamin self-assembly stimulates its GTPase activity. J Biol Chem 271(37): 22310-4

Wu W, Wu LG (2007): Rapid bulk endocytosis and its kinetics of fission pore closure at a central synapse. Proc Natl Acad Sci U S A 104(24): 10234-9 
Wu LG, Ryan TA, Lagnado L (2007): Modes of vesicle retrieval at ribbon synapses, calyxtype synapses, and small central synapses. J Neurosci 27(44): 11793-802

www.endocytosis.org/

Xu J, McNeil B, Wu W, Nees D, Bai L, Wu LG (2008): GTP-independent rapid and slow endocytosis at a central synapse. Nat Neurosci 11(1): 45-53

Yamashita T, Hige T, Takahashi T (2005): Vesicle endocytosis requires dynamin-dependent GTP hydrolysis at a fast CNS synapse. Science $\underline{307(5706)}$ : 124-7

Yao Q, Chen J, Cao H, Orth JD, McCaffery JM, Stan RV, McNiven MA (2005): Caveolin-1 interacts directly with dynamin-2. J Mol Biol 348(2): 491-501

Yoshida Y, Kinuta M, Abe T, Liang S, Araki K, Cremona O, Di Paolo G, Moriyama Y, Yasuda T, De Camilli P, et al. (2004): The stimulatory action of amphiphysin on dynamin function is dependent on lipid bilayer curvature. EMBO J 23(17): 3483-91

Zenisek D, Steyer JA, Feldman ME, Almers W (2002): A membrane marker leaves synaptic vesicles in milliseconds after exocytosis in retinal bipolar cells. Neuron $\underline{35(6)}$ : 108597

Zhang Q, Li Y, Tsien RW (2009): The dynamic control of kiss-and-run and vesicular reuse probed with single nanoparticles. Science 323(5920): 1448-53

Zheng J, Cahill SM, Lemmon MA, Fushman D, Schlessinger J, Cowburn D (1996): Identification of the binding site for acidic phospholipids on the $\mathrm{pH}$ domain of dynamin: implications for stimulation of GTPase activity. J Mol Biol 255(1): 14-21

Zheng J, Shen W, He DZ, Long KB, Madison LD, Dallos P (2000): Prestin is the motor protein of cochlear outer hair cells. Nature 405(6783): 149-55

\section{Teile der Ergebnisse dieser Arbeit wurden veröffentlicht in:}

Boumil RM, Letts VA, Roberts MC, Lenz C, Mahaffey CL, Zhang ZW, Moser T, Frankel WN (2010):

A missense mutation in a highly conserved alternate exon of dynamin-1 causes epilepsy in fitful mice. PLoS Genet $\underline{6(8)}$ : e1001046 


\section{Danksagung}

Herrn Prof. Dr. med. T. Moser danke ich für die Überlassung des Dissertationsthemas, für wichtige Anregungen und die Betreuung der Arbeit.

Im Besonderen möchte ich mich auch bei Herrn Dr. Jakob Neef für seine stete Unterstützung, fachlichen Ratschläge und eine gute persönliche Zusammenarbeit bedanken.

Außerdem danke ich Herrn Christian Rüdiger, Frau Dr. Darina Khimich, Herrn Dr. Andreas Neef, Frau Dr. Nicola Strenzke, Herrn Gerhard Hoch und Frau Dr. Tina Pangrsic für ihre immer vorhandene Hilfsbereitschaft und vielen kleinen Tipps, die mir die Arbeit erleichtert haben. 


\section{Lebenslauf}

Am 17.05.1982 wurde ich als erstes Kind von Joachim und Ursula Lenz, geborene Hähnel, in Hamburg-Wandsbek geboren. Nach meiner Schulzeit, die ich 2001 am Gymnasium Trittau mit dem Abitur abschloss, verbrachte ich ein Jahr in Frankreich. An der Faculté des Lettres de Nice belegte ich innerhalb eines Studienganges, vergleichbar mit einem „Studium generale“, Kurse im Bereich der Kunstgeschichte, Philosophie und Psychologie.

Nach Aufnahme als Stipendiatin in die Deutsche Studienstiftung nahm ich zum Wintersemester 2002 das Studium der Humanmedizin an der Universität Marburg auf und schloss im September 2004 den vorklinischen Abschnitt ab. Für den klinischen Abschnitt wechselte ich an die Universität Göttingen, an der ich im Mai 2009 den zweiten Abschnitt der ärztlichen Prüfung bestand. Das Praktische Jahr absolvierte ich beginnend im Februar 2008 im St. Martini Krankenhaus in Duderstadt, im St. Micheal's Hospital in Toronto, Kanada, und im Klinikum Bremen Mitte.

Die Arbeit an der vorliegenden Dissertation begann ich im Februar 2007 und führte sie im Anschluss an das Staatsexamen fort.

Seit April 2010 bin ich als Assistenzärztin in der Abteilung für Innere Medizin am St. Gertraudenkrankenhaus in Berlin tätig. 